\title{
International consensus on terminology to be used in the field of echinococcoses
}

Dominique A. Vuitton ${ }^{1, *}$, Donald P. McManus ${ }^{2}$, Michael T. Rogan ${ }^{3}$, Thomas Romig ${ }^{4}$, Bruno Gottstein ${ }^{5}$, Ariel Naidich ${ }^{6}$, Tuerhongjiang Tuxun ${ }^{7}$, Hao Wen ${ }^{7}$, Antonio Menezes da Silva ${ }^{8}$, and the World Association of Echinococcosis ${ }^{\mathrm{a}}$

${ }^{1}$ National French Reference Centre for Echinococcosis, University Bourgogne Franche-Comté and University Hospital, FR-25030 Besançon, France

2 Molecular Parasitology Laboratory, Infectious Diseases Division, QIMR Berghofer Medical Research Institute, AU-4006 Brisbane, Queensland, Australia

3 Department of Biology and School of Environment \& Life Sciences, University of Salford, GB-M5 4WT Manchester, United Kingdom

${ }_{5}^{4}$ Department of Parasitology, Hohenheim University, DE-70599 Stuttgart, Germany

${ }^{5}$ Institute of Parasitology, School of Medicine and Veterinary Medicine, University of Bern, CH-3012 Bern, Switzerland

${ }^{6}$ Department of Parasitology, National Institute of Infectious Diseases, ANLIS “Dr. Carlos G. Malbrán”, AR-1281 Buenos Aires, Argentina

${ }^{7}$ WHO Collaborating Centre for Prevention and Care Management of Echinococcosis and State Key Laboratory of Pathogenesis, Prevention and Treatment of High Incidence Diseases in Central Asia, CN-830011 Urumqi, PR China

${ }^{8}$ Past-President of the World Association of Echinococcosis, President of the College of General Surgery of the Portuguese Medical Association, PT-1649-028 Lisbon, Portugal

Received 18 March 2020, Accepted 7 April 2020, Published online 3 June 2020

\begin{abstract}
Echinococcoses require the involvement of specialists from nearly all disciplines; standardization of the terminology used in the field is thus crucial. To harmonize echinococcosis terminology on sound scientific and linguistic grounds, the World Association of Echinococcosis launched a Formal Consensus process. Under the coordination of a Steering and Writing Group (SWG), a Consultation and Rating Group (CRG) had the main missions of (1) providing input on the list of terms drafted by the SWG, taking into account the available literature and the participants' experience; and (2) providing independent rating on all debated terms submitted to vote. The mission of the Reading and Review Group (RRG) was to give an opinion about the recommendation paper in terms of readability, acceptability and applicability. The main achievements of this process were: (1) an update of the current nomenclature of Echinococcus spp.; (2) an agreement on three names of diseases due to Echinococcus spp.: Cystic Echinococcosis (CE), Alveolar Echinococcosis (AE) and Neotropical Echinococcosis (NE), and the exclusion of all other names; (3) an agreement on the restricted use of the adjective "hydatid" to refer to the cyst and fluid due to E. granulosus sensu lato; and (4) an agreement on a standardized description of the surgical operations for CE, according to the "Approach, cyst Opening, Resection, and Completeness" (AORC) framework. In addition, 95 "approved" and 60 "rejected" terms were listed. The recommendations provided in this paper will be applicable to scientific publications in English and communication with professionals. They will be used for translation into other languages spoken in endemic countries.
\end{abstract}

Key words: Cystic Echinococcosis, Alveolar Echinococcosis, Neotropical Echinococcosis: Echinococcus spp., Terminology, Formalized consensus.

Résumé - Consensus international sur la terminologie à utiliser dans le domaine des échinococcoses. Les échinococcoses impliquent l'intervention de spécialistes de presque toutes les disciplines et une standardisation de la terminologie utilisée dans le domaine est donc cruciale. Pour harmoniser la terminologie des échinococcoses sur des bases scientifiques et linguistiques bien étayées, l'Association Mondiale de l'Échinococcose a entrepris un processus de «Consensus Formalisé ». Sous la coordination d'un Groupe de Pilotage et de Rédaction (GPR), un Groupe de Consultation et de Classement (GCC) a reçu les missions suivantes : (1) fournir un avis sur une liste de termes établie par le GPR, en prenant en compte les références scientifiques disponibles et l'expérience des participants ; (2) fournir un classement indépendant sur tous les termes débattus et soumis au vote. La mission du Groupe de Lecture et de Revue critique (GLR) était de donner un avis formel sur l'article de recommandations en

*Corresponding author: dominique.vuitton@univ-fcomte. fr

${ }^{a}$ World Association of Echinococcosis, President: Nazmyie Altintas, Turkey; the indexed list of Contributors, members of the World Association of Echinococcosis is given in Appendix.

This is an Open Access article distributed under the terms of the Creative Commons Attribution License (https://creativecommons.org/licenses/by/4.0), which permits unrestricted use, distribution, and reproduction in any medium, provided the original work is properly cited. 
termes de facilité de lecture, d'acceptabilité et d'applicabilité. Les principales avancées obtenues au terme de ce processus sont les suivantes: (1) une actualisation de la nomenclature actuelle des espèces d'Echinococcus ; (2) un accord sur les noms des trois principales maladies humaines dues aux espèces d'Echinococcus : l'échinococcose kystique (EK), l'échinococcose alvéolaire (EA) et l'échinococcose néotropicale (EN), à l'exclusion de toute autre dénomination ; (3) la restriction de l'usage de l'adjectif « hydatique » au kyste et au liquide/fluide produit par E. granulosus sensu lato ; et (4) une description standardisée des interventions chirurgicales pour l'EK, selon le système AORC (pour « Approche », « Ouverture », « Résection » et « Complétude »). De plus, 95 termes « approuvés » et 60 termes « rejetés » ont été listés. Les recommandations données dans cet article seront applicables aux publications scientifiques en anglais et à la communication avec les professionnels. Elles seront utilisées pour la traduction dans les autres langues parlées dans les zones d'endémie.

\section{Introduction}

Echinococcus species (spp.) are parasites of the class Cestoda and belong to the phylum Platyhelminthes; they cause a variety of diseases in humans, most importantly cystic echinococcosis (CE; also found in scientific publications and professional/public communications under "hydatid cyst", or "hydatid disease", "hydatidosis", "echinococcus cysticus", etc.), alveolar echinococcosis (AE; also found under "alveococcosis", "echinococcus alveolaris", "alveolar hydatid", "alveolar hydatidosis", "alveolar hydatid disease", "multilocular hydatid cyst", "multilocular hydatid disease", "multilocular hydatidosis", etc.), and neotropical echinococcosis (NE; also found under "polycystic echinococcosis", "polycystic hydatid disease", "hydatidosis of the New World", etc.) [35]. The simple enumeration of the various alternative names of the diseases, still in use in 2020, readily shows the absence of standardization of the terminology used in this field. Echinococcoses are zoonoses, and the complexity of the life cycle of the various species of Echinococcus involved, the variety of their hosts, as well as the impact of the diseases due to Echinococcus spp. on public health, require the involvement of specialists from nearly all disciplines (medicine and surgery, veterinary medicine, zoology, parasitology, ecology, agriculture, public health, economics, etc.) which have their own history and their own jargon. However, they must cooperate to solve the multiple problems of Echinococcus spp. infection, within the "OneHealth" concept. This makes the use of a common vocabulary crucial. Time has thus come for standardization of the terminology in the field of echinococcosis.

From Hippocrates, who first described the cysts in patients more than 2400 years ago [18], to the 20th century, languages of Greek and Latin origin have served to name the parasites/ diseases associated with Echinococcus spp. because in the Western world, countries around the Mediterranean were the known endemic regions for $\mathrm{CE}$, the only recognized Echinococcus-related disease [13]. In the 19th century, physicians and researchers of German and Russian languages and in the 20th century, of French and English languages [18] brought new terms, and $\mathrm{AE}$, then $\mathrm{NE}$, were added to the list of Echinococcus-related diseases. At the end of the 20th century, China was recognized the main endemic region for $\mathrm{CE}$ and AE. Meanwhile, publishing in English became more and more common for physicians and scientists working in the field of echinococcosis worldwide, and everyone had to work with the variety of words and expressions describing Echinococcus spp. and echinococcosis in international publications in English
[77]. Differences in wording, in the various professional environments, as well as in the various endemic countries, have become sources of misunderstanding, with influences related to the local language of the professionals.

The first decade of the 21st century, with the development of molecular biology techniques and the complete elucidation of the genomes of E. granulosus (Batsch, 1786) [87] and E. multilocularis (Leuckart, 1863) [73], has seen the emergence of new species within the genus Echinococcus, that have increased and refined our taxonomic knowledge of these parasites; such developments have also had an impact on several domains of echinococcosis research including not only genomics, proteomics and metabolomics, but also immunology and epidemiology $[81,86]$. There has been and still is coexistence of already defined species based on genetic sequences with "types", and "strains", based on morphological characteristics [55]. A better definition of the limits of the species has led to an agreement between specialists on the definition and names of the "new" species, and nine species are now recognized and characterized by the sequences of their genomes, and defined in terms of host species and endemic areas [81]. The application of binomial nomenclature for genera and species is now governed by various internationally agreed codes of rules, of which the "International Code of Zoological Nomenclature (ICZN)" governs the scientific designation of parasites (https:// www.iczn.org/the-code/the-international-code-of-zoologicalnomenclature/the-code-online/). This international system must be followed, and any new species designation has to be registered for its international use. However, the translation of the "new" Echinococcus species defined by specialists into common usage by professionals has not yet been achieved, and many publications still use "E. granulosus" as a single species name responsible for CE.

The situation is also problematic for disease names and all other terms and expressions. This may be due to the status of echinococcoses as "orphan" diseases or "neglected diseases" (e.g., for the World Health Organization they are now recognized as "Neglected Tropical Diseases" (https://www.who.int/ neglected_diseases/diseases/en/), even though most human cases and animal infections are not in tropical areas). For "non-neglected" diseases, authoritative international scientific societies have fixed the terminology and published recommendations that are regularly updated. The World Federation of Parasitologists has endorsed the Standardised Nomenclature of Parasitic Diseases (SNOPAD), initially published in 1988 for animal parasitic diseases by the World Association for the Advancement of Veterinary Parasitology, and has established 
rules for the names of parasitic diseases [32] (cf. https://www. waavp.org/documents/snopad-guidelines/\#.XS9gBvIza00). The disease names are derived from the genus of the parasite with a suffix in "-osis" (e.g., Echinococcus would give "echinococcosis"). The rule is simple and clear; but the application of this rule has not been consistently followed and, especially for echinococcosis, coexistence of various names prevails, with a subsequent impact on database searching and misunderstanding between researchers and professionals [33, 34]. Other terms used in the "echinococcosis field" are equally ill-defined.

The "Asociación Internacional de Hidatidología" was founded in 1941 in Colonia del Sacramento (Uruguay), during the first "International South American Conference to Fight against Hydatidosis", aiming at coordinating echinococcosis control, especially in the endemic countries of South America, and organizing conferences. From 1951 to the end of the 1990s, Spanish, French and English were the official languages of the biennial "World Congress of Hydatidology", the main activity of the "International Association of Hydatidology" (IAE). At the 26th congress in Bucharest, Romania, in 2015, the name of the association in English was officially changed to "World Association of Echinococcosis (WAE)", a formal step towards the adoption of "echinococcosis" for the denomination of the diseases (and of the field of research in general). In 1985, the WHO Informal Working Group on Echinococcosis (IWGE) was created, with the double aim of creating a network of scientists working in basic sciences in the realm of echinococcosis, and in standardizing practices for the diagnosis and treatment of Echinococcus spp. - related diseases, in line with the priorities of the WHO [18].The group is currently working on a Technical Manual to help clinicians in the care management of patients with echinococcosis. Both professional entities (IAE and IWGE) hold their main meeting at the same location and have always joined efforts to issue manuals on echinococcosis including veterinary aspects, prevention and control [15-17], or write and update guidelines for diagnosis and treatment of patients with echinococcosis [10, 83]. In a plenary session of the 27th World Congress of Echinococcosis (WCE) in Algiers, Algeria, 2017, the need for harmonizing the terminology of echinococcosis, on sound scientific and linguistic grounds, was stressed; a working group and a consensus process were established to provide recommendations applicable to scientific publications in English, and to the communication between professionals. Such recommendations should then be used as a basis for translation into other languages spoken in endemic countries for communication, teaching and training. This report and its illustrations (Tables and Figures) and Appendix are the ultimate result of the process.

\section{Materials and methods}

The methodology proposed to the participants in the working groups established at the 27th WCE was the "Formal consensus" approach, as used by the French "Haute Autorité de Sante" (https://www.has-sante.fr/upload/docs/application/pdf/ 2018-03/good_practice_guidelines_fc_method.pdf), inspired by both the Delphi process [30] and the Consensus Conference methods [19]. As the methodology was initially described to set up guidelines for good clinical practices, the method was slightly modified, as described below, to fit with the objectives of the present work, i.e. an agreement on terminology and good publishing practices. All participants in the various groups involved in the "formal consensus" process are cited as "associated authors" in the final publication (names in Appendix).

\section{Definition and modalities of constitution of the Working Groups}

\section{Steering and Writing Group (SWG)}

The mission of the SWG was: (1) to draft the list of words and expressions, and provide a critical analysis of their scientific and linguistic relevance, from the international scientific literature and all available sources (international nomenclature, international recommendations, historical notes, etymology), and submit it to the participants in the Consultation and Rating Group (CRG); (2) to collect and discuss the feedback from the participants in the CRG, and if necessary to submit difficult cases to appropriate external experts; (3) to draft the final lists of words and expressions and submit them to rating by the participants in the CRG; (4) to select 12 experts in the various disciplines of interest to the field of echinococcosis, not involved in the CRG, as members of the Reading and Review Group (RRG); (5) to analyze the rating data and draft the initial version of the Recommendation Paper, including the final tables with recommended terminology, to be submitted to the RRG; (6) to consider the remarks of the RRG on the draft, finalize the paper and the tables with the members of the CRG, and submit it to the appropriate journal; and (7) to ensure the follow-up of the paper and the dissemination of its content to end-users.

The composition of the SWG, chaired by a project manager, was approved by the president and the members of the WAE attending the 27th WCE, and three topics of interest were proposed, each coordinated by two members of the SWG, experts in the area.

\section{Consultation and Rating group (CRG)}

The mission of the CRG in the "formal consensus" process was (1) in the first step of consultation, to provide input on the initial list of terms and expressions drafted by the SWG, taking into account the available literature in all fields and the personal experience of the various participants; (2) in the second step of consultation, to participate in the poll, and provide independent rating on all words and expressions submitted to vote by the SWG; and (3) to finalize the text of the paper with the SWG after its evaluation by the RRG, and before its submission to the appropriate journal.

Sub-groups, corresponding to the three topics of interest were composed on a voluntary basis at the 27th WCE, and completed after a call for volunteering launched by email by the SWG after the congress. On their request, participants could belong to more than one subgroup. The list of the CRG participants who were involved in the whole process, and their country/countries of residence and field work, is provided in the Appendix. For the "Species and epidemiology", "Biology and immunology" and "Clinical aspects" subgroups of the 


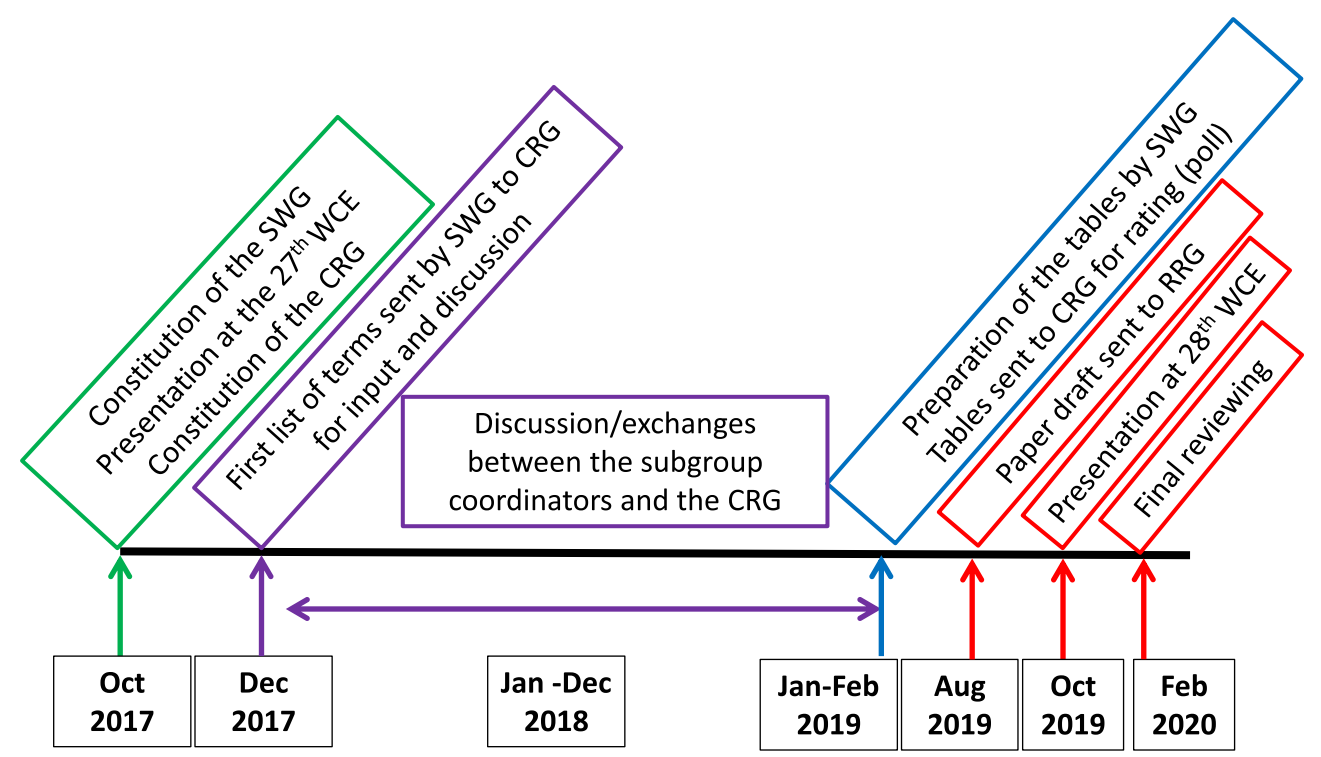

Figure 1. Time schedule and main activities within the "Formal consensus" process for the definition of the terminology of echinococcosis.

CRG, 17, 18, and 14 participants were identified, respectively from 15 countries in total. The project manager coordinated all activities of the groups but was not involved in any rating; however, other members of the SWG who volunteered for the task could be involved in rating but only for those subgroups they were not coordinating.

\section{Reading and Review Group (RRG)}

The mission of the RRG, multidisciplinary and multiprofessional, was to give a formal opinion on the content and form of the initial version of the paper and the recommendations it may contain, especially in terms of applicability, acceptability, and readability in their own domain. According to the rules of the "formal consensus" process, the participants in the RRG would offer an advisory opinion on an individual basis, without de novo questioning the decisions from the votes obtained in the first 2 steps of the process. The list of the RRG participants (four experts for each topic) who were involved in the reviewing process, and their country/countries of residence and field of expertise, is given in the Appendix.

\section{Schedule of the process}

The time schedule of the process, from October 2017 to February 2020, is given in Figure 1. The main steps included: (1) constitution of the SWG, presentation of the project, and constitution of the CRG; (2) provision of a list of words and expressions, with arguments for their acceptance or rejection, provided by the SWG to the participants in the CRG; (3) input from the participants in the CRG and open discussion; (4) constitution of the RRG by the SWG; (5) a preliminary summary by the SWG, and preparation of three lists of words and expressions for each of the three topics, according to three levels of decision: (a) a priori approved terms, (b) a priori rejected terms, (c) debated issues submitted to vote; (6) vote on "debated issues" by the participants in the CRG; (7) analysis of data and drafting of the Recommendation Paper by the SWG; (8) reviewing of the draft by the RRG; (9) last review by the CRG; (10) submission of the manuscript by the SWG; and (11) follow-up of the publication process and dissemination of the recommendations by the SWG.

Except for the first kick-off meeting at the 27th WCE and the final presentation at the 28th WCE in Lima, Peru, and given the worldwide extent of the consultation group and absence of funding, there were no further face-to-face meetings; all discussions and exchanges were managed by email. The project manager and members of the SWG answered all messages sent by the members of the CRG and all contributions were taken into account at any stage.

\section{Analysis of the poll}

Medians and means of the ratings, on a possible agreement range from 1 to 10 , were calculated for the answers to each question. A majority of agreement for approval or rejection was considered when more than half of the ratings were equal to or higher than 5, or equal to or lower than 5, respectively. Unanimous approval or rejection was defined as ratings higher than or lower than 5 for all voters, respectively. Agreement for rejection was defined for a median equal to 3.5 or lower, and majority or unanimity of ratings; agreement for approval was defined for a median equal to 7.5 and higher; and majority or unanimity of ratings. A question was deemed "undecided" when the median was between 3.5 and 7.5 and/or there was no majority of ratings. After the poll and when needed, i.e. whenever the result of the votes was "undecided" and/or whenever there was no full agreement on the definition of a term, the SWG submitted the term/expression to further discussion between specialists in order to reach final agreement. To this purpose, subgroups of specialists (e.g., surgeons) were constituted to propose final agreement. 


\section{Results}

\section{Final composition of the CRG subgroups}

For the "Species and epidemiology" subgroup, 1 participant could not be reached by email and 1 never answered emails; the final rating was thus provided independently by 15 participants, from 10 countries. For the "Biology and immunology" subgroup, three participants could not be reached; five participants from the same research team worked together for the final rating; thus the final rating was provided independently by 11/15 participants from 11 countries. For the "Clinical aspects" subgroup, one participant could not be reached and one did not answer emails; 2 participants from the same research group worked together for the final rating; thus the final rating was provided by $11 / 12$ participants from 8 countries.

\section{Results of the first stage of consultation}

The first stage of consultation generated numerous comments with associated arguments and references from all participants in the CRG. This input was carefully collated in a summary version of the preliminary tables by the SWG. In case of need, other experts of the specific field were consulted by the coordinators of the subgroups, and their opinion was brought to the attention of the CRG participants. The synthetic tables as well as additional pictures if necessary (especially for the subgroup on "Biology and immunology"), were again sent to all participants to obtain initial evaluation of possible consensus, and set up a list of still "debated issues".

For the "Species and epidemiology" subgroup, it was agreed that the nomenclature of old and new species of Echinococcus should follow the rules of the ICZN. Thus, the names of the species (and their number) listed in the tables reflect the results of current taxonomic research and do not preclude future changes, provided these are based on convincing new evidence. There was also a consensus on the use of the " $G$ " genotypes in cases where genetic differences are apparent, but where - based on current knowledge - these differences are deemed too small to warrant recognition of the variants as named taxa. In addition, the term "genotype" should be reserved for characterization using molecular biology/sequencing, and "strain" or "type" should be reserved for characterization using morphological and host-range characteristics. Consequently, there were no "debated issues" for this subgroup. However, definitions and clarifications on species names and on other words and expressions regarding this topic were given in provisional tables; they were submitted for approval or rejection in the second stage of the process (with an answer of the "YES/NO" type).

For the "Biology and immunology" subgroup, there was far more debate since there is no official institution in charge of such terminology. Divergences appeared about the various stages of development of the Echinococcus spp. in their intermediate hosts, and particularly on the definition of the term metacestode. Other minor divergences were noted on the use of certain words to designate the cells and components of these parasites, either adult or larval, as well as the host's reaction. References were provided by parasitology and immunology specialists to support data interpretation, thus the use of specific words. From that stage of the consultation, there was general agreement that the adjective "hydatid" should only be used for E. granulosus sensu lato; as this was a sensitive issue, it was however kept in the "debated issues" submitted to vote, both for the "Biology and immunology" and for the "Clinical aspects" subgroups. For details on the names of the various components of the egg of all Echinococcus spp. and of the cyst in CE, it was decided to provide a figure that would fix the definitions of the various words (Figs. 2A, 2B and 2C). The definition of "cyst" was initially the main disagreement between "parasitologists" (2-layer cyst) and "clinicians" (3-layer cyst). At the end of the first stage, it was finally agreed by all experts, whatever their field of expertise, that all cysts due to Echinococcus spp. and, especially for clinicians, those due to E. granulosus s.l., included two "layers" (and not "membranes") of parasite origin and one layer of host origin, thus three layers. This clarification helped when defining several derived terms.

For the "Clinical aspects" subgroup, it was readily agreed that the names of diseases due to the various species of Echinococcus should follow the rules proposed by the SNOPAD and the generic name "echinococcosis" should always be used, irrespective of the species and type of disease. "Cystic" and "Alveolar" should be used as adjectives to designate the diseases due to E. granulosus (Batsch, 1786) sensu lato, and to E. multilocularis (Leuckart, 1963), respectively. Some discussion remained for the use of the adjective "hydatid", and for the names of the diseases due to E. oligarthra (Diesing, 1863) and E. vogeli Rausch and Bernstein, 1972, in South America. Most of the debated issues concerned the names of therapeutic interventions (surgical or using other techniques); however, the common definition of "cyst", shared by parasitologists and clinicians, led to an easier consensus on the meaning of "cystectomy".

\section{Results of the second stage of consultation}

\section{Agreement for approval or rejection}

A few terms proposed in the lists for "approval" or "rejection" at the end of the first stage of the process still received objections from participants in the CRG. More precision (or references) were provided in order to reach a final consensus on these terms and their definition. Approved terms were provisionally included in Tables 1A (Genetics and epidemiology), 1B (Biology and immunology) and 1C (Clinical aspects). Rejected terms were provisionally included in Tables 2A (Genetics and epidemiology), 2B (Biology and immunology) and 2C (Clinical aspects).

\section{Poll on debated issues}

Among the 39 final participations in the poll about "debated issues" nine were incomplete; the questionnaire was sent back to these participants for completion; precise answers were eventually obtained. The ratings provided for the poll on "debated issues" were analyzed in order to obtain means and medians, and thus a final score for approval or rejection of each term. Results of the median rating for the "debated terms", and whenever useful the agreement between participants, are given in the "Comments" column of Tables 1A-1C and 2A-2C. Objections and concerns on the use of some terms were re-discussed by 


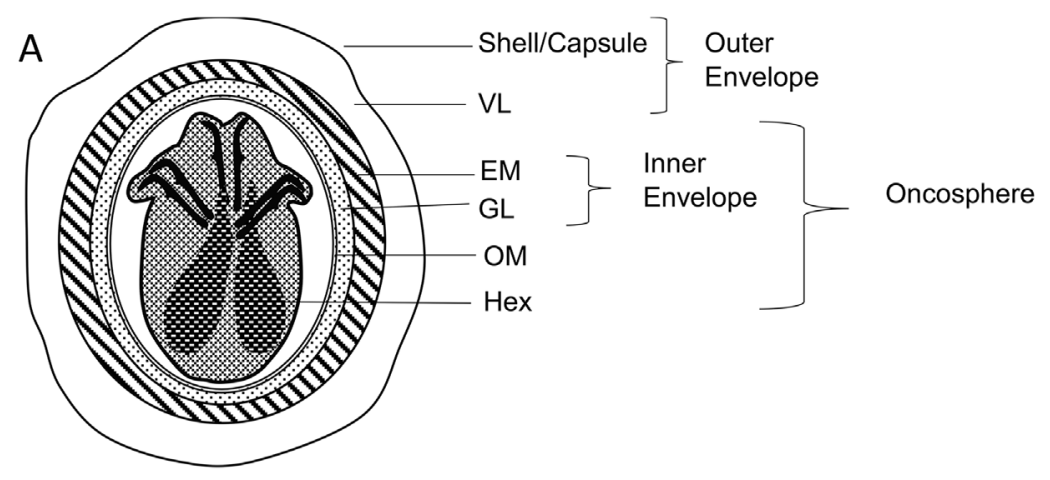

B

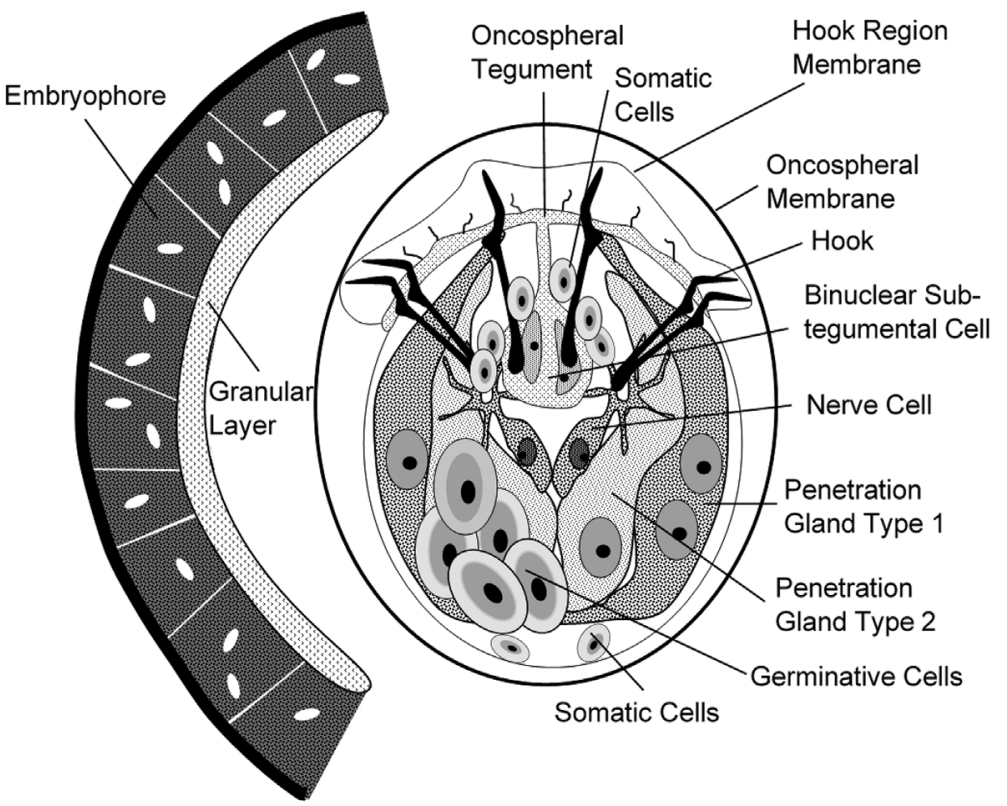

Figure 2A and B. General description of the egg and oncosphere of Echinococcus spp, according to Jabbar et al., 2010 [27]. (A) Schematic diagram of an oncosphere illustrating the structure and bilateral symmetry in the pattern of hooks and cellular organization of the hexacanth embryo. VL: vitelline layer; EM: embryophore; GL: granular layer; OM: oncospheral membrane; Hex: hexacanth embryo. (B) Cellular organization of the oncosphere. Oncospheres are approximately $25 \times 30 \mu \mathrm{m}$.

specialists before making a final decision on their final rejection or approval, and minor modifications in the wording of definitions were made in order to obtain a final consensus. An important result of the poll, since it was distinctly and clearly agreed upon both by the participants in the "Biology and immunology" subgroup and those in the "Clinical aspects" subgroup, was on the word "hydatid". According to the polls, all names of diseases or operations composed from the radical "hydatid" (e.g., in "hydatid-osis" or "hydatid-ectomy", etc.) should be abandoned, and the adjective "hydatid", whenever used, should never be used to qualify entities different from those due to E. granulosus sensu lato, thus never be used for E. multilocularis, $E$. vogeli and E. oligarthra. A final discussion on the characterization of the surgical procedures aimed at removing CE cysts eventually retained a simple framework that should be used whenever surgical operations are described in publications, with four levels of mandatory qualification, regarding (1) Approach: "laparotomy", "laparoscopy" or "robotic"; (2) Cyst Opening: "non-opened cyst" (NOP) versus "opened-cyst" (OP); (3) Resection type: "cystectomy”, "hepatectomy", or "liver transplantation"; and (4) Completeness of resection: "total", "subtotal", and "partial". Description of the AORC unified framework for surgical interventions in $\mathrm{CE}$ is given in Figures $3 \mathrm{~A}$ and $3 \mathrm{~B}$. Precise description of the procedure actually performed should complete the mandatory terms (description of the removed parasite layers, area in square centimetres or percentage of cyst actually resected, closure of communications with bile ducts, etc.).

\section{Review by the RRG and meeting at the 28th WCE in Lima, Peru}

Feedback from the RRG members usually addressed minor aspects of text readability and/or definitions/descriptions in the Tables. Clarification was provided by the reviewers on the definition of the species and their hosts, especially regarding species involved in NE. The major issues raised by one reviewer (clinician) concerned the definition of the "cyst", 


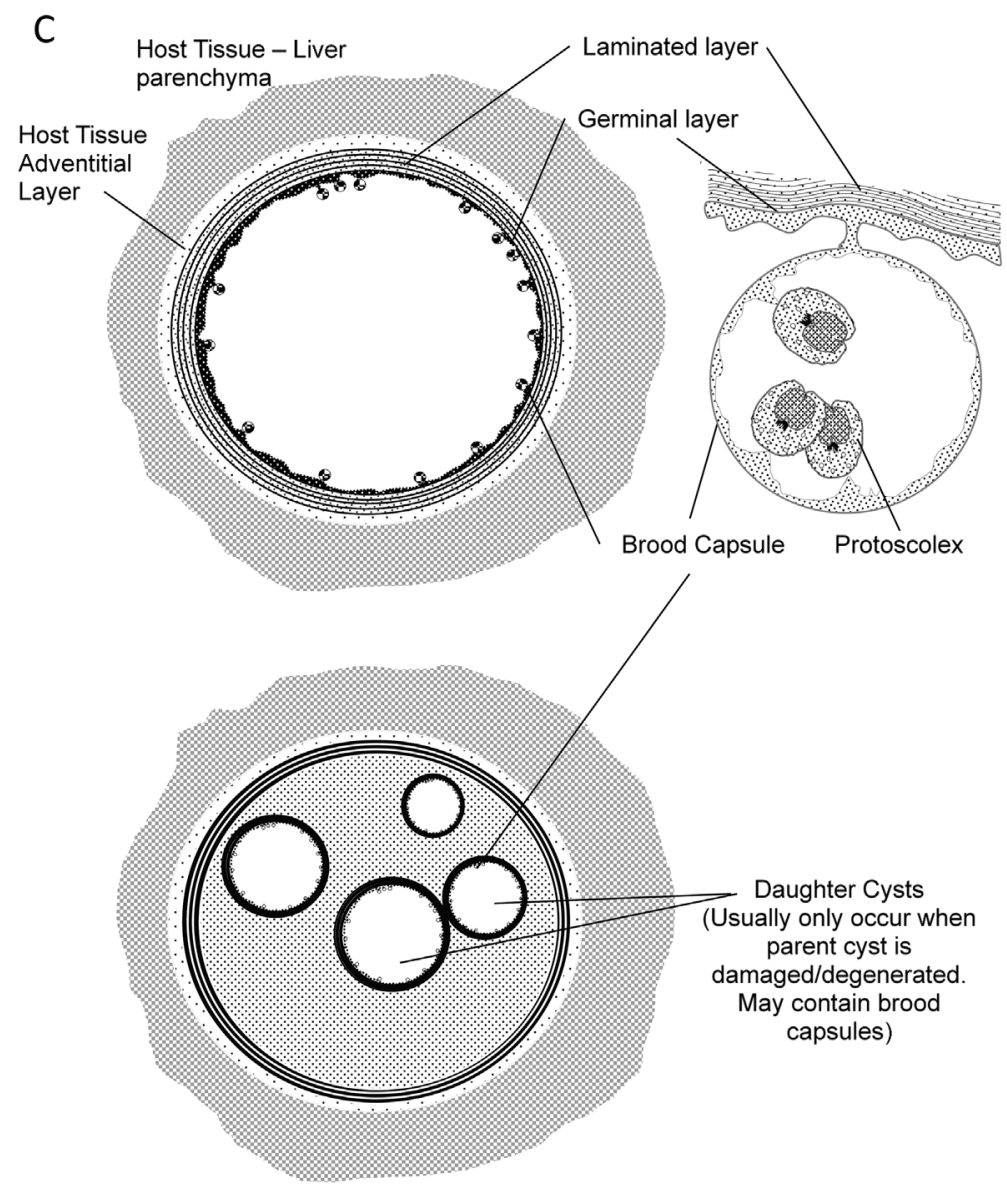

Figure 2C. General description of the metacestode of Echinococcus spp. (see also Table 1B and Fig. 3).

and the retention of the adjective "hydatid", even in its very restrictive sense as described in Tables $1 \mathrm{~B}$ and $1 \mathrm{C}$. However, because of the clear results of the consensus process, these objections could not be taken into account in the final version. At the meeting of the WHO-IWGE held in Lima, Peru, during the 28th WCE, the still debated issues were raised and final adjustments were made between the SWG and the writers of the WHO-IWGE Technical Manual on CE treatment. Words and expressions finally approved and rejected after the poll and the last discussions were added to the list of approved and rejected terms. Terms finally approved (95 items) are thus included in Tables 1A (Genetics and epidemiology), 1B (Biology and immunology) and 1C (Clinical aspects). Rejected terms (60 items) are included in Tables 2A, (Species and epidemiology), 2B (Biology and immunology) and 2C (Clinical aspects). To facilitate consultation, Tables 1A-1C and $2 \mathrm{~A}-2 \mathrm{C}$ are organized by topics of interest (A, B and C), and within each topic, in alphabetic order of the words or expressions.

\section{Discussion}

This 2-year multidisciplinary and international exchange of views has allowed physicians, veterinarians and basic science researchers to freely discuss opinions about terms used in all fields relating to Echinococcus spp., and to reach a consensus on the use of the most appropriate ones, based on sound scientific and/or linguistic grounds. When evidence was not available, consensus was based on reasoned arguments, including usage when no suitable alternative was found, confirmed by a poll. This is the first and only endeavour of this type in the domain of echinococcosis; and it is endorsed by the WAE. Definitions of 155 terms and expressions and recommendations provided in Tables $1 \mathrm{~A}-1 \mathrm{C}$ and $2 \mathrm{~A}-2 \mathrm{C}$ and Figures $2 \mathrm{~A}-2 \mathrm{C}$ and 3 should be followed in the future by all scientists writing scientific papers in English; scientific editors and referees/reviewers should recommend article authors to use the approved terms. These recommendations should help the recognized experts, involved in scientific work on echinococcosis at the international level, to set up a similar list of recommended and rejected words in their country language(s), so that similar wording could be used by all professionals. Major advances promoted by the multidisciplinary work on echinococcosis terminology were: (1) the confirmation of the current recognition of nine species of Echinococcus; (2) an agreement on the names of the three types of diseases due to Echinococcus spp. and rejection of all others; (3) the restriction of the adjective "hydatid" to E. granulosus s.l.; and (4) the proposal of the "AORC" framework to describe surgical interventions in $\mathrm{CE}$. 


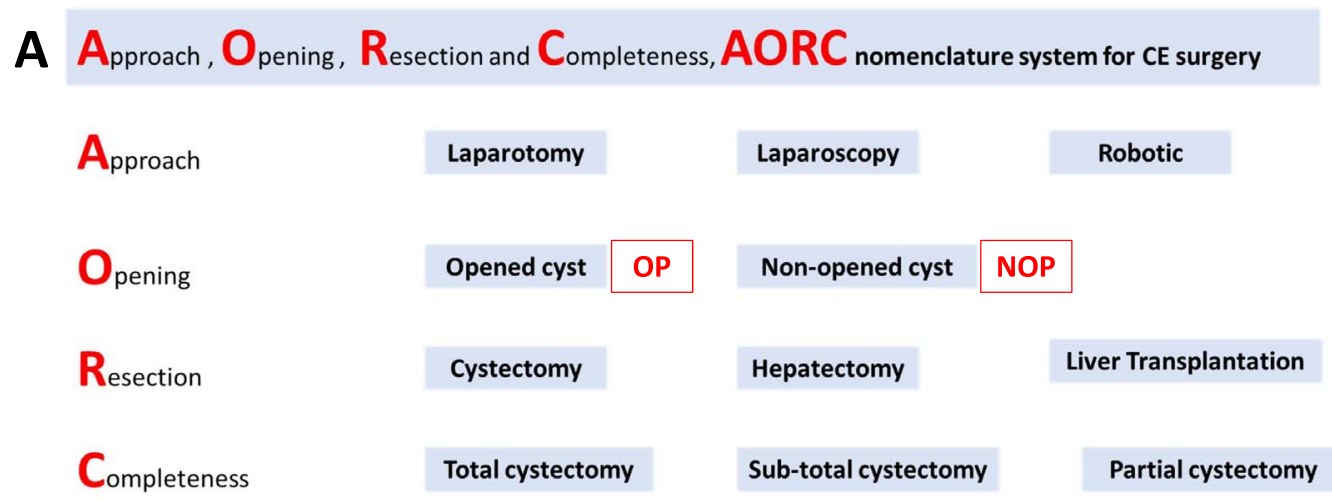

\section{B Completeness Total Sub-total
(of the cystectomy)}

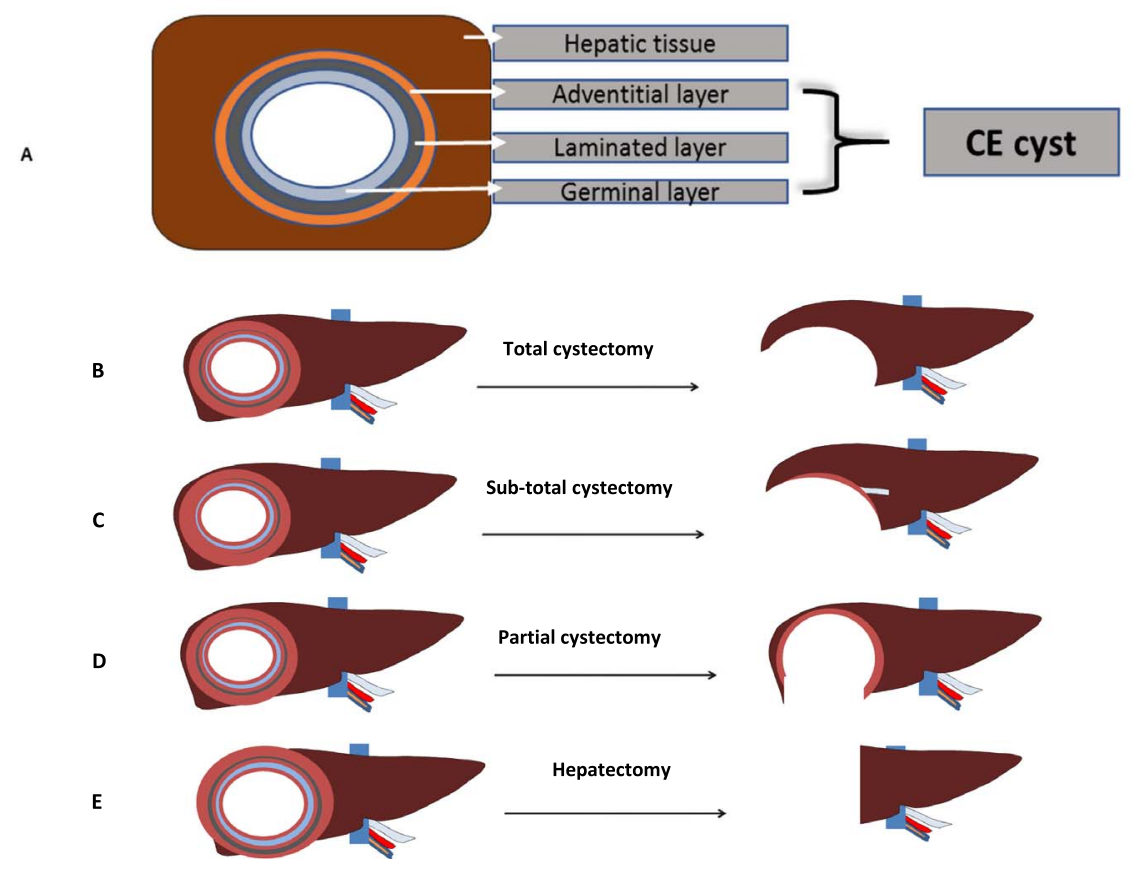

Figure 3. "AORC" nomenclature framework for CE surgery. (A) (top) - Vocabulary and acronyms. AORC: acronym for Approach, Opening, Resection and Completeness; CE: cystic echinococcosis; OC: opened cyst; NOC: non-opened cyst. (B) (bottom) - A. Schematic structure of CE cyst: the CE cyst consists (from inside to outside) of the germinal layer, laminated layer and adventitial layer. B. Total cystectomy requires the resection of all three layers completely. C. Subtotal cystectomy requires the nearly total resection of all three layers; only parts of the adventitial layer are preserved because of surgical safety. D. Partial cystectomy refers to the incomplete resection of any of three layers (usually of the adventitial layer) due to technical and safety issue. E. Hepatectomy requires the en bloc resection of part of liver parenchyma, following the rules of hepatic resection.

The participants involved in the work were representative of the "echinococcosis" scientific community. Half of the 61 participants in the three working groups belonged to the top 50 experts in the area (as cited from their publications retrieved with the key words "echinococcosis": http://expertscape.com/ex/ echinococcosis or "hepatic echinococcosis": http://expertscape. com/ex/echinococcosis\%2C+hepatic). Health professionals and young researchers were also involved in the CRG; there was a balanced proportion of researchers and professionals. The participants in the three groups were from 15 endemic countries, and all five continents were represented with a balance of male and female contributors to the debate. Recruitment of the participants in the CRG at the 27th WCE on a volunteer basis enabled researchers and professionals from the Maghreb and Middle East countries, highly endemic countries for $\mathrm{CE}$, to participate in the CRG. 
Table 1A. Recommended terms for the genetics and epidemiology of Echinococcus species.

\begin{tabular}{|c|c|c|c|}
\hline Word/expression & Definition & $\begin{array}{c}\text { Arguments for acceptance, references, } \\
\text { linguistic clarifications }\end{array}$ & Comments \\
\hline $\begin{array}{l}\text { Echinococcus } \\
\text { Rudolphi, } 1801 \\
\text { (Cestoda: Taeniidae) }\end{array}$ & $\begin{array}{l}\text { Genus in the family } \\
\text { Taeniidae Ludwig, 1886, } \\
\text { order Cyclophyllidea, } \\
\text { class Cestoda, phylum } \\
\text { Platyhelminthes, } \\
\text { kingdom Animalia. }\end{array}$ & $\begin{array}{l}\text { International nomenclature; name } \\
\text { of the genus Echinococcus [67]; must } \\
\text { be written in italics with first letter in } \\
\text { capital letter; abbreviation "E." } \\
\text { (italics followed by a dot) when in } \\
\text { a binomen (i.e. a generic name } \\
\text { and a specific name) or in a trinomen } \\
\text { (a generic name, a specific name and } \\
\text { a subspecific name - this is rare). }\end{array}$ & $\begin{array}{l}\text { The genus name Alveococcus (for the } \\
\text { species Alveococcus multilocularis } \\
\text { (Leuckart, 1863) Abuladze, 1959) was } \\
\text { erected to separate E. multilocularis } \\
\text { from the other species. There is no } \\
\text { longer a taxonomic basis for such a } \\
\text { separation, but the name is still used } \\
\text { occasionally, particularly in Russian } \\
\text { literature. See also Table 2A. }\end{array}$ \\
\hline
\end{tabular}

$\begin{array}{ll}\text { Echinococcus sp. } & \begin{array}{l}\text { One species within } \\ \text { the genus } \\ \text { Echinococcus. }\end{array}\end{array}$

Echinococcus spp. More than one (or all) species within the genus Echinococcus.

\section{Echinococcus}

canadensis

(Webster \&

Cameron,

1961)

Echinococcus equinus (Williams \& Sweatman, 1963)
A species within the E. granulosus sensu lato species cluster.
The abbreviation "sp." (not italics) stands for a species, the identity of which is not known (e.g. in case of an undetermined Echinococcus isolate)

The abbreviation "spp." does not indicate a species with the taxonomic definition of "species", but stands for "species pluralis" (the Latin for "multiple species"), hence the roman letters (not italics).

spp is followed by a dot (because it is the abbreviation of a Latin expression; see e.g., i.e., as examples), thus: "spp."

E. canadensis (Webster \& Cameron, 1961) [80] corresponds to the previous "G6/G7", "G8" and "G10" genotypes, identified by DNA sequencing [52] (see GenBank: https://www.ncbi.nlm. nih.gov/genbank/); E. canadensis belongs to E. granulosus s.l. Genotypes may be used to differentiate between distinct molecular sequences, within the defined species; the word "strain" should no longer be used.

E. equinus (Williams \& Sweatman, 1963) [84] corresponds to the previous "G4" genotype, identified by DNA sequencing [52] (see GenBank: https:// www.ncbi.nlm.nih.gov/genbank/). E. equinus belongs to E. granulosus s.l. [66]

E. felidis Ortlepp, 1937 [59], was first described as such in 1937 by Ortlepp from the lion, Panthera leo, in South Africa; it is now recognized as a distinct species, identified by DNA sequencing [52] (see GenBank: https://www.ncbi. nlm.nih.gov/genbank/collab/); E. felidis belongs to E. granulosus s.l. [26]
E. canadensis cycle may involve camels and goats (G6 genotype), pigs (G7) and cervids (G8 and G10) as intermediate hosts and dogs (as well as wolves for G8 and G10) as definitive hosts; however, sheep, cattle and other ungulates may also be infected by E. canadensis, which is the second species within E. granulosus s.l., after E. granulosus s.s., to infect humans. G6 and G7 may in future be separated from this species, so at present the expression " $E$. canadensis cluster" is recommended.

E. equinus cycle usually involves members of the horse family as intermediate hosts and dogs as definitive hosts. It is also known from a wildlife cycle involving lions and zebras $[9,78]$.

It is associated with disease in nonhuman primates (lemurs) [9, 12]. However, the zoonotic potential of E. equinus infection (i.e. infection in humans) has not yet been convincingly demonstrated [2].

E. felidis cycle involves lions as definitive hosts, and it is only known from warthogs and hippos as intermediate hosts; E. felidis infection has not been recognized to be associated with disease in humans up to now [25]

$\begin{array}{ll}\text { Echinococcus } & \text { A species within the } \\ \text { felidis Ortlepp, } & \text { E. granulosus sensu } \\ 1937 & \text { lato species cluster. }\end{array}$


Table 1A. (Continued)

\begin{tabular}{|c|c|c|c|}
\hline Word/expression & Definition & $\begin{array}{c}\text { Arguments for acceptance, references, } \\
\text { linguistic clarifications }\end{array}$ & Comments \\
\hline $\begin{array}{l}\text { Echinococcus } \\
\text { granulosus } \\
\text { (Batsch, 1786) } \\
\text { sensu lato }\end{array}$ & $\begin{array}{l}\text { The concept of E. granulosus } \\
\text { as one species cluster that } \\
\text { contains all agents of cystic } \\
\text { echinococcosis. }\end{array}$ & $\begin{array}{l}\text { "sensu lato" and "sensu stricto" } \\
\text { are used, when a species name } \\
\text { (here: E. granulosus (Batsch, } \\
\text { 1786)) [7] is used in different } \\
\text { concepts: in a wider sense (s.l.) } \\
\text { that includes e.g. cryptic } \\
\text { species, or in a more restricted } \\
\text { concept (s.s.) [52]. } \\
\text { "sensu lato" should be in italics } \\
\text { (although this is debated), without } \\
\text { capital letters as first letters. The } \\
\text { abbreviation of each word in } \\
\text { "sensu lato" is followed by a } \\
\text { dot (because it is the abbreviation } \\
\text { of Latin words; see e.g., i.e., } \\
\text { as examples), thus: "s.l." }\end{array}$ & $\begin{array}{l}\text { "granulosus" should be followed by "sensu } \\
\text { lato" whenever the precise species has not } \\
\text { been determined. } \\
\text { For publications on the clinical aspects of } \\
\text { echinococcosis, as the clinical descriptions } \\
\text { of the disease "cystic echinococcosis"(CE) } \\
\text { fits with all those species within } \\
\text { E. granulosus sensu lato that are } \\
\text { responsible for disease in humans, the use } \\
\text { of } E \text {. granulosus sensu lato is allowed } \\
\text { when there was no identification of the real } \\
\text { species. For publications on basic research } \\
\text { and epidemiology, molecular identification } \\
\text { of the real species is necessary; it should be } \\
\text { performed and indicated in the Materials } \\
\text { and Methods section. }\end{array}$ \\
\hline
\end{tabular}

\section{Echinococcus granulosus (Batsch, 1786)

\begin{abstract}
A species within the E. granulosus sensu lato species cluster.
\end{abstract} sensu stricto

Echinococcus multilocularis

(Leuckart, 1863)
A species in the genus Echinococcus.

\section{"sensu stricto" and "sensu lato" are used, when a species name (here: E. granulosus (Batsch, 1786)) [7] is used in different concepts: in a wider sense (s.l.) that includes e.g. cryptic species, or in a more restricted concept (s.s.) [52, 66]. \\ "sensu stricto", which is the equivalent of a species, should be in italics (although this is debated), without capital letters as first letters. The abbreviation of each word in "sensu stricto" is followed by a dot (because it is the abbreviations of Latin words; see e.g., i.e., as examples), thus: "s.s." E. granulosus s.s. belongs to E. granulosus s.l. [66]}

E. multilocularis (Leuckart, 1863)

[50], is the agent of the disease "alveolar echinococcosis" (AE) in humans $[35,52]$
E. granulosus sensu stricto corresponds to the previous "G1", "G2", a microvariant of "G3", and "G3" genotypes, identified by DNA sequencing (see GenBank: https:// www.ncbi.nlm.nih.gov/genbank/); its cycle usually involves sheep as intermediate hosts and dogs as definitive hosts; cattle and other ungulates may also be infected by E. granulosus sensu stricto A strongly diverging genotype from Africa ("G Omo") is provisionally retained in E. granulosus s.s., but will have to be reclassified in the future [79].
E. multilocularis was clearly distinguished from $E$. granulosus sensu lato in the middle of the 20th century [18, 77]. It involves a variety of rodents and lagomorphs as intermediate hosts depending on the geographical area, humans as accidental intermediate hosts, and various species of foxes, dog and wolf as definitive hosts. The disease caused by E. multilocularis, characterized by lesions composed of an aggregate of microcysts embedded in a granulomatous host's reaction, is distinct from that caused by E. granulosus s.l. as well as those caused by E. vogeli and E. oligarthra.

Since then, no major genetic polymorphism has been found within E. multilocularis that would distinguish new species or even strains. For phylogeographic studies (variability at a continental scale), genetic polymorphism within the micro-satellite EmSB may be used [42]. 
Table 1A. (Continued)

\begin{tabular}{|c|c|c|}
\hline Word/expression & Definition & $\begin{array}{c}\text { Arguments for acceptance, references, } \\
\text { linguistic clarifications }\end{array}$ \\
\hline $\begin{array}{l}\text { Echinococcus } \\
\text { oligarthra } \\
\text { (Diesing, 1863) }\end{array}$ & $\begin{array}{l}\text { A species in the } \\
\text { genus Echinococcus. }\end{array}$ & $\begin{array}{l}\text { E. oligarthra (Diesing, 1863) [14] } \\
\text { is a species found in South, } \\
\text { Central and North America } \\
\text { (Mexico) [52, 58]. } \\
\text { The component "arthra", } \\
\text { originally proposed by } \\
\text { Diesing, comes from the ancient } \\
\text { Greek å } \rho \rho \alpha \text {-arthra (joints) which } \\
\text { is the plural of á } \rho \rho \rho \text {-arthron } \\
\text { (joint). The name is therefore } \\
\text { not an adjective, but a noun in } \\
\text { apposition, which does not change } \\
\text { its ending according to the } \\
\text { gender of the generic name. } \\
\text { This was recognized earlier but } \\
\text { subsequently ignored. }\end{array}$ \\
\hline $\begin{array}{l}\text { E. ortleppi } \\
\text { Lopez-Neyra } \\
\text { \& Soler Planas, } \\
1943\end{array}$ & $\begin{array}{l}\text { A species within the } \\
\text { E. granulosus sensu } \\
\text { lato species cluster. }\end{array}$ & $\begin{array}{l}\text { E. ortleppi Lopez-Neyra \& Soler } \\
\text { Planas, } 1943 \text { [51] corresponds to } \\
\text { the previous "G5" genotype, } \\
\text { identified by DNA sequencing } \\
{[1,52,66] \text { (see GenBank) }}\end{array}$ \\
\hline $\begin{array}{l}\text { E. shiquicus } \\
\text { Xiao, Qiu, Nakao, } \\
\text { Li, Yang, Chen, } \\
\text { Schantz, } \\
\text { Craig \& Ito, } 2005\end{array}$ & $\begin{array}{l}\text { A species in the } \\
\text { genus } \\
\text { Echinococcus. }\end{array}$ & $\begin{array}{l}\text { E. shiquicus Xiao et al., } 2005 \\
\text { [85] is a species phylogenetically } \\
\text { close to E. multilocularis [52] } \\
\text { which was identified in the } \\
\text { county of Sêrxü (in Tibetan, } \\
\text { 石渠县 in Mandarin Chinese (pinyin: } \\
\text { Shíqú Xiàn)) in Sichuan province, } \\
\text { Qinghai-Tibet plateau region of } \\
\text { Western PR China }\end{array}$ \\
\hline $\begin{array}{l}\text { E. vogeli Rausch \& } \\
\text { Bernstein, } 1972\end{array}$ & $\begin{array}{l}\text { A species in } \\
\text { the genus } \\
\text { Echinococcus. }\end{array}$ & $\begin{array}{l}\text { E. vogeli Rausch \& Bernstein, } 1972 \\
\text { [62] is an Echinococcus species } \\
\text { found only in South and } \\
\text { Central America. }\end{array}$ \\
\hline
\end{tabular}

E. vogeli natural cycle mainly involves paca (Cuniculus paca) as intermediate hosts; it has also been documented in other rodents such as agouti (Dasyprocta spp.), and the bush dog (Speothos venaticus) and domestic dogs as definitive hosts [65]; $E$. vogeli is responsible for a disease in humans distinct from cystic and alveolar echinococcosis, often called "polycystic echinococcosis", because of the presentation of the disease [35]. "Neotropical echinococcosis" is the expression recommended to qualify the human infection due either to E. vogeli or to E. oligarthra: see also Table 1C.

$\begin{array}{lll}\text { G genotypes } & \text { Genotypes identified } & \text { Genotypes may be used to } \\ \text { within the species } & \text { differentiate between distinct } \\ \text { E. granulosus s.l., } & \text { molecular sequences, within the } \\ \text { previously identified } & \text { defined species or complexes; } \\ \text { as "strains". } & \text { the word "strain" should no longer } \\ & \text { be used when genetic characterization } \\ & \text { has been performed [52, 55]. }\end{array}$

Further definition of new species is still possible. Waiting for such definitions, $\mathrm{G}$ genotypes should be kept, in addition to the current species name, if necessary. has been performed $[52,55]$. 
Table 1A. (Continued)

\begin{tabular}{|c|c|c|c|}
\hline Word/expression & Definition & $\begin{array}{c}\text { Arguments for acceptance, references, } \\
\text { linguistic clarifications }\end{array}$ & Comments \\
\hline G1 and G3 genotypes & $\begin{array}{l}\text { Genotypes individualized } \\
\text { within E. granulosus } \\
\text { sensu stricto. }\end{array}$ & $\begin{array}{l}\text { The word "genotype" should be } \\
\text { used; it is more appropriate than } \\
\text { "strain" since it is based on } \\
\text { genotyping and not on other } \\
\text { techniques (especially morphological) } \\
\text { previously used to distinguish } \\
\text { between strains }[52,55] .\end{array}$ & $\begin{array}{l}\text { Keeping the distinction between genotypes } \\
\text { may be necessary for phylogeographic } \\
\text { studies and in some circumstances for } \\
\text { echinococcosis control (targeting animal } \\
\text { hosts and specific cycles) [38, 41]. Best } \\
\text { target for identification of G1 and G3 } \\
\text { seems to be the nad5 gene region [39]. } \\
\text { G1 is the most common genotype in sheep; } \\
\text { G2 was first described as "Tasmanian } \\
\text { sheep strain" but is actually cosmopolitan; } \\
\text { G3 was initially identified from water } \\
\text { buffalo, but is now also known from other } \\
\text { intermediate hosts. } \\
\text { G2 is considered a microvariant of G3 [40]. }\end{array}$ \\
\hline G6/G7 G8 G10 & $\begin{array}{l}\text { Genotypes } \\
\text { individualized } \\
\text { within E. canadensis } \\
\text { (Webster \& } \\
\text { Cameron, 1961). }\end{array}$ & $\begin{array}{l}\text { Pending further distinction between } \\
\text { accepted species, genotypes within } \\
\text { E. canadensis should be qualified by the } \\
\text { previously accepted "G" numbers } \\
\text { G6/G7, G8 and G10 [49, 66]. } \\
\text { Genotypes may be used to differentiate } \\
\text { between distinct molecular sequences, } \\
\text { within the defined species; the word } \\
\text { "strain" should no longer be used. }\end{array}$ & $\begin{array}{l}\text { G9 is no longer recognized as a distinct } \\
\text { genotype; it is probably a microvariant of } \\
\text { G7; the genotypic cluster G6/7 is the } \\
\text { second most important agent of human } \mathrm{CE} \\
\text { worldwide; further distinction between } \\
\text { species within the } E \text {. canadensis cluster has } \\
\text { been proposed, but has not been accepted } \\
\text { yet }[48,53,54,57] \text {. }\end{array}$ \\
\hline
\end{tabular}

Table 1B. Recommended terms for the biology and immunology of Echinococcus species.

\begin{tabular}{|c|c|c|c|}
\hline $\begin{array}{l}\text { Word/ } \\
\text { expression }\end{array}$ & Definition & $\begin{array}{c}\text { Arguments for acceptance; references; } \\
\text { linguistic clarifications }\end{array}$ & Comments \\
\hline $\begin{array}{l}\text { *Aborted } \\
\text { (cyst, lesion), } \\
\text { Adjective }\end{array}$ & $\begin{array}{l}\text { Non-viable parasitic structure as } \\
\text { evidenced by imaging (complete } \\
\text { calcification in AE, CE5 cyst in } \\
\text { CE) or histological examination } \\
\text { (absence of viable parasitic cells). }\end{array}$ & $\begin{array}{l}\text { Could be used in clinical or } \\
\text { experimental situations when } \\
\text { evidence of absence of } \\
\text { viability is not obtained by } \\
\text { transplantation or in vitro } \\
\text { culture. }\end{array}$ & $\begin{array}{l}\text { Distinct from "non-viable"; the } \\
\text { definition was approved unanimously } \\
\text { by the voters; the adjective "aborted" } \\
\text { was preferred to the alternative } \\
\text { "died-out" by the majority of voters } \\
\text { (median: 10). }\end{array}$ \\
\hline $\begin{array}{l}\text { *Adult form, } \\
\text { Expression }\end{array}$ & $\begin{array}{l}\text { Sexual reproduction stage of } \\
\text { Echinococcus spp. parasites in } \\
\text { their definitive hosts. }\end{array}$ & $\begin{array}{l}\text { More popular alternative expression } \\
\text { to the specific scientific expression } \\
\text { "strobilar stage" to designate this } \\
\text { step in the development of } \\
\text { Echinococcus spp. cestodes; } \\
\text { expression coherent with "larval } \\
\text { form" in the intermediate hosts. }\end{array}$ & $\begin{array}{l}\text { "Adult" may include all stages of } \\
\text { development in the } \\
\text { definitive host (fertile or immature } \\
\text { worms i.e. with the last segment } \\
\text { containing eggs } \\
\text { or not). } \\
\text { This expression with its definition was } \\
\text { approved by the majority of voters } \\
\text { (median: } 10 \text { ) }\end{array}$ \\
\hline $\begin{array}{l}\text { *Adventitial } \\
\text { layer, } \\
\text { Expression }\end{array}$ & $\begin{array}{l}\text { Partly cellular and fibrous } \\
\text { layer of host origin surrounding the } \\
\text { inner } 2 \text { layers of parasite origin } \\
\text { (germinal and laminated layers) of } \\
\text { the metacestode in the intermediate } \\
\text { host of } \\
\text { E. granulosus sensu lato. }\end{array}$ & $\begin{array}{l}\text { The expression was approved } \\
\text { in order to have a coherent } \\
\text { denomination of the various "layers" of } \\
\text { the hydatid cyst, irrespective of their } \\
\text { origin (parasite or host). } \\
\text { As for "germinal membrane" } \\
\text { and "laminated membrane", } \\
\text { the use of the expression "adventitial } \\
\text { membrane" is } \\
\text { not relevant. }\end{array}$ & $\begin{array}{l}\text { "Adventitia" was an alternative term; it } \\
\text { was rejected by voters (median: } 2 \text { ). The } \\
\text { expression "adventitial layer" with its } \\
\text { definition was approved by the majority } \\
\text { of voters (median: 10) } \\
\text { The correct description of the parasitic } \\
\text { structures in the intermediate host thus } \\
\text { includes } 3 \text { similar expressions, from } \\
\text { inside to outside: } \\
\text { - Germinal layer } \\
\text { - Laminated layer } \\
\text { - Adventitial layer }\end{array}$ \\
\hline
\end{tabular}


Table 1B. (Continued)

\begin{tabular}{|c|c|c|}
\hline $\begin{array}{l}\text { Word/ } \\
\text { expression }\end{array}$ & Definition & $\begin{array}{l}\text { Arguments for acceptance; references; } \\
\text { linguistic clarifications }\end{array}$ \\
\hline $\begin{array}{l}\text { *Border } \\
\text { (periparasitic), } \\
\text { Noun }\end{array}$ & $\begin{array}{l}\text { For both E. granulosus s.l. and } \\
\text { E. multilocularis, structures that } \\
\text { surround the laminated layer, } \\
\text { at the border with the organ } \\
\text { parenchyma. }\end{array}$ & $\begin{array}{l}\text { Alternative term to } \\
\text { "boundary" }\end{array}$ \\
\hline $\begin{array}{l}\text { Brood } \\
\text { capsule, } \\
\text { Expression }\end{array}$ & $\begin{array}{l}\text { Element budding from } \\
\text { the germinal layer } \\
\text { which produces protoscoleces. }\end{array}$ & No synonyms. \\
\hline $\begin{array}{l}* \text { Cyst } \\
\text { (echinococcal } \\
\text { or hydatid), } \\
\text { Noun }\end{array}$ & $\begin{array}{l}\text { Anatomical entity produced by } \\
\text { the growth of the metacestode of } \\
\text { Echinococcus spp. distinct from the } \\
\text { surrounding organ parenchyma and } \\
\text { filled with fluid, which includes } \\
\text { (from outside to inside) } \\
\text { - Adventitial layer (of host origin, } \\
\text { even reduced to a few infiltrating } \\
\text { cells or to fibrous tissue) } \\
\text { - Laminated layer (of parasite } \\
\text { origin) } \\
\text { Germinal layer (of parasite } \\
\text { origin) } \\
\text { - Cyst fluid (and its content, of both } \\
\text { parasite and host origin). }\end{array}$ & $\begin{array}{l}\text { The word "cyst" should be reserved to } \\
\text { the clinical (or experimental) situation } \\
\text { in CE ("hydatid" cyst) or NE; it may be } \\
\text { observed by a variety of imaging } \\
\text { techniques such as ultrasound imaging, } \\
\text { computed tomography, or magnetic } \\
\text { resonance imaging. } \\
\text { The international classification of CE } \\
\text { cysts is based on ultrasound imaging } \\
\text { with } 5 \text { CE stages [82] } \\
\text { Two types of CE3 cysts (a and b) are } \\
\text { now described [10, 31]. }\end{array}$ \\
\hline
\end{tabular}

\section{* Cyst fluid, Expression Liquid secreted by the germinal layer of Echinococcus spp. larval form and collected at the center of the "cyst" (for $E$. granulosus s.l.) or hosts, including experimental models. of the "microcysts" (for \\ E. multilocularis). \\ Should be reserved for in vivo \\ situations: cysts in $\mathrm{CE}$, and $\mathrm{NE}$, and microcysts of $\mathrm{AE}$ in human and animal}

*Echinococcal, Adjective

Fertile (strobilar Adjective proposed to qualify anything relating to all Echinococcus spp. irrespective Completely generic term that does not assume the species and/or stage of Echinococcus spp.

of the species, of the pathology, or Based on the recommendations of the of the clinical presentation of the World Federation of Parasitologists disease that occurs in humans or in regarding the names of parasitic animal intermediate or definitive hosts. diseases [32]. https://www.waavp.org/documents/ snopad-guidelines/\#.XS9gBvIza00

Should be restricted to the

Product of the hermaphrodite fecundation in the last proglottis of the adult form of Echinococcus spp. parasites; released in the feces stages preceding ingestion by the intermediate host and oncosphere release [27].

of the definitive hosts and the environment.

tage/adult form

or worm),

Adjective
Adult form/strobilar stage (worm) of Echinococcus spp. in the of which contains eggs (i.e. infectious to intermediate hosts).
Production of eggs, observable in the last segment of the adult form implies that the worm is fertile (conversely, absence of eggs does not automatically imply that it is non-fertile; it may just be "immature")
The distinction between "vesicle fluid" and "cyst fluid" was approved by all voters (median: 10); they also approved the use of "cyst" for the in vivo situation only.

The term "hydatid" is more common, but also more confusing, and should be restricted to E. granulosus $s$. $l$. Usage of "echinococcal" with the generic definition was approved by the majority of voters (median: 8).

See Figures 2A-2C for detailed description and terminology.

Please see also the definition of "fertile" for the parasitic structures in the intermediate host, and the definition of "immature", in this table. 
Table 1B. (Continued)

\begin{tabular}{lll}
\hline $\begin{array}{l}\text { Word/ } \\
\text { expression }\end{array}$ & \multicolumn{1}{c}{ Definition } & $\begin{array}{l}\text { Arguments for acceptance; } \\
\text { references; linguistic clarifications }\end{array}$ \\
\hline $\begin{array}{l}\text { *Fertile } \\
\text { (metacestode, }\end{array}$ & $\begin{array}{l}\text { Larval parasitic structure that } \\
\text { contains viable protoscoleces } \\
\text { and thus allows infection of the } \\
\text { larva, cyst, }\end{array}$ & $\begin{array}{l}\text { Production of protoscoleces by the } \\
\text { germinal layer and their release in } \\
\text { the parasitic fluid (whatever the } \\
\text { Adjective }\end{array}$ \\
or in some pathological or & $\begin{array}{l}\text { This adjective with its definition for } \\
\text { species) implies that the metacestode }\end{array}$
\end{tabular}

\section{Germinal layer,} Expression

*Germinative cell, Expression

Hooks, Noun

\section{*Hydatid, \\ Adjective}

Hydatid, Noun experimental circumstances production of newly developed metacestodes in the intermediate host.

Inner cellular part of Echinococcus spp. metacestode, which includes several types of cells and produces several types of biological components of the metacestode (cyst fluid, brood capsules, and protoscoleces).

Pluripotent somatic stem cell with some homologies but also differences to neoblasts of freeliving flatworms. Germinative cells are the only mitotically active cells in the metacestode and give rise to all differentiated cells.

Appendices of the adult form of Echinococcus spp. parasites that allow them to attach to the intestinal wall of the definitive hosts.

Refers to Echinococcus spp. metacestode in intermediate hosts;

more specifically refers to the metacestode of Echinococcus granulosus s.l.
The term "layer" should be preferred to "germinal membrane" because of the complexity of the various "layers" of the cyst, and the possible confusion of "membrane" with the cell "membrane", which has a specific definition in biology.

Most commonly used expression in the literature, with this definition [47].

However, it must be noted that not all cells of the germinal layer are germinative cells.

This term should be used because all hooks on the scolex of Echinococcus spp. have the same size.

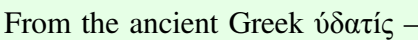

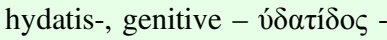
hydatidos (vesicle/bladder full of water), "hydatid", which describes the larval stage of Echinococcus spp. (metacestode) should never be used for the adult stage of Echinococcus spp.

In order to avoid confusion between human diseases caused by the various species, "hydatid" should not be used

to designate anything relating to alveolar echinococcosis (or E. multilocularis) or neotropical echinococcoses (or E. vogeli or E. oligarthra).

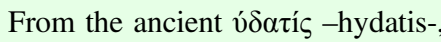

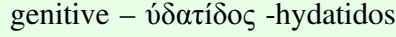
(vesicle/bladder full of water). Usable with this definition only for purely parasitological descriptions.
The correct description of the parasitic structures in the intermediate host includes three similar expressions, from inside to outside:

- Germinal layer

- Laminated layer

- Adventitial layer

See also Figures 2A-2C.

The expression was approved by the majority of voters (median: 8) against the alternative "germinal" (median: 3).

The restriction of the definition of the adjective "hydatid" to the metacestode of E. granulosus s.l. was approved unanimously by the voters (median: 10).
Should be restricted (by usage, not strictly by definition) to the metacestode of

E. granulosus s.l. It should not be used for the metacestode of E. multilocularis. 
Table 1B. (Continued)

\begin{tabular}{|c|c|c|}
\hline $\begin{array}{l}\text { Word/ } \\
\text { expression }\end{array}$ & Definition & $\begin{array}{l}\text { Arguments for acceptance; } \\
\text { references; linguistic clarifications }\end{array}$ \\
\hline $\begin{array}{l}\text { *Hydatid fluid, } \\
\text { Expression }\end{array}$ & $\begin{array}{l}\text { Liquid secreted by the } \\
\text { germinal layer of } \\
\text { Echinococcus spp. } \\
\text { metacestode. }\end{array}$ & $\begin{array}{l}\text { Following the suggestion of using } \\
\text { "hydatid" only to qualify nouns or } \\
\text { expressions related to E. granulosu } \\
\text { s.l. (see above), this expression } \\
\text { should also be restricted to these } \\
\text { species. For any other species "fluid } \\
\text { should be preceded by the } \\
\text { taxonomic name of the species, or } \\
\text { the expression "cyst fluid" (for in } \\
\text { vivo situations) or "vesicle fluid" (fo } \\
\text { in vitro situations) could be used. }\end{array}$ \\
\hline $\begin{array}{l}* * \text { Immature } \\
\text { (strobilar } \\
\text { stage/adult } \\
\text { form), } \\
\text { Adjective }\end{array}$ & $\begin{array}{l}\text { Strobilar stage/adult form of } \\
\text { Echinococcus spp. in the } \\
\text { definitive host the last } \\
\text { segment of which does not } \\
\text { contain eggs (i.e. at least } \\
\text { temporarily non-infectious to }\end{array}$ & $\begin{array}{l}\text { "Immature" just indicates that the } \\
\text { adult form has not fully developed } \\
\text { to the stage of egg production; it } \\
\text { does not imply that the adult worm } \\
\text { will never become fertile, as could } \\
\text { suggest the alternative "non-fertile' }\end{array}$ \\
\hline
\end{tabular}

\section{*Infiltrate (periparasitic), Noun}

\section{Laminated \\ layer,}

Expression

*Larva,

Noun

Larval form,

Expression
Histological components (cellular and fibrous) of host origin in alveolar echinococcosis; opposite to the "adventitial layer" of CE cysts, the cellular and fibrous infiltrate in $\mathrm{AE}$ has no clear limits with the surrounding liver parenchyma.

Peripheral acellular outer part of Echinococcus spp. metacestode, mostly composed of mucopolysaccharides.

Asexual reproduction stage of Echinococcus spp. parasites in their intermediate host.

Asexual reproduction form of Echinococcus spp. parasites in their intermediate hosts.

Alternative term to "infiltration".

The laminated layer is produced by the parasite and exerts important functions in the interaction between the metacestode and the intermediate host [21]. The term "layer" should be preferred because of the complexity of the various "layers" of the metacestode, and the possible confusion of "membrane" with the cell "membrane", which has a specific definition in biology.

Generally used as a popular equivalent of "metacestode".

Expression coherent with the recommended expression "adult form".
See also the entry "non-fertile" in Table $2 \mathrm{~B}$ regarding the strobilar stage/adult form; and also "nonfertile", approved for the metacestode in the intermediate host, in this table.

This adjective was added by the SWG, on experts' suggestion, to the list of approved terms after the poll.

The use of "infiltrate" was approved by all voters but one (median: 10).

The correct description of the parasitic structures in the intermediate host includes 3 similar expressions, from inside to outside:

- Germinal layer

- Laminated layer

- Adventitial layer

See also Figures 2A-2C.

All voters but 2 considered that "larva" and "metacestode" were synonymous; however, metacestode should be preferred for scientific communication; see also the entry "larval form".

The expression may be used as an equivalent of metacestode (or of larva)

for communication to the public and to professionals. 
Table 1B. (Continued)

\begin{tabular}{|c|c|c|c|}
\hline $\begin{array}{l}\text { Word/ } \\
\text { expression }\end{array}$ & Definition & $\begin{array}{l}\text { Arguments for acceptance; } \\
\text { references; linguistic clarifications }\end{array}$ & Comments \\
\hline $\begin{array}{l}\text { **Metacestode } \\
\text { (singular) } \\
\text { metacestodes } \\
\text { (plural), } \\
\text { Noun }\end{array}$ & $\begin{array}{l}\text { Asexual reproduction } \\
\text { form of Echinococcus } \\
\text { spp. parasites in their } \\
\text { intermediate hosts; } \\
\text { second phase of } \\
\text { development which } \\
\text { includes all stages from } \\
\text { the post-oncospheral } \\
\text { stage to the fertile stage } \\
\text { (with production of } \\
\text { protoscoleces, if any). }\end{array}$ & $\begin{array}{l}\text { Scientific designation of cestode } \\
\text { parasites in their intermediate } \\
\text { hosts; larva is an alternative noun } \\
\text { usable for communication to the } \\
\text { public and to professionals. } \\
\text { The approved definition is } \\
\text { supported by textbooks of } \\
\text { veterinary parasitology [28] and } \\
\text { those on Echinococcus spp. [72]. }\end{array}$ & $\begin{array}{l}\text { As the voters did not agree } \\
\text { on the definition of } \\
\text { "metacestode" (i.e. stages } \\
\text { of development included } \\
\text { in the definition), this was } \\
\text { further discussed by } \\
\text { experts after the poll, and } \\
\text { the final definition (shown } \\
\text { in the second column) was } \\
\text { approved. }\end{array}$ \\
\hline $\begin{array}{l}\text { *Microcysts } \\
\text { (echinococcal, } \\
\text { E. multilocularis, } \\
\text { AE), Noun, } \\
\text { microcystic, } \\
\text { Adjective }\end{array}$ & $\begin{array}{l}\text { Multiple small cysts } \\
\text { (under } 1 \mathrm{~cm} \text { of diameter) } \\
\text { with germinal layer, } \\
\text { laminated layer and } \\
\text { periparasitic infiltrate of } \\
\text { host's cells and fibrosis, } \\
\text { characteristic of AE } \\
\text { lesions (due to } \\
\text { E. multilocularis). }\end{array}$ & $\begin{array}{l}\text { Should be reserved for AE lesions } \\
\text { in vivo; may be observed with } \\
\text { selected imaging techniques such } \\
\text { as Magnetic Resonance Imaging } \\
\text { (T2-weighted images) in humans } \\
\text { or preclinical models, and/or } \\
\text { histological examination in } \\
\text { experimental models. } \\
\text { Microcysts are parasitic structures, } \\
\text { distinct from the central necrotic } \\
\text { cavity often developed in the AE } \\
\text { lesions ("pseudocyst" should be } \\
\text { used for this cavity). See also the } \\
\text { entry "pseudocyst" in this table. } \\
\text { The noun "microcysts"[6] may } \\
\text { replace the expression "multiple }\end{array}$ & $\begin{array}{l}\text { In this situation, "micro" } \\
\text { does not refer to } \\
\text { "microscopic" but to } \\
\text { "small" (from ancient } \\
\text { Greek } \mu 1 \kappa \rho \text { ó -micros } \\
\text { (small)) macroscopic } \\
\text { aggregated cysts in AE, } \\
\text { opposite to the "big" - } \\
\text { often isolated - cysts in } \\
\text { CE or E. oligarthra-NE or } \\
\text { multicystic presentation of } \\
\text { E. vogeli-NE. This noun } \\
\text { with this definition was } \\
\text { approved by } 8 / 10 \text { voters } \\
\text { (median: 9). }\end{array}$ \\
\hline
\end{tabular}

\author{
*Non-fertile \\ (metacestode, \\ larva, cyst, \\ microcyst. ..), \\ Adjective

*Non-viable
(metacestode,
larva, cyst,
microcyst,
protoscolex. ..),
Adjective

Oncosphere, Noun
Parasitic structure in the intermediate host that does not contain viable protoscoleces, and thus is unable to infect definitive hosts.

Parasitic structure in the intermediate host that does not contain living cells able to proliferate in appropriate conditions, i.e. which does not grow when transplanted into a new intermediate host, or put into culture in vitro.

Infectious form of Echinococcus spp. parasites resulting from the release from the egg through the action of proteolytic enzymes in the digestive system of intermediate hosts. replace the expression "multiple small round cysts" found in Kodama et al., 2003[43].

A "non-fertile" metacestode may be "viable"; these adjectives are not synonymous [22].

"Non-viable" implies that the parasitic structure does not grow when transplanted into the same or a new intermediate host, or put into culture in an appropriate medium in vitro. However, non-invasive evaluation of non-viability in vivo is still imperfect [22].

Should be restricted to the stage following ingestion by the intermediate host, just before the cell proliferation stage (postoncospheral stage) that will constitute the metacestode.
This definition of "nonfertile" for the metacestode in intermediate hosts was approved by all voters but one (median: 10)

This definition of "viable" for the metacestode in intermediate hosts was approved by all voters (median: 10).

See Figures 2A and 2B for detailed description and terminology [27]. 
Table 1B. (Continued)

\begin{tabular}{|c|c|c|c|}
\hline $\begin{array}{l}\text { Word/ } \\
\text { expression }\end{array}$ & Definition & $\begin{array}{l}\text { Arguments for acceptance; } \\
\text { references; linguistic clarifications }\end{array}$ & Comments \\
\hline $\begin{array}{l}\text { Pericyst, Noun; } \\
\text { pericystic, Adjective }\end{array}$ & $\begin{array}{l}\text { Tissue surrounding the cyst. } \\
\text { Regarding echinococcosis, the } \\
\text { adjective applies to } \\
\text { E. granulosus sensu lato only: } \\
\text { tissue/structure (e.g. liver, lung, } \\
\text { adrenal gland, brain, etc.) that } \\
\text { surrounds the CE cyst which }\end{array}$ & $\begin{array}{l}\text { As the cyst, in E. granulosus sensu } \\
\text { lato infection, includes } \\
\text { the adventitial layer, the } \\
\text { pericyst only corresponds to } \\
\text { the organ parenchyma (plus vessels } \\
\text { and ducts) which surrounds the cyst. } \\
\text { Should not be used in }\end{array}$ & $\begin{array}{l}\text { In the clinical (or animal/ } \\
\text { experimental) situation in CE, the } \\
\text { noun "pericyst" (or the adjective } \\
\text { "pericystic") should not be used to } \\
\text { designate the adventitial layer } \\
\text { (which is "periparasitic", not } \\
\text { "pericystic"). }\end{array}$ \\
\hline
\end{tabular}

Periparasitic, Adjective

\section{*Post-oncospheral} stage, Expression

\section{*Proglottis \\ (singular), \\ proglottides (plural), Noun}

\section{Protoscolex \\ (plural: \\ protoscoleces), Noun}

Scolex (plural: scoleces), Noun
Stage between the oncosphere and the fully constituted metacestode.
For E. multilocularis: tissue/ structures that surround the laminated layer of E. multilocularis microcysts.

Part of the adult form of Echinococcus spp. parasites resulting from the segmentation of the scolex in the intestine of definitive hosts.

Prefiguration of the scolex, produced by the brood capsules budding to the outside of the germinal layer of Echinococcus spp. metacestode and released

in the cyst (CE) or micro-cyst (AE) fluid.

First segment ("head") of the adult form of cestodes.
Referring to the Greek origin of the word ( $\gamma \lambda \tilde{\omega} \tau \tau i ́$ : strap), "proglottis (sing), proglottides (plur) should be preferred to "proglottid"; in British English, the original plural of words from other languages is kept, hence "proglottides".

From the ancient Greek " $\sigma \kappa \omega \dot{\omega} \lambda \varepsilon \xi$ "scolex (worm), genitive: $\sigma \kappa \omega \dot{\lambda \varepsilon \kappa o \varsigma}$ -scolecos, and not -scolicos; the plural form is $\sigma \kappa \dot{\omega} \lambda \varepsilon \kappa \varepsilon \varsigma$, scoleces, and not scolices; with the prefix “ $\pi \rho \tilde{\omega} \tau o \varsigma "-p r o t o s$ (first/before).

From the ancient Greek " $\sigma \kappa \omega \dot{\omega} \lambda \varepsilon \xi$ ", scolex (worm), genitive: $\sigma \kappa \omega \dot{\lambda} \varepsilon \kappa \circ \varsigma$ -scolecos, and not -scolicos; the plural form is $\sigma \kappa \dot{\omega} \lambda \varepsilon \kappa \varepsilon \varsigma$, scoleces, and not scolices.
In the clinical (or animal/ experimental) situation in $\mathrm{CE}$, "periparasitic" (which includes the adventitial layer and the normal parenchyma of the organ) should not be a synonym for "pericystic" (which only includes the normal parenchyma of the organ; see also the definition of "(hydatid) cyst" and Figs. 2A-2C).

From a developmental biology/ immunology point of view, the early stages of development in the intermediate host are crucial as this is the time when the parasite is most susceptible to killing [21, 76]; agreement on this point was unanimous (median: 10).

Both spellings "proglottis" and "proglottid" were in use. However, the majority of voters (median: 9) selected the original (Greek) spelling.

For illustration of the formation of the protoscoleces, see Figure 1 in Koziol et al., 2016 [46].

The plural form of scolex (and of all derived words) should definitely be "scoleces". 
Table 1B. (Continued)

\begin{tabular}{|c|c|c|c|}
\hline $\begin{array}{l}\text { Word/ } \\
\text { expression }\end{array}$ & Definition & $\begin{array}{l}\text { Arguments for acceptance; } \\
\text { references; linguistic clarifications }\end{array}$ & Comments \\
\hline Segment, Noun & $\begin{array}{l}\text { Part of the adult form of } \\
\text { Echinococcus spp. parasites } \\
\text { resulting from segmentation of } \\
\text { the scolex in the intestine of } \\
\text { definitive hosts. }\end{array}$ & English equivalent of "proglottis". & $\begin{array}{l}\text { May be used as a popular } \\
\text { equivalent of "proglottis" in } \\
\text { reviews for students and } \\
\text { professionals, or } \\
\text { communication to the public, } \\
\text { etc. }\end{array}$ \\
\hline $\begin{array}{l}* * \text { Strobilar stage, } \\
\text { Expression }\end{array}$ & $\begin{array}{l}\text { Sexual reproduction stage (also } \\
\text { called "adult form") of } \\
\text { Echinococcus spp. parasites in } \\
\text { their definitive hosts. }\end{array}$ & $\begin{array}{l}\text { Specific scientific expression to } \\
\text { designate this step in the } \\
\text { development of Echinococcus spp. } \\
\text { cestodes. }\end{array}$ & $\begin{array}{l}\text { Like its more popular } \\
\text { synonym "adult form", it } \\
\text { includes all stages of } \\
\text { development in the definitive } \\
\text { host (fertile or immature } \\
\text { worms i.e. with the last } \\
\text { segment containing eggs or } \\
\text { not). }\end{array}$ \\
\hline Suckers, & Appendices of the adult form of & No synonyms. & See also Figures $2 \mathrm{~A}-2 \mathrm{C}$. \\
\hline
\end{tabular}

Noun
*Vesicle fluid,
Expression

Expression

*Vesicle (parasitic or echinococcal), Noun

*Viable
(metacestode,
germinal layer,
larva, cyst,
microcyst,
protoscoleces...),
Adjective

*Worm, Noun

Strobilar stage of Echinococcus spp. parasite in its definitive hosts (popular term).

Anatomical entity produced by the growth in vitro of the metacestode of Echinococcus spp. regardless of the species.

Parasitic structure of the metacestode which contains living cells able to proliferate in appropriate conditions.

Echinococcus spp. parasites hosts and to feed from it.

Liquid produced in vitro by the metacestode of Echinococcus spp., regardless of the species. which allow them to attach to the

Should be reserved for the in vitro situation where the fluid is devoid of host components, and when the Echinococcus spp.-derived nature is clear from the context.

Should be reserved for the in vitro situation where the vesicles are devoid of host components.

"Viable" implies that the structure (of any type) may grow in the same or a new intermediate host or in appropriate in vitro culture medium; viable parasitic structures may or may not contain protoscoleces (parasite stage necessary for the infection of definitive hosts). However, noninvasive evaluation of viability in vivo is still imperfect [22].

Used as an even more popular equivalent of "strobilar stage" than "adult form".
The distinction between "vesicle fluid" (in vitro situation) and cyst fluid (in vivo situation) and usage of the noun "vesicle" for in vitro cultures only were approved by all voters but one (median: 10).

The distinction between "vesicle" (in vitro) and cyst (in vivo) and usage of the noun "vesicle" for in vitro cultures only, were approved by all voters but one (median: 10).

This definition of "viable" for the metacestode in intermediate hosts was approved by all voters (median: 10).
May be a source of confusion with non-parasitic worms. However, it is tolerated because it is useful for teaching, reviews for students and professionals, and communication to the public.

\footnotetext{
* Agreement obtained at the second stage of the consultation (the participants in the Consultation and Rating Group had to rate their approval or rejection of the words/expressions independently on a scale from 0 to 10; whenever relevant, the median of the votes and the nature of the agreement (majority or unanimity) are given in the "Comments" column

Agreement to recommend a word that was not selected at the first stage of consultation; the approval was obtained at the second stage after further discussion between experts or after recommendation by the RRG.
} 
Table 1C. Recommended terms for the clinical aspects of echinococcosis.

\begin{tabular}{|c|c|c|c|}
\hline Word/expression & Definition & $\begin{array}{c}\text { Reasons for acceptance, references, } \\
\text { linguistic clarifications }\end{array}$ & Additional contributors opinion, if any \\
\hline $\begin{array}{l}\text { Alveolar } \\
\text { echinococcosis, } \\
\text { Expression } \\
\text { (abbreviation: AE) }\end{array}$ & $\begin{array}{l}\text { Disease due to } \\
\text { E. multilocularis, with } \\
\text { multiple microcysts giving } \\
\text { an "alveolar" aspect on } \\
\text { sectioning of the infected }\end{array}$ & $\begin{array}{l}\text { Widely used since the recognition of the } \\
\text { disease in the 19th century [18, 78]. From } \\
\text { the name of the species "Echinococcus" } \\
\text { and the Latin adjective "alveolar", } \\
\text { genitive -alveolaris" (composed of or } \\
\text { relating to "alveoli"/small holes/air }\end{array}$ & $\begin{array}{l}\text { Recommended by the WHO-IWGE } \\
\text { since its first "Guidelines" [83] } \\
\text { Differentiates the disease due to } \\
\text { E. multilocularis from that due to } \\
\text { E. granulosus sensu lato easily. }\end{array}$ \\
\hline
\end{tabular}

\section{*Anti-parasitic treatment, \\ Expression}

*CE cyst,

Expression
*Complicated (echinococcosis, CE, AE, cyst. . .), Adjective
Pharmacological or biological treatment of echinococcosis, able to kill Echinococcus spp. or stop or delay their development at the various stages of the parasitic cycle.

Anatomical lesion due to infection with Echinococcus granulosus sensu lato, excluding all other species of Echinococcus.

In $\mathrm{CE}, \mathrm{AE}$ or $\mathrm{NE}$ : spontaneous or provoked events (including after therapeutic interventions) that occur in the $\mathrm{CE} / \mathrm{NE}$ cyst/AE lesion.

\section{in the lung). The expression conforms to} the recommendation of the WFP; the preceding adjective provides precision on the morphology of the lesion (alveolar). The adjective "alveolar" clearly indicates the morphological aspect of the lesions (especially in the liver).

Absence of precision regarding the type of disease leads to misunderstanding between experts, stakeholders and policy makers.

May apply to the various stages of Echinococcus spp.-related infections, in the intermediate host (including humans) and in the definitive host (pets, domestic or wild animals). Type of drugs or treatment schedules may be different for the various stages and the various diseases [10, 35, 74, 75].

Alternative name to designate a cyst/cysts due to infection with E. granulosus sensu lato. From the abbreviation of "cystic echinococcosis"

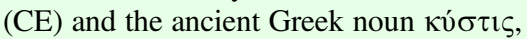
-cystis- (anatomical bladder). The expression should be used for clinical cases (cysts observed in cystic echinococcosis in humans or intermediate animal hosts) or in vivo experiments in animals [35, 81]. In agreement with the international WHO-IWGE classification of cysts due to E. granulosus sensu lato infection, from ultrasound examination (CE1 to CE5) [82].

\section{Clinical definition. Complications}

may be:

- Rupture (outside or in structures of the infected organ),

- Compression or invasion of internal structures of the infected organ or of neighboring organs,

- Superinfection of the CE/NT cyst or of the AE pseudo-cyst with bacteria or fungi,

- Anaphylactic (IgE-dependent allergic) reactions due to echinococcal antigens,

- Compression or invasion of internal structures/tissues (e.g. for bone or brain) in $\mathrm{CE} / \mathrm{NE}$ and $\mathrm{AE}$ [35].
This expression was unanimously accepted by voters (median: 10) to replace definitively the noun "chemotherapy", excluding all other options. See also Table 2C.

A majority of voters (and a few RRG members) preferred to use "CE cyst" only and reject the use of hydatid cyst (median 8); however, there was no unanimity (3 voters rating under 6 ). Because the "Biology and Immunology subgroup supported the use of "hydatid" restricted to E. granulosus s.l., at least temporarily, because of the widely used expressions "hydatid cyst" and "hydatid fluid", both expressions will be tolerated. Using "CE cyst" is highly recommended.

The adjective "complicated", for echinococcosis, should not be used to designate the simple growth of the parasite (with or without pain) if there are no consequences on the structures of the infected organ or on the neighboring organs. The large size of the cyst and its proximity to bile ducts or vessels in the liver (or bronchi or vessels in the lung, or vital structures in the brain) are not "per se" complications; even though they make the surgical treatment more difficult or impossible, they are just anatomical particularities.

The term, with this definition, was accepted unanimously by the voters (median: 10). 
Table 1C. (Continued)

\begin{tabular}{|c|c|c|c|}
\hline Word/expression & Definition & $\begin{array}{l}\text { Reasons for acceptance, references, } \\
\text { linguistic clarifications }\end{array}$ & Additional contributors opinion, if any \\
\hline $\begin{array}{l}\text { Cystectomy, } \\
\text { Noun }\end{array}$ & $\begin{array}{l}\text { Removal of a cyst, } \\
\text { whatever its nature; } \\
\text { more specifically, } \\
\text { removal of a CE cyst } \\
\text { (anatomical lesion } \\
\text { due to the infection } \\
\text { by E. granulosus s.l. } \\
\text { or E. oligarthra). }\end{array}$ & 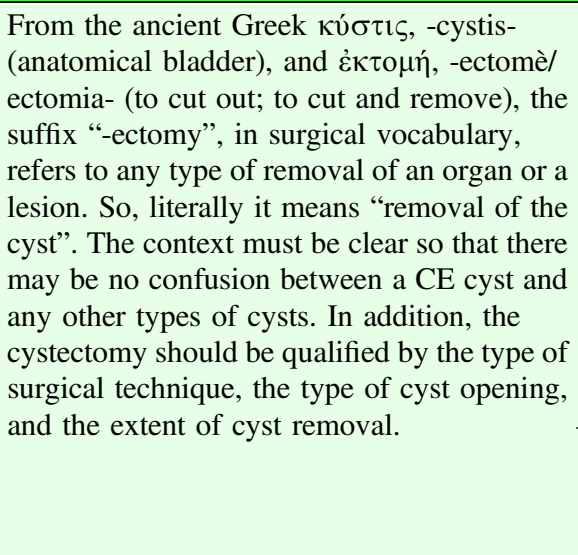 & $\begin{array}{l}\text { Should never be used alone, without } \\
\text { qualification, in a scientific/medical publication. } \\
\text { The recommended order for qualification follows } \\
\text { the AORC framework: } \\
\text { - Type of Approach (A): laparotomy, } \\
\text { laparoscopy or robotic, } \\
\text { - Type of cyst Opening (O): opened-cyst (OC) or } \\
\text { non-opened cyst (NOC), } \\
\text { - Type of Resection (R): cystectomy, } \\
\text { hepatectomy (segmentectomy, lobectomy or } \\
\text { pneumonectomy, for the lung). } \\
\text { - Completeness of cyst removal (C): total, subtotal } \\
\text { or partial. See also Figure } 3 \text { for the description of } \\
\text { the AORC framework with the definition of its } \\
\text { various components in liver CE surgery. }\end{array}$ \\
\hline
\end{tabular}

\section{Cystic echinococcosis, \\ Expression \\ E. granulosus sensu lato.} (abbreviation: CE)

\section{$* / * *$ Cystoid,}

Adjective

(Adjective

common to

"BiologyImmunology" and to "Clinical Aspects")
The expression conforms to the recommendation of the WFP; the preceding adjective, from the Middle French "cystique", from the ancient Greek

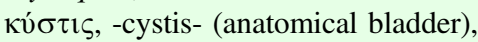
provides precision on the morphology of lesion (cystic).

Absence of precision regarding the type of disease leads to misunderstanding between experts, stakeholders and policy makers.

Hypodense, cyst-like From the ancient Greek eĩ $\delta o \varsigma$-eïdosimage observed at $\mathrm{CT}$ in $\mathrm{AE}$ lesions. (shape), the suffix "-id" (with the infix "-o-" whenever useful in a given language) refers to anything "which has the shape of ... something"; thus "cystoid": which has the shape of a cyst (without being a real cyst). In $\mathrm{AE}$, the cystoid structures observed on imaging may be due to the central, liquefied necrosis in advanced $\mathrm{AE}$ lesions or to other cyst-like components such as conglomerate of microcysts or in very small lesions, occasionally, a hypodense solid necrosis. As these structures do not correspond to a parasitological entity, a specific word should differentiate these pathological cyst-like macroscopic structures from the real parasitic "cysts" of CE.

*Daughter cyst, Expression
Newly formed hydatids inside (and far less frequently outside, if any) the CE cyst in the development of Echinococcus granulosus s.l. Not applicable to E. multilocularis/AE.
This expression has been in use for a century, All suggested names for this metacestode translated from the French "vésicule fille" (daughter vesicle), proposed by Dévé (the word "vésicule" being feminine in French, hence "daughter"). It is the established-byuse name of such anatomical structures which are derived from the germinal layer, in case of aggression of the metacestode (see Figs. 2A-2C) [18, 64, 68] (median for "daughter cyst", daughter hydatid, and daughter vesicle: 2,1 and 3, respectively; means $4.63,1.72$ and 4.70 , respectively).

The word "daughter" evokes sexual reproduction (which does not exist for the metacestode), and "cyst" a complete CE cyst structure, with a fully developed adventitial layer (which is generally
Recommended by the WHO-Informal Working Group on Echinococcosis (WHO-IWGE) since its first "Guidelines"[83]. Differentiates the disease due to E. granulosus sensu lato, from those due to E. multilocularis, E. oligarthra and E. vogeli, respectively.

This adjective was proposed and published for the classification of AE lesions at computed tomography (CT) scanning in 2016 [23] and used thereafter in other publications. Although the adjective "pseudocystic" was preferred by the majority of voters (median: 9 for the "BiologyImmunology group and 7 for the "Clinical Aspects group), the adjective "cystoid" was maintained after the poll to describe cyst-like images observed using computed tomography scanning and which cannot be attributed unequivocally to the necrotic cavity present in advanced lesions of AE. hardly present in this structure). However, the adjective "secondary" was considered by the participants in the CRG to be irrelevant for this situation (used for the growth of new cysts after protoscolex spillage), and the noun "vesicle" was accepted by biologists with restricted use for in vitro culture of the metacestode; hence the decision of the SWG to keep the "historical", albeit inexact, wording. 
Table 1C. (Continued)

\begin{tabular}{llll}
\hline Word/expression & \multicolumn{1}{c}{ Definition } & \multicolumn{1}{c}{$\begin{array}{c}\text { Reasons for acceptance, references, } \\
\text { linguistic clarifications }\end{array}$} & Additional contributors opinion, if any \\
\hline $\begin{array}{l}\text { *Disseminated } \\
\text { (CE or AE, or }\end{array}$ & $\begin{array}{l}\text { Clinical form of } \\
\text { cystic or alveolar or } \text {, Adjective } \\
\text { neo-tropical } \\
\text { echinococcosis } \\
\text { disseminated to } \\
\text { more than one } \\
\text { organ/tissue. }\end{array}$ & $\begin{array}{l}\text { The definition implies that the cysts/lesions } \\
\text { are not in a single organ; it does not assume } \\
\text { the nature of dissemination (e.g. multiple } \\
\text { location of infection; local/regional invasion; }\end{array}$ & $\begin{array}{l}\text { This definition was accepted by the majority of } \\
\text { metastasis) }\end{array}$ \\
& &
\end{tabular}

Echinococcosis

(plural:

Disease(s) related to infection with

Echinococcoses), parasites of the

Noun genus.
Recommended by the World Federation of Parasitologists (WFP) (i.e. name of the genus followed by the suffix -osis) The English name of the World Association of Echinococcosis (WAE; previously "International Association of Hydatidology) was modified in 2015 at the 26th World Congress of Echinococcosis in Bucharest, Romania, to follow this rule. for Endoscopic Retrograde CholangioPancreatography, Expression

\section{Ex-vivo liver resection with auto- \\ transplantation \\ (ELRA),}

Expression

\section{Hepatectomy}

In $\mathrm{CE}$ and $\mathrm{AE}$ diagnostic procedures, no exploration of the pancreatic ducts is performed, but the acronym ERCP is

Per-endoscopic technique used to explore the biliary and pancreatic ducts, commonly used even though the pancreatic disease; it may or may not be associated with sphincterotomy or other additional procedures.

Surgical operation which includes:

- Total hepatectomy followed by

- Ex-vivo resection of the pathological parts of the liver associated with

- Various types of reconstruction of the bile ducts and/or vessels then by

- Re-implantation ("autotransplantation") of the liver orthotopically. exploration is not performed.

Surgical technique used for the treatment of advanced AE. The expression includes all steps of the procedure; so it should be preferred to partial expressions such as

"ex-vivo liver resection" or "autotransplantation". The abbreviation was proposed by the surgical team that has performed most of these procedures and includes all main terms of the expression [2]. regardless of the
Without precision regarding the type of disease, this noun can only be used when all diseases due to Echinococcus spp. are considered together, and preferably used as a plural (echinococcoses); it should be avoided in epidemiological, clinical, and mechanistic studies covering all 3 diseases. Besides this "generic" usage, distinction should always be made between cystic echinococcosis (CE), due to E. granulosus sensu lato (s.l.), alveolar echinococcosis (AE), due to E. multilocularis, and neotropical echinococcosis (NE), due to E. vogeli or E. oligarthra.

Performance of the ERCP may be only for diagnostic purposes; however, usually it has a therapeutic intent and is the first step of perendoscopic biliary drainage. In scientific publications, this distinction should be clearly stated.

The numerous alternative expressions and acronyms should no longer be used.
Removal of the liver From the ancient Greek $\tilde{\eta} \pi \alpha \rho$, -hepar; or part of it. genitive $\tilde{\eta} \pi \alpha \tau$ o $\varsigma$-hepatos (liver), and the

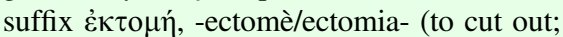
to cut and remove); in the surgical vocabulary it refers to any type of removal of an organ or a lesion. So, literally it means "removal of the liver" (which is literally correct only in liver transplantation). Various types are described, valid for all types of diseases subject to liver surgery.
Should always be qualified, according to the usual definitions of hepatic surgery, and of the liver segments; definitions are valid for the application to all types of diseases, including echinococcosis [29]. 
Table 1C. (Continued)

\begin{tabular}{|c|c|c|c|}
\hline Word/expression & Definition & $\begin{array}{c}\text { Reasons for acceptance, references, linguistic } \\
\text { clarifications }\end{array}$ & Additional contributors opinion, if any \\
\hline $\begin{array}{l}\text { *Hydatid cyst, } \\
\text { Expression (word } \\
\text { common to } \\
\text { "Biology - } \\
\text { Immunology" and } \\
\text { to "Clinical } \\
\text { aspects") }\end{array}$ & $\begin{array}{l}\text { Anatomical lesion due } \\
\text { to infection with } \\
\text { Echinococcus granulosus } \\
\text { sensu lato, excluding all } \\
\text { other species of } \\
\text { Echinococcus. }\end{array}$ & 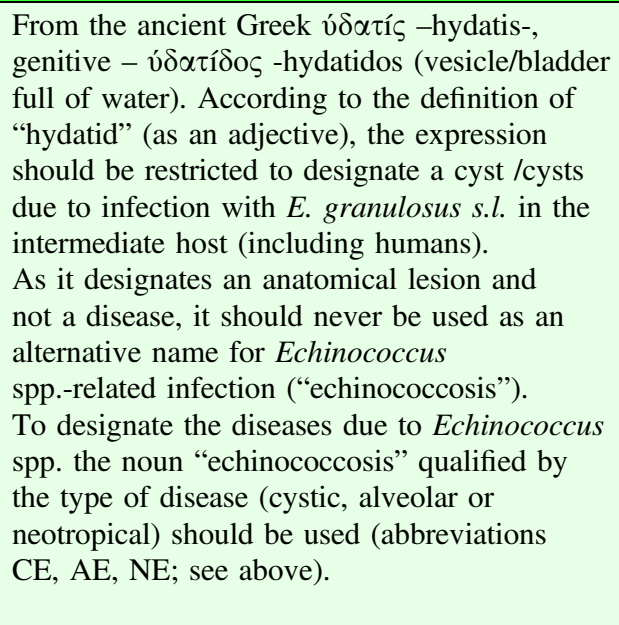 & $\begin{array}{l}\text { As it adds to confusion in epidemiological } \\
\text { and clinical studies, it should never be used } \\
\text { to designate the anatomical lesion due to } \\
\text { E. multilocularis infection. The definition } \\
\text { was approved by the unanimity of voters } \\
\text { (median: 10). } \\
\text { A majority of voters preferred to totally } \\
\text { reject the use of "hydatid cyst" (median } 8 \\
\text { for the specific question; see above "CE } \\
\text { cyst"). As there was no unanimity and as } \\
\text { the "Biology and Immunology" subgroup } \\
\text { supported the use of "hydatid" restricted to } \\
\text { E. granulosus s.l., at least temporarily, } \\
\text { because of the widely used expression } \\
\text { "hydatid cyst", both expressions will be } \\
\text { tolerated. Nevertheless, the use of "CE } \\
\text { cyst" is highly recommended. }\end{array}$ \\
\hline
\end{tabular}

\section{**Laparoscopy, Surgical approach} Noun

**Laparotomy, Noun performed for operations in the abdomen or pelvis using small incisions (usually $0.5-1.5 \mathrm{~cm}$ ) with the aid of a camera.

Surgical approach which includes a large opening of the abdomen.

\section{Modified catheterization technique, Expression Mo-CAT, Acronym}

*Multicystic (echinococcosis; images), Adjective multiple aggregated cysts observed on imaging or during surgery in the same organ
Percutaneous procedure for treatment of CE cysts that results in removal of the cyst layers, possibly including daughter cysts, in addition to the cyst fluid and protoscoleces.

Any type of echinococcosis with under laparoscopy. To be preferred to "coelioscopy", more used in gynecology. Qualifies any surgical intervention performed under laparotomy.
Qualifies any surgical intervention performed
Avoids the confusing use of "polycystic", which currently refers both to cystic or alveolar observed on imaging, and to E. vogeli infection; also avoids confusion with polycystic liver (and kidney) disease. echinococcosis with multiple large size-cysts

Similar techniques (such as PEVAC) previously The mode of percutaneous puncture described are no longer in use [36, 71, 81]. The name of the procedure and the acronym "Mo-CAT" clearly distinguish this procedure from the conventional PAIR and from the "standard catheterization technique" $[3,61]$

Should be added to the noun or expression describing any type of intervention, if this surgical intervention is performed by laparoscopy. See also Figure 3 and the description of the AORC framework with the definition of its various components in liver CE surgery.

Should be added to the noun or expression describing any type of intervention, if this surgical intervention is performed by laparotomy. See also Figure 3 and the description of the AORC framework with the definition of its various components in liver CE surgery.

guidance (e.g. ultrasound-guided, CTguided) should also be given, as well as the type/size of catheterization and aspiration. The expression and its acronym were accepted by the majority of voters (median: 10).

The adjective "multicystic" should not be used to qualify the usual "alveolar" aspect of the aggregated "microcysts" in AE. It should not be used to qualify cases of CE or NE with multiple separated and independent cysts observed on imaging or during surgery in the same organ or different organs; see the definition of "multiple cyst-". This term was accepted by the majority of voters (median: 10). See also "polycystic", the rejected term, in Table 2C.
Clearly distinguishes the "multicystic" aspect of lesions and the presence of multiple cysts.
Should not be used to qualify cases of AE with multiple lesions. Should not be used to qualify cases with aggregated cysts in the same organ (i.e. "multicystic" CE or NE); see the definition of "multicystic".
$* *$ Multiple cyst-, Any type of
Expression used as echinococcosis (except Adjective AE) with multiple separated and independent cysts observed on imaging or during surgery in the same organ or different organs. 
Table 1C. (Continued)

\begin{tabular}{|c|c|c|c|}
\hline Word/expression & Definition & $\begin{array}{l}\text { Reasons for acceptance, references, } \\
\text { linguistic clarifications }\end{array}$ & Additional contributors opinion, if any \\
\hline $\begin{array}{l}\text { Neotropical } \\
\text { echinococcoses, } \\
\text { Expression } \\
\text { (abbreviation: NE) }\end{array}$ & $\begin{array}{l}\text { Diseases due to } \\
\text { E. vogeli or E. oligarthra. }\end{array}$ & $\begin{array}{l}\text { Conforms to the recommendation by the } \\
\text { WFP (echinococcosis); the preceding } \\
\text { adjective provides precision on the } \\
\text { particularity of the diseases (neotropical) } \\
\text { [36]. "Neotropical" evokes the unique } \\
\text { geographic distribution of the Echinococcus } \\
\text { spp. involved (in the tropical areas of the } \\
\text { New World). }\end{array}$ & $\begin{array}{l}\text { Although the expression does not give any } \\
\text { information on the morphology of the lesion } \\
\text { ("polycystic" in E. vogeli infection; } \\
\text { "unicystic" in E. oligarthra infection), it has } \\
\text { been in use for a while in the literature and } \\
\text { was approved by the South American } \\
\text { Working Group on E. vogeli and } \\
\text { E. oligarthra; it usefully distinguishes the } \\
\text { diseases caused by these species from CE and } \\
\text { AE (see definitions above). }\end{array}$ \\
\hline
\end{tabular}

**New CE cyst(s), Appearance of a new CE The definition covers all new cysts that Expression cyst in a location different from where a CE cyst was diagnosed before.

have appeared in a patient after a first diagnosis; the new cyst may have appeared spontaneously (e.g. during a "Watch and Wait" period of follow-up) or after any type of treatment.

**Non-opened cyst (total cystectomy), Expression NOC, Acronym
Linguistically more correct than "close(d) cystectomy" (a cyst can be "non-opened"

Surgical operation which does not include cyst opening before cyst removal during the surgical procedure, a cystectomy (cystectomy). Only applies cannot be close or closed) [81]. This to $\mathrm{CE}$, and for total cystectomy; it is not relevant for $\mathrm{AE}$.

expression clearly describes the situation of the cyst (non-opened) and the highly reduced risk of dissemination of protoscoleces or germinal membrane fragments related to the surgical procedure.

Linguistically more correct than "open cystectomy" (a cyst can be opened during the surgical procedure, a cystectomy cannot) [81].

This expression clearly describes the situation of the cyst (opened) and the potential risk of dissemination of protoscoleces or germinal membrane fragments related to the surgical procedure.

(Orthotopic) Liver Removal of the recipient's transplantation, liver followed by the Expression OLT, Acronym

PAIR, Acronym for Puncture, Aspiration, Injection of protoscolecide, Reaspiration, Expression transplantation of the donor's liver (or part of liver) at the same anatomical location.

Surgical technique used for the treatment of advanced cases of $\mathrm{AE}$, and more rarely of CE. Often used for "allotransplantation of the liver"; does not include auto-transplantation.

Percutaneous treatment of Accepted name and acronym to designate CE cysts using needle puncture and use of protoscolecide agents. the procedure, since its description by Ben Amor et al., 1986 [8] in French (same acronym), and its first publication in English by Gargouri et al., in 1990 [20]. It describes the 4 steps of the procedure which does not include catheterization of the cyst. The procedure was evaluated and its indications clarified by the WHO-IWGE [10].
This expression was added by the SWG after the poll, in agreement with the writers of the WHO-IWGE Technical Manual. It excludes all cases of cyst recurrence or reactivation, as well as "secondary echinococcosis" (see the definitions of "reactivation" "recurrence", and secondary echinococcosis" in this Table 1C).

Newly introduced expression, resulting from the discussion between members of the "Clinical aspects" subgroup of the CRG. The adjective expression "non-opened cyst", its acronym "NOC" and its definition, to qualify more precisely the total cystectomy, were accepted by a majority of voters (median: 10) See also Figure 3 and the description of the AORC framework with the definition of its various components in liver CE surgery.

Newly introduced expression, resulting from the discussion between members of the "Clinical aspects" subgroup of the CRG. The adjective expression "opened cyst", its acronym "OC", and its definition, to qualify more precisely the total cystectomy, were accepted by a majority of voters (median: 10) See also Figure 3 and the description of the AORC framework with the definition of its various components in liver $\mathrm{CE}$ surgery.

The adjective "orthotopic" (and its abbreviation "O") is facultative, since the great majority of liver transplantations in humans are orthotopic.

The name and acronym must be used only for the initially described procedure, with needle puncture, manual syringe aspiration, without catheterization or other associated techniques. 
Table 1C. (Continued)

\begin{tabular}{|c|c|c|c|}
\hline Word/expression & Definition & $\begin{array}{l}\text { Reasons for acceptance, references, } \\
\text { linguistic clarifications }\end{array}$ & Additional contributors opinion, if any \\
\hline $\begin{array}{l}\text { *Partial } \\
\text { (cystectomy), } \\
\text { Adjective }\end{array}$ & $\begin{array}{l}\text { Surgical intervention } \\
\text { that only partially } \\
\text { removes the } 3 \text { layers } \\
\text { of the CE cyst. }\end{array}$ & $\begin{array}{l}\text { Opposite to "subtotal" which only leaves } \\
\text { parts of the adventitial layer in place, this } \\
\text { may include a partial removal of any layer } \\
\text { (including parts of the germinal layer and } \\
\text { laminated layer); usually only the adventitial } \\
\text { layer is left. }\end{array}$ & $\begin{array}{l}\text { By definition, in this situation, the CE cyst has to } \\
\text { be opened (first or second intent opening). The } \\
\text { adjective and its definition were accepted by a } \\
\text { majority of voters (median: 8); however, a } \\
\text { complementary discussion was necessary to } \\
\text { precisely agree on the differences between } \\
\text { "subtotal" and "partial". See also Figure } 3 \text { and the } \\
\text { description of the AORC framework with the } \\
\text { definition of its various components in liver CE } \\
\text { surgery. }\end{array}$ \\
\hline
\end{tabular}

$\begin{array}{ll}* / * * \text { Percutaneous } & \text { Imaging-guided } \\ \text { pseudocyst } & \text { percutaneous } \\ \text { drainage, } & \text { transhepatic } \\ \text { Expression } & \text { interventional } \\ & \text { technique used for } \\ & \text { the drainage of the } \\ & \text { central "pseudocyst" } \\ & \text { in advanced lesions } \\ & \text { of AE. Applies to } \\ & \text { AE only. }\end{array}$

**Percutaneous post-surgery cavity drainage, Expression

\begin{tabular}{|c|c|}
\hline $\begin{array}{l}\text { Perendoscopic } \\
\text { biliary drainage } \\
\text { Expression }\end{array}$ & $\begin{array}{l}\text { Non-surgical } \\
\text { interventional } \\
\text { technique used for } \\
\text { the drainage of the } \\
\text { biliary tree, through } \\
\text { ERCP. }\end{array}$ \\
\hline
\end{tabular}

*Peri-adventitial (cystectomy), Adjective

Protoscolecide, Noun protoscolecidal, Adjective

Total cystectomy performed without opening the cyst, and which uses the dissection space between the adventitial layer and the "normal" liver parenchyma to remove the cyst totally.

Compound (natural or chemical) which is able to kill the protoscoleces.
For the treatment of AE, this expression is preferred to "cavity drainage" since it refers to the typical "pseudocyst" resulting from the necrosis of AE lesions; "cavity drainage" is more commonly used for the drainage/ treatment of the postoperative cavities after surgery for CE (cystectomy). In AE, such drainage has no temporal relationship with any other interventional treatment.

A clearly different expression for the drainage of the cystoid necrotic cavity in $\mathrm{AE}$ versus the treatment of $\mathrm{CE}$ with postoperative residual cavity was considered useful. The "post-surgery" temporal performance of such drainage is clearly indicated in the expression.

The procedure, which applies both to $\mathrm{CE}$ and $\mathrm{AE}$, may or may not include biliary stenting $[4,71]$.

The adjective indicates more precisely that the resection is performed outside the adventitial layer (i.e. the adventitial layer is included in the resected cyst) $[37,81]$.

From the ancient Greek " $\sigma \kappa \omega \lambda \lambda \varepsilon \xi$ ”-scolex not -scolicos; plural $\sigma \kappa \omega ่ \lambda \varepsilon \kappa \varepsilon \varsigma$, scoleces, and not scolices), with the prefix
The expression was accepted by the majority of voters (median: 10). No acronym was fixed. In any description of the procedure, the mode of percutaneous puncture guidance (e.g. ultrasoundguided, CT-guided) should also be given, as well as the type/size of catheterization and aspiration.

This expression was added by the SWG after the poll, after recommendation by the RRG, in order to clearly distinguish the respective situations in $\mathrm{AE}$ and $\mathrm{CE}$. In any description of the procedure, the mode of percutaneous puncture guidance (e.g. ultrasound-guided, CT-guided) should also be given, as well as the type/size of catheterization and aspiration.

The procedure does not include a curative action on the $\mathrm{CE}$ cyst or on the $\mathrm{AE}$ lesion; it only treats complications of the diseases and/or of their surgical treatment. In scientific publications, if biliary stenting is associated with the procedure, this should be specifically mentioned, as well as the type, size, and number of stents.

The use of this adjective for the description of cystectomy is facultative. The adjective "periadventitial" and its definition, to qualify more precisely the total cystectomy, were accepted by a majority of voters (median: 10) See also Figure 3 and the description of the AORC framework with the definition of its various components in liver CE surgery.

Should be used instead of "scolicide", (worm), genitive: $\sigma \kappa \omega \dot{\lambda \varepsilon \kappa o \varsigma}$-scolecos, and "scolecide" and "protoscolicide". See also " $\pi \rho \tilde{\omega} \tau o \varsigma "$-protos (first/before), and the Latin suffix - "-cide", from "caedere" (to kill).
Table $2 \mathrm{C}$, about the rejected alternative words. 
Table 1C. (Continued)

\begin{tabular}{|c|c|c|c|}
\hline Word/expression & Definition & $\begin{array}{c}\text { Reasons for acceptance, references, } \\
\text { linguistic clarifications }\end{array}$ & Additional contributors opinion, if any \\
\hline $\begin{array}{l}\text { */**Pseudocyst, } \\
\text { Noun, and } \\
\text { pseudocystic, } \\
\text { Adjective (Noun } \\
\text { and Adjective } \\
\text { common to } \\
\text { "Biology- } \\
\text { Immunology" and } \\
\text { to "Clinical } \\
\text { Aspects") }\end{array}$ & $\begin{array}{l}\text { Irregular cyst-like } \\
\text { anatomical entity due to the } \\
\text { central necrosis in } \mathrm{AE} \\
\text { lesions at advanced stages. }\end{array}$ & $\begin{array}{l}\text { From the ancient Greek " } \psi \varepsilon v \delta \eta ́ s "- \\
\text { "pseudès- (= false, deceptive, } \\
\text { misleading) that designates something } \\
\text { which looks like something but is not; } \\
\text { thus "pseudocyst": anatomical entity } \\
\text { which looks like a cyst but is not a } \\
\text { cyst. The terms differentiate the cyst- } \\
\text { like necrotic cavity in AE from the } \\
\text { real "cyst" of CE (with its parasitic } \\
\text { structure including the } 3 \text { layers). This } \\
\text { structure does not correspond to a } \\
\text { parasitological entity. In medicine, the } \\
\text { term "pseudocyst" is generally used } \\
\text { for the necrotic cavities that develop }\end{array}$ & $\begin{array}{l}\text { The terms were approved by the } \\
\text { majority of voters (median: 9). The } \\
\text { context and the organ being different } \\
\text { from pancreatitis, and the formation of } \\
\text { the cavity also being due to liquefied } \\
\text { necrosis of an inflammatory lesion, it } \\
\text { was considered that the words } \\
\text { "pseudocyst" and "pseudocystic" could } \\
\text { also be used in AE. However, the } \\
\text { adjective "cystoid" was maintained to } \\
\text { qualify cyst-like structures (irrespective } \\
\text { of their anatomical nature) observed at } \\
\text { imaging (especially at CT-scan) in AE } \\
\text { lesions. }\end{array}$ \\
\hline
\end{tabular}

PTBD, Acronym, for Percutaneous Transhepatic Biliary Drainage, Expression

\section{***activation, Noun}

Non-surgical interventional technique used for the drainage of the biliary tree, which is used in $\mathrm{AE}$ or complicated CE, after percutaneous puncture.

Appearance of daughter cyst (s) in the solid matrix of spontaneously inactivated CE4 cysts that shows an evolution towards a CE3b stage.

Appearance of an active CE cyst (types CE1-3, usually CE3b) in the same location where a treated cyst was located, independently of the type of previous treatment.
Following its definition in oncology, the term "recurrence" is reserved for the post-therapeutic situation; the term "reactivation" applies to non-treated cysts.
No synonyms. Expression and acronym widely used in the medical literature, whatever the application. The procedure applies both to $\mathrm{CE}$ and $\mathrm{AE}$ and does not include a curative action on the $\mathrm{CE}$ cyst or on the $\mathrm{AE}$ lesion.

The term "reactivation" is reserved for spontaneously inactivated cysts (observed after an initial diagnosis of CE4 cyst, with or without formal "Watch and Wait" follow-up).

Mode of formation distinct from that of daughter cysts; the adjective "secondary" should, however, be restricted to the appearance of new $\mathrm{CE}$ cysts in the peritoneum, pleura or meningeal space because of spontaneous or per-treatment spillage of the cyst content.
The mode of percutaneous puncture guidance (e.g. ultrasound-guided, CTguided) should also be given, as well as the type/size of catheterization.

This term was added by the SWG after the poll, in agreement with the writers of the WHO-IWGE Technical Manual, in order to clearly distinguish the various situations regarding new lesions or changes in lesions that appeared spontaneously or after attempts at treatment.

This term was added by the SWG after the poll, in agreement with the writers of the WHO-IWGE Technical Manual, in order to clearly distinguish the various situations regarding new lesions or changes in lesions that appeared spontaneously or after attempts at treatment.

NB: the occurrence of a post-surgical cavity needs to be excluded before a diagnosis of recurrence is made (cf. the definition of "percutaneous post-surgical cavity drainage", in this Table 1C).

This expression was added by the SWG after the poll, to clearly distinguish this situation from the development of "daughter cyst". The expression was approved by the writers of the WHOIWGE Technical Manual, in order to clearly distinguish the various situations regarding new $\mathrm{CE}$ cysts or changes in $\mathrm{CE}$ cysts that appeared spontaneously or after attempts at treatment. 
Table 1C. (Continued)

\begin{tabular}{|c|c|c|c|}
\hline Word/expression & Definition & $\begin{array}{c}\text { Reasons for acceptance, references, } \\
\text { linguistic clarifications }\end{array}$ & $\begin{array}{l}\text { Additional contributors } \\
\text { opinion, if any }\end{array}$ \\
\hline $\begin{array}{l}\text { *Standard } \\
\text { catheterization } \\
\text { (technique), } \\
\text { Expression S-CAT, } \\
\text { Acronym }\end{array}$ & $\begin{array}{l}\text { Modification of the } \\
\text { PAIR technique } \\
\text { which includes the } \\
\text { insertion of a catheter } \\
\text { left or not in the cyst } \\
\text { temporarily for the } \\
\text { treatment of selected } \\
\text { CE cysts. }\end{array}$ & $\begin{array}{l}\text { The name of the procedure and the } \\
\text { acronym "S-CAT" clearly } \\
\text { distinguish this procedure from the } \\
\text { conventional PAIR and from the } \\
\text { "modified catheterization technique" } \\
\text { ("Mo-CAT") }[3,35] \text {. }\end{array}$ & $\begin{array}{l}\text { The expression and its } \\
\text { acronym were accepted } \\
\text { unanimously by the voters } \\
\text { (median: 10) It was also } \\
\text { proposed to complete the } \\
\text { description by the following } \\
\text { mentions: } \\
\text { - One-session S-CAT: the } \\
\text { catheter is removed during } \\
\text { the first procedure; } \\
\text { - Multiple-session S-CAT: } \\
\text { the catheter is removed at } \\
\text { another session. } \\
\text { The mode of percutaneous } \\
\text { puncture guidance (e.g. } \\
\text { ultrasound-guided, CT- } \\
\text { guided) should also be given, } \\
\text { as well as the type/size of } \\
\text { catheterization. }\end{array}$ \\
\hline $\begin{array}{l}* / * * \text { Sub-total } \\
\text { (cystectomy), } \\
\text { Adjective }\end{array}$ & $\begin{array}{l}\text { Nearly total } \\
\text { cystectomy with } \\
\text { incomplete removal } \\
\text { of the adventitial } \\
\text { layer of a CE cyst }\end{array}$ & $\begin{array}{l}\text { Situation that occurs when limited } \\
\text { parts of the cyst cannot be removed } \\
\text { safely because of the proximity of } \\
\text { blood vessels or other anatomical } \\
\text { structures (e.g. bile ducts, bronchi, } \\
\text { brain anatomical structures with } \\
\text { critical functions). To be qualified of } \\
\text { "subtotal", the cystectomy must } \\
\text { remove the totality of the germinal } \\
\text { and laminated layer; only limited } \\
\text { parts of the adventitial layer are left. }\end{array}$ & $\begin{array}{l}\text { By definition, in this situation } \\
\text { (as in "partial cystectomy), } \\
\text { the cyst has to be opened } \\
\text { (second intent opening). The } \\
\text { adjective and its definition } \\
\text { were accepted by a majority } \\
\text { of voters (median: 10); } \\
\text { however, a complementary } \\
\text { discussion after the poll was } \\
\text { necessary to precisely agree } \\
\text { on the differences between } \\
\text { "subtotal" and "partial". } \\
\text { See also Figure } 3 \text { and the } \\
\text { description of the AORC } \\
\text { framework with the definition } \\
\text { of its various components in } \\
\text { liver CE surgery. }\end{array}$ \\
\hline $\begin{array}{l}* \text { Total } \\
\text { (cystectomy), } \\
\text { Adjective }\end{array}$ & $\begin{array}{l}\text { Complete removal of } \\
\text { a CE cyst, including } \\
\text { the content (fluid and } \\
\text { protoscoleces) and all } \\
\text { layers of the cyst } \\
\text { (germinal, laminated } \\
\text { and adventitial } \\
\text { layers. }\end{array}$ & $\begin{array}{l}\text { The adjective "total" insists on the } \\
\text { complete removal of the CE cyst by } \\
\text { the surgical operation (the "C", for } \\
\text { "completeness" of the AORC } \\
\text { framework). It does not prejudge of } \\
\text { the opening or not of the cyst at any } \\
\text { time of the procedure. This } \\
\text { operation, when performed on a } \\
\text { non-opened cyst, was sometimes } \\
\text { called "peri-cystectomy"; however, a } \\
\text { proper definition of the CE cyst is } \\
\text { against the use of this word (see } \\
\text { Tables } 1 \mathrm{~B} \text { and } 2 \mathrm{C} \text { and Figs. } 2 \mathrm{~A}-2 \mathrm{C} \text { ). }\end{array}$ & $\begin{array}{l}\text { The adjective "total", } \\
\text { speaking of cystectomy, and } \\
\text { its definition were accepted } \\
\text { by all voters but one (median: } \\
\text { 10). } \\
\text { See also Figure } 3 \text { and the } \\
\text { description of the AORC } \\
\text { framework with the definition } \\
\text { of its various components in } \\
\text { liver CE surgery. }\end{array}$ \\
\hline
\end{tabular}

\footnotetext{
* Agreement obtained at the second stage of the consultation (the participants in the Consultation and Rating Group had to rate their approval or rejection of the words/expressions independently on a scale from 0 to 10; whenever relevant, the median of the votes and the nature of the agreement (majority or unanimity) are given in the "Comments" column.

* Agreement to recommend a word that was not selected at the first stage of consultation; the approval was obtained at the second stage after further discussion between experts or after recommendation by the RRG.

*/*** Agreement obtained at the second stage of the consultation; however the final definition was obtained after further discussions with the members of the RRG.
} 
Table 2A. Rejected terms for the genetics and epidemiology of Echinococcus species.

\begin{tabular}{|c|c|c|c|}
\hline Word/expression & Definition & $\begin{array}{l}\text { Reasons for rejection, references, } \\
\text { linguistic clarifications }\end{array}$ & Comments \\
\hline $\begin{array}{l}\text { Alveococcus, } \\
\text { Noun }\end{array}$ & $\begin{array}{l}\text { Non-valid genus name often } \\
\text { used in the Russian/ex-Soviet } \\
\text { Union literature to include } \\
\text { Echinococcus multilocularis } \\
\text { (Leuckart, 1863) which } \\
\text { actually belongs to the } \\
\text { Echinococcus genus. }\end{array}$ & $\begin{array}{l}\text { E. multilocularis (Leuckart, 1863) } \\
\text { belongs to the Echinococcus genus } \\
\text { [50, 67]. The International Code for } \\
\text { Zoological Nomenclature should be } \\
\text { followed (see Table 1A) [52]. } \\
\text { Only those approved species names } \\
\text { in the genus Echinococcus mentioned } \\
\text { in Table 1A should be used. }\end{array}$ & $\begin{array}{l}\text { The genus Alveococcus Abuladze, } 1959 \\
\text { (including Alveococcus multilocularis } \\
\text { (Leuckart, 1863)), still used } \\
\text { occasionally, particularly in Russian } \\
\text { literature, was erected to separate } \\
\text { E. multilocularis from the other species. } \\
\text { There is no longer a taxonomic basis for } \\
\text { this different genus name. }\end{array}$ \\
\hline $\begin{array}{l}\text { Echinococcus } \\
\text { alveolaris, } \\
\text { Expression }\end{array}$ & $\begin{array}{l}\text { Non-valid species name } \\
\text { sometimes - and even recently } \\
\text { - used in the German and } \\
\text { Turkish literature to designate } \\
\text { either the species Echinococcus } \\
\text { multilocularis or the disease } \\
\text { "alveolar echinococcosis"[60]. }\end{array}$ & $\begin{array}{l}\text { To designate the cestode, the } \\
\text { International Code for Zoological } \\
\text { Nomenclature should be followed } \\
\text { (see Table 1A) } \\
\text { To designate the disease, the } \\
\text { recommendations of the World Federation } \\
\text { of Parasitologists (WFP) should be } \\
\text { followed (see Table 1C) }\end{array}$ & Should definitively be abandoned. \\
\hline $\begin{array}{l}\text { Echinococcus } \\
\text { cysticus, } \\
\text { Expression }\end{array}$ & $\begin{array}{l}\text { Non-valid species name } \\
\text { sometimes used in the German } \\
\text { and Turkish literature to } \\
\text { designate either the species } \\
\text { Echinococcus granulosus } \\
\text { s.l. or the disease "cystic } \\
\text { echinococcosis"[44] }\end{array}$ & $\begin{array}{l}\text { To designate the cestode, the } \\
\text { International Code for Zoological } \\
\text { Nomenclature should be followed } \\
\text { (see Table 1A) } \\
\text { To designate the disease, the } \\
\text { recommendations of the World Federation } \\
\text { of Parasitologists (WFP) should be } \\
\text { followed (see Table 1C). }\end{array}$ & Should definitively be abandoned. \\
\hline $\begin{array}{l}\text { Echinococcus } \\
\text { granulosis }\end{array}$ & $\begin{array}{l}\text { Non-valid species name with } \\
\text { wrong orthography, } \\
\text { often found in publications. }\end{array}$ & $\begin{array}{l}\text { To designate the cestode, the } \\
\text { International Code for Zoological } \\
\text { Nomenclature should be followed } \\
\text { (see Table 1A). }\end{array}$ & Simply wrong. \\
\hline $\begin{array}{l}\text { Echinococcus } \\
\text { granulosus sensu } \\
\text { lato species } \\
\text { (non-exhaustive, } \\
\text { following alphabetic } \\
\text { order), Synonymous } \\
\text { expressions: } \\
\text { E. borealis } \\
\text { E. cameroni } \\
\text { E. cepanzoi } \\
\text { E. intermedius } \\
\text { E. longimanubrius } \\
\text { E. lycaontis } \\
\text { E. minimus } \\
\text { E. patagonicus }\end{array}$ & $\begin{array}{l}\text { Non-valid historical or recently } \\
\text { proposed species names for } \\
\text { Echinococcus spp. within the } \\
\text { Echinococcus granulosus sensu } \\
\text { lato complex that were later } \\
\text { synonymized with the currently } \\
\text { recognized species. }\end{array}$ & $\begin{array}{l}\text { Recently proposed species names should } \\
\text { not be used, unless a case } \\
\text { can be made (e.g. by molecular } \\
\text { studies) that they merit } \\
\text { recognition as separate species. }\end{array}$ & $\begin{array}{l}\text { Only those approved species names in } \\
\text { the genus Echinococcus mentioned in } \\
\text { Table 1A should be used. } \\
\text { Pending precise definition of additional } \\
\text { species within Echinococcus } \\
\text { granulosus sensu lato, besides the } \\
\text { currently accepted "species" } \\
\text { (see Table 1A), "G" genotypes should } \\
\text { be used [52-54, 57, 66]. }\end{array}$ \\
\hline $\begin{array}{l}\text { Echinococcus } \\
\text { oligarthrus, } \\
\text { Echinococcus } \\
\text { oligarthus, } \\
\text { Expressions }\end{array}$ & $\begin{array}{l}\text { Non-valid names of the species } \\
\text { among Echinococcus spp. } \\
\text { which is responsible for one } \\
\text { of the clinical forms of } \\
\text { "neotropical echinococcoses" }\end{array}$ & $\begin{array}{l}\text { Often referred to as E. oligarthrus } \\
\text { (or even oligarthus), the species } \\
\text { was originally described as Taenia } \\
\text { oligarthra (Diesing, 1863) by } \\
\text { Diesing [14]. } \\
\text { Linguistic and historical arguments } \\
\text { are convincing [52, 58, 81]. } \\
\text { See Table } 1 \mathrm{~A} \text {. } \\
\text { The component } \alpha \rho \rho \alpha \text {-arthra (joints) - is } \\
\text { the plural of ä } \theta \rho o v \text {-arthron (joint). The } \\
\text { name is therefore not an adjective, but a } \\
\text { noun in apposition, which does not change } \\
\text { its ending according to the gender of the } \\
\text { generic name. This was recognized earlier } \\
\text { but subsequently ignored. }\end{array}$ & $\begin{array}{l}\text { In this case, there was no mistake in the } \\
\text { original name of species given by } \\
\text { Diesing; variants were used mistakenly } \\
\text { afterwards in the scientific literature. } \\
\text { However, the genus "Echinococcus" } \\
\text { was subsequently identified and } \\
\text { replaced the genus "Taenia". }\end{array}$ \\
\hline
\end{tabular}


Table 2A. (Continued)

\begin{tabular}{llll} 
Word/expression & \multicolumn{1}{c}{ Definition } & \multicolumn{1}{c}{$\begin{array}{c}\text { Reasons for rejection, references, } \\
\text { linguistic clarifications }\end{array}$} & \multicolumn{1}{c}{ Comments } \\
\hline $\begin{array}{l}\text { Echinococcus } \\
\text { sibiricensis } \text { (Rausch } \\
\text { \& Schiller, 1954), }\end{array}$ & $\begin{array}{l}\text { Non-valid historical name for } \\
\text { Expression }\end{array}$ & $\begin{array}{l}\text { E. multilocularis } \text { (Leuckart, 1863) } \\
\text { is currently the only accepted } \\
\text { name in the international } \\
\text { nomenclature [18, 50, 63, 77]. }\end{array}$ & $\begin{array}{l}\text { The species described as } \\
\text { E. sibiricensis } \text { (Rausch \& Schiller, } \\
\text { 1954), was subsequently found to be } \\
\text { conspecific with E. multilocularis } \\
\text { (Leuckart, 1863) [63]. }\end{array}$ \\
\hline
\end{tabular}

Table 2B. Rejected terms for the biology and immunology of Echinococcus species.

\begin{tabular}{lll}
\hline Word/expression & \multicolumn{1}{c}{ Definition } & \multicolumn{1}{c}{$\begin{array}{c}\text { Reasons for rejection, references, } \\
\text { linguistic clarifications }\end{array}$} \\
\hline $\begin{array}{l}\text { *Adult worm, } \\
\text { Expression }\end{array}$ & $\begin{array}{l}\text { Sexual reproduction stage } \\
\text { Echinococcus spp. parasites in their } \\
\text { definitive hosts. }\end{array}$ & $\begin{array}{l}\text { Sometimes used as equivalent of "adult } \\
\text { form". } \\
\text { Adult worm may be considered redundant, } \\
\text { since worms are adult forms of helminths. } \\
\text { In addition, "adult form" in the definitive } \\
\text { host corresponds to "larval form" in the } \\
\text { intermediate host. }\end{array}$
\end{tabular}

*Adventitia, Fibrous and cellular layer between Noun the laminated layer of the hydatid in E. granulosus s.l. infection and the normal parenchyma of the host organ where the metacestode developed.

$\begin{array}{ll}\text { *Boundary } & \text { Structures that surround the } \\ \text { (periparasitic), } & \text { laminated layer of the hydatid of } \\ \text { Noun } & \begin{array}{l}\text { Echinococcus spp. metacestodes in } \\ \text { their intermediate hosts, at the } \\ \text { border with the organ parenchyma. }\end{array}\end{array}$

*Died-out (cyst, lesion), Adjective

Non-viable parasitic structure as evidenced by imaging (complete calcification in AE, CE5 cyst in CE) or histological examination (absence of viable parasitic cells).

*Germinal cell, Pluripotent somatic stem cell with Expression some homologies but also differences to neoblasts of freeliving flatworms. Germinative cells are the only mitotically active cells in the metacestode and give rise to all differentiated cells.

\section{Germinal membrane, Inner cellular layer of the Expression Echinococcus spp. metacestode.}

Hooklets, Noun

Appendices of the adult worm of Echinococcus spp. parasites allowing them to attach to the intestinal wall of the definitive hosts.
Word of Latin origin, "adventitia" is the outermost connective tissue covering of an organ, vessel, or other biological structure. In the CE cyst, this poorly cellular and mostly fibrous layer results from the host immune reaction to E. granulosus sensu lato metacestode.

Alternative noun to "border"; "border" is more common in pathology terminology.

Could be used in clinical or experimental situations when evidence of absence of

viability is not obtained by transplantation or in vitro culture.

Alternative expression to designate germinative cells. Same adjective as in the expression "germinal layer" where these cells are located. However, not all cells in the germinal layer correspond to this definition.

This term should be avoided and the term "layer" should be preferred because of the complexity of the various "layers" of the hydatid, and the possible confusion of "membrane" with the cell "membrane", which has a specific definition in biology.

This term, a diminutive of "hooks", is also "Hook" is the only term recommended. used to designate these structures of the scolex and adult form of Echinococcus spp.; it should be avoided because the term "hooklet" infers a smaller version of a hook, i.e. that two forms are present, a larger "hook" and a smaller "hooklet" as in the haptor of some Monogenean parasites.
As "adventitia" may be used for any "adventitial layer", which refers to the parasite "germinal layer" and "laminated layer", was preferred by the voters for this structure of host origin (median: 2, for "adventitia").

Rejected because of usage (median: 0 ).

Rejected by a majority of voters (median: 10, for rejection).

The germinal layer also contains other cell types such as muscle cells, nerve cells, and calcareous corpuscle-

producing cells. This was an argument to reject the adjective "germinal" for such cells (median: 3 ).

Germinal layer is the recommended expressions to designate the inner cellular "layer" of parasite origin in the Echinococcus spp. metacestode. The expression was rejected by majority of voters (median: 3 ).

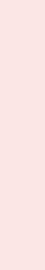
biological structure, the use of 
Table 2B. (Continued)

\begin{tabular}{ll}
$\begin{array}{l}\text { Word/ } \\
\text { expression }\end{array}$ & \multicolumn{1}{c}{ Definition } \\
\hline $\begin{array}{l}\text { Hydatic, } \\
\text { Adjective }\end{array}$ & Related to Echinococcus spp. \\
*Infiltration \\
(periparasitic), and fibrous) from host origin in \\
Noun & $\begin{array}{l}\text { Histological components (cellular } \\
\text { alveolar echinococcosis }\end{array}$
\end{tabular}

\section{Laminated Outer acellular layer of the membrane, Echinococcus spp. metacestode. Expression}

Neoblast, Somatic stem cell type which Noun shares homologies with Echinococcus spp. metacestodes, but also display significant differences.

**Non-fertile Adult form/worm of (adult form Echinococcus spp. whose or worm), last segment does not Expression contain eggs. germinative cells from

Reasons for rejection, references,
linguistic clarifications
allicism for "hydatid" used as an
djective.
Alternative noun to "infiltrate";
riltrate is more common in pathology
rminology; infiltration has a slightly
flammatory in the whole organ).

This term should be avoided and the term "layer" should be preferred because of the complexity of the various "layers" of the hydatid, and the possible confusion of "membrane" with the cell "membrane", which has a specific definition in biology.

Specific of planarians (and other free-living flatworms).

Alternative to "immature" (adult form or worm). However, non-fertile could imply that this worm is not able to become fertile (which is wrong for the majority of adult Echinococcus spp. forms, especially in the definitive host in vivo).

"Primary cell" is not a specific

Primary cells, All cells that result from lytic Expression digestion of the Echinococcus spp. metacestode and can be kept in culture using the "primary cell cultivation system".

*Proglottid, Orthographic variant of Noun (singular), Proglottids (plural),

Noun "proglottis": part of the adult form of Echinococcus spp. parasites resulting from segmentation of the scolex in the intestine of definitive hosts.

Protoscolices Prefiguration ("proto") of the (Plural of "scolex", produced by the brood protoscolex), capsules budding from the Noun germinal layer of Echinococcus spp. metacestode and released in the cyst fluid.

Scolices

(Plural of

First segment ("head") of the scolex), adult form of cestodes.

Noun

Totipotent Stem cells in the germinal somatic stem layer of Echinococcus spp. cell, Expression

cell type of Echinococcus spp.
Proglottid is an alternative to proglottis in several dictionaries; the plural "proglottids" is commonly used in the USA (American English). Referring to the Greek origin of the word, "proglottis (sing), proglottides (plur) should be preferred.

From the ancient Greek " $\sigma \kappa \dot{\omega} \lambda \varepsilon \xi$ " -scolex (worm), genitive: $\sigma \kappa \omega \dot{\lambda} \varepsilon \kappa o \varsigma$ scolecos, and not -scolicos; the plural form is $\sigma \kappa \omega \dot{\lambda} \varepsilon \kappa \varepsilon \varsigma$, scoleces, and not scolices; with the prefix " $\pi \rho \tilde{\omega} \tau 0 \varsigma$ "protos (first/before).

From the ancient Greek " $\sigma \kappa \omega \lambda \lambda \varepsilon \xi$ ”scolex (worm), genitive: $\sigma \kappa \omega \dot{\lambda \varepsilon \kappa o \varsigma ~-~}$ scolecos, and not -scolicos; the plural form is $\sigma \kappa \omega \lambda \lambda \varepsilon \kappa \varepsilon \zeta$, scoleces, and not scoleces.

Alternative to "germinative cells"; however, the real totipotent cell, with specific markers, has not been identified yet [45]. metacestode, but a "culture system" [70]. and nerve cells [45]. expression to designate the outer acellular "layer" of parasite origin in the Echinococcus spp. metacestode.

Should not be used for Echinococcus spp.

In vitro-reared adult forms of Echinococcus spp. do not contain eggs; they exhibit some differences from the in vivo developed adult forms, and they are presumably non-fertile [56].

However, the adjective "non-fertile" cannot be accepted for the usual situation of in vivo developed Echinococcus spp. adult forms/worms.

Primary cells are a mixture of "germinative cells" ( $80 \%$ at the beginning), muscle cells

This spelling was rejected by a majority of voters (7/10; median: 3 )

Protoscoleces is the correct plural form, according to the etymology of the word.

Scoleces is the correct plural form, according to the etymology of the word.

Pending a better definition of the really totipotent cells in the germinal layer of Echinococcus spp. metacestode, a single expression "germinative cell" should be kept. 
Table 2B. (Continued)

\begin{tabular}{llll}
\hline Word/expression & \multicolumn{1}{c}{ Definition } & $\begin{array}{l}\text { Reasons for rejection, references, linguistic } \\
\text { clarifications }\end{array}$ & \multicolumn{1}{c}{ Comments } \\
$\begin{array}{lll}\text { *Transitional larva, } \\
\text { Expression }\end{array}$ & $\begin{array}{l}\text { Stage of Echinococcus spp. } \\
\text { between the oncosphere and the } \\
\text { fully developed hydatid (i.e. first } \\
\text { stage in the metacestode } \\
\text { development). }\end{array}$ & $\begin{array}{l}\text { Alternative expression to "post-oncospheral" } \\
\text { stage, but less precise to qualify a stage of a } \\
\text { metacestode since it may apply to any larva. In } \\
\text { addition, "transitional" may qualify any other } \\
\text { stages of development (e.g. when brood } \\
\text { capsules produce protoscoleces). }\end{array}$ & $\begin{array}{l}\text { Rejected by all voters } \\
\text { but } 2 \text { (median: 0). }\end{array}$ \\
\hline
\end{tabular}

* Agreement to reject the term obtained at the second stage of the consultation (the participants in the Consultation and Rating Group had to rate their approval or rejection of the words/expressions independently on a scale from 0 to 10; whenever relevant, the median of the votes is given in the "Comments" column).

Agreement to reject a term that was not selected at the first stage of consultation; the agreement was obtained at the second stage after further discussion between experts or after recommendation by the RRG.

Table 2C. Rejected terms for the clinical aspects of echinococcosis.

\begin{tabular}{|c|c|c|c|}
\hline Word/expression & Definition & $\begin{array}{l}\text { Reasons for rejection, references, } \\
\text { linguistic clarifications }\end{array}$ & Comments \\
\hline $\begin{array}{l}\text { *Adventitial (cystectomy), } \\
\text { Adjective } \\
\text { *Sub-adventitial } \\
\text { (cystectomy), } \\
\text { Adjective }\end{array}$ & $\begin{array}{l}\text { Total cystectomy (usually } \\
\text { performed without opening the } \\
\text { cyst) which uses the dissection } \\
\text { space between the adventitial } \\
\text { layer and the "normal" liver } \\
\text { parenchyma to remove the cyst } \\
\text { more easily. }\end{array}$ & $\begin{array}{l}\text { Proposed alternatives to "peri- } \\
\text { adventitial" to qualify this surgical } \\
\text { technique [35]. }\end{array}$ & $\begin{array}{l}\text { The adjectives do not indicate } \\
\text { clearly if the resection is } \\
\text { performed inside or outside the } \\
\text { adventitial layer. } \\
\text { The adjectives, with their } \\
\text { definition, were rejected by a } \\
\text { majority of voters (median: } 0 \text { ). }\end{array}$ \\
\hline $\begin{array}{l}\text { Alveococcosis, } \\
\text { Noun }\end{array}$ & $\begin{array}{l}\text { Disease related to infection with } \\
\text { E. multilocularis. }\end{array}$ & $\begin{array}{l}\text { Historical name for the infection due to } \\
\text { E. multilocularis in Russia/Russian } \\
\text { language and Russia-related countries. } \\
\text { Not compliant with the } \\
\text { recommendations of the World } \\
\text { Federation of Parasitologists (WFP), } \\
\text { since it is built from the name of a } \\
\text { wrong genus. }\end{array}$ & $\begin{array}{l}\text { Not in use in other countries/ } \\
\text { languages than Russia/Russian } \\
\text { The only recommended name is } \\
\text { "Alveolar echinococcosis (AE)" } \\
\text { (see Table 1C). }\end{array}$ \\
\hline $\begin{array}{l}\text { *Anti-infectious, } \\
\text { *Anti-infective, } \\
\text { (therapy/treatment/drug), }\end{array}$ & $\begin{array}{l}\text { Drug treatment (usually } \\
\text { chemical) of echinococcosis, } \\
\text { opposed to or associated with } \\
\text { surgery (on the model of } \\
\text { infectious diseases therapy). }\end{array}$ & $\begin{array}{l}\text { Although they are commonly used for } \\
\text { the treatment of infectious diseases, } \\
\text { these adjectives infer prevention as well } \\
\text { as (and even rather than) } \\
\text { treatment."Anti-parasitic" is more exact, } \\
\text { and more appropriate for parasitic } \\
\text { diseases. }\end{array}$ & $\begin{array}{l}\text { The adjectives "anti-infectious" } \\
\text { and "anti-infective" were rejected } \\
\text { by all voters (median: } 10 \text { ). }\end{array}$ \\
\hline $\begin{array}{l}\text { Chemotherapy, } \\
\text { Noun }\end{array}$ & $\begin{array}{l}\text { Drug treatment (usually } \\
\text { chemical) of echinococcosis, } \\
\text { opposed to or associated with } \\
\text { surgery (on the model of cancer } \\
\text { therapy) }\end{array}$ & $\begin{array}{l}\text { The word was used at the first trials of } \\
\text { mebendazole/albendazole, for the } \\
\text { treatment of echinococcosis, in the } \\
1980 \text { s, to stress the "chemical" nature of } \\
\text { the treatment and oppose this treatment } \\
\text { to surgery which was the only } \\
\text { therapeutic option. Has been used } \\
\text { commonly thereafter. }\end{array}$ & $\begin{array}{l}\text { Even though echinococcosis } \\
\text { shares some particularities with } \\
\text { cancer, the word "chemotherapy" } \\
\text { has gained a strong cancer- } \\
\text { related meaning which may } \\
\text { cause confusion, especially when } \\
\text { echinococcosis occurs in cancer } \\
\text { patients because of the } \\
\text { immunosuppressive effect of the } \\
\text { anti-cancer chemotherapy. In } \\
\text { addition, not all drugs against } \\
\text { echinococcosis are chemical (cf. } \\
\text { immunotherapy and other } \\
\text { biotherapies). It should be } \\
\text { abandoned for the use of "anti- } \\
\text { parasitic" therapy (or treatment, } \\
\text { or drugs). See also Table 1C. }\end{array}$ \\
\hline
\end{tabular}


Table 2C. (Continued)

\begin{tabular}{lll} 
Word/expression & \multicolumn{1}{c}{ Definition } & \multicolumn{1}{c}{$\begin{array}{c}\text { Reasons for rejection, references, } \\
\text { linguistic clarifications }\end{array}$} \\
$\begin{array}{lll}\text { *Closed } \\
\text { cystectomy, }\end{array}$ & $\begin{array}{l}\text { Surgical operation which does } \\
\text { not include cyst opening before } \\
\text { cyst removal (cystectomy). }\end{array}$ & $\begin{array}{l}\text { Widely used by surgeons; however, } \\
\text { linguistically incorrect: a cystectomy - } \\
\text { Only applies to CE, and for total }\end{array}$ \\
& $\begin{array}{l}\text { "closed", and a cyst is rather "non- } \\
\text { cystectomy; it is not relevant for } \\
\text { AE. }\end{array}$ & $\begin{array}{l}\text { opened" than "closed" (the surgeon does } \\
\text { not close the cyst, he/she may have it } \\
\text { non-opened) [81]. }\end{array}$
\end{tabular}

\section{*Daughter hydatid,} Expression

\section{*Daughter} vesicle, Expression

Echinococcus alveolaris, Expression

Echinococcus cysticus, Expression

Hydatic, Adjective

Hydatid disease, Expression

\section{Hydatid} polycystosis, Expression
Newly formed hydatids inside (and far less frequently outside, if Although it fits well with the descrip any) the CE cyst in the development of Echinococcus granulosus s.l. Not applicable to E. multilocularis/AE.

Newly formed hydatids inside Alternative term to "daughter cyst". As a (and far less frequently outside, if literal translation, the use of "vesicle" any) the CE cyst in the development of Echinococcus granulosus s.l. Not applicable to E. multilocularis/AE of the "hydatid", as a noun, it is not established by usage. would fit with the initial description by Dévé ("vésicule fille" in French).

Comments

The majority of voters rejected the expression (median: 3).The expression should be replaced by "non-opened cyst (NOC) -cystectomy".

See also Table $1 \mathrm{C}$ and Figure 3 and the description of the AORC framework with the definition of its various components in liver CE surgery.

The term with this definition was rejected by the majority of voters (median: 1).

The majority of voters rejected all suggested names for this metacestode structure (median: 3; mean: 4.7, for "daughter vesicle"). The arguments which prevailed to reject "daughter vesicle" and eventually approve the historical expression "daughter cyst" was first the worldwide usage and second the agreement by the participants in the subgroup "Biology and immunology" to restrict the use of "vesicle" to the metacestode of Echinococcus spp. in vitro only, whatever the species.

Disease related to infection with Name for the infection due to E. multilocularis.

E. multilocularis sometimes used in German-speaking countries. Not compliant with the recommendations of the WFP.

Mix of the name of the genus and the adjective qualifying the disease (in Latin...).

The only recommended name is "Alveolar echinococcosis (AE)" (see Table 1C).

Mix of the name of the genus and the $\begin{array}{ll}\text { Disease related to infection with } & \text { Name for the infection due to } \\ \text { E. granulosus sensu lato (s.l.). } & \text { E. granulosus s.l. sometimes used in }\end{array}$ German-speaking countries Not compliant with the recommendations The only recommended name is "Cystic of the WFP.

Related to Echinococcus spp. Gallicism for "hydatid", used as an adjective ("hydatique", in French).

Disease related to infection with Commonly used alternative name to Echinococcus spp. designate either all diseases due to Echinococcus spp. or the diseases due to E. granulosus sensu lato. This disease name does not fit with the unified recommendations of the WFP. echinococcosis (CE)" (see Table 1C).

Should not be used in English.

This noun should not, in any cases, be used for alveolar echinococcosis or neotropical echinococcosis; it should not be used for E. granulosus s.l. infection in humans either: the only recommended name is "Cystic echinococcosis (CE)" (see Table 1C). In addition, usage of this name increases Use of "hydatid" as an adjective should be confusion among clinicians and decision restricted to infection due to E. granulosus makers between the diseases due to E. granulosus sensu lato and E. multilocularis, respectively.

s.l. (see Tables $1 \mathrm{~B}$ and $1 \mathrm{C}$ ) in the intermediate hosts.

Cystic (or other) echinococcoses Sometimes used in publications. Source with multiple cysts of confusion with polycystic (nonparasitic) diseases (see "polycystic").
The adjective "multicystic" is now proposed as a non-specific description of any type of cystic echinococcosis when several/many macroscopic cysts are present and visible at imaging (see Table 1C).

Use of "hydatid" as an adjective should be restricted to infection due to $E$. granulosus s.l. (see Table 1C) in the intermediate hosts. 
Table 2C. (Continued)

\begin{tabular}{|c|c|c|}
\hline Word/expression & Definition & $\begin{array}{l}\text { Reasons for rejection, references, } \\
\text { linguistic clarifications }\end{array}$ \\
\hline $\begin{array}{l}\text { *Hydatidectomy, } \\
\text { Noun }\end{array}$ & $\begin{array}{l}\text { Partial cystectomy, } \\
\text { including the removal of } \\
\text { the germinal and } \\
\text { laminated layers of } \\
\text { E. granulosus sensu lato } \\
\text { cysts after cyst opening }\end{array}$ & $\begin{array}{l}\text { From the definition of "hydatid" } \\
\text { (see Table 1B), this noun could replace } \\
\text { "partial cystectomy", with less ambiguity } \\
\text { (especially regarding surgeon's evaluation } \\
\text { between "subtotal" and "partial"). }\end{array}$ \\
\hline $\begin{array}{l}\text { Hydatidosis, } \\
\text { Noun }\end{array}$ & $\begin{array}{l}\text { Disease related to } \\
\text { infection with } \\
\text { Echinococcus spp. }\end{array}$ & $\begin{array}{l}\text { Commonly used name to designate the } \\
\text { diseases due to Echinococcus spp. This } \\
\text { disease name does not fit with the } \\
\text { recommendations of the WFP } \\
\text { In addition, usage of this name increases } \\
\text { confusion among clinicians and decision } \\
\text { makers between the diseases due to } \\
\text { E. granulosus s.l. and } \\
\text { E. multilocularis, respectively. }\end{array}$ \\
\hline
\end{tabular}

*Open cystectomy, Expression

\section{Pericystectomy}

\section{Polycystic} echinococcosis, Expression

\section{Polycystic,} Adjective
Surgical operation which includes cyst opening before cyst removal (cystectomy). Only applies to CE; may be at first or second intent; it is not relevant for $\mathrm{AE}$.

Removal of a CE cyst which includes all layers of the cyst (including the adventitial layer).

Disease related to infection with $E$. vogeli (stressing the multicystic type/presentation of E. vogeli infection).
Wrongly used to designate the operation which includes the adventitial layer of the cyst in CE. The prefix "peri" is not useful, since the adventitial layer is part of the cyst; "cystectomy" is thus the appropriate word. Stricto sensu, the "pericyst" is the normal organ parenchyma that surrounds the cyst (see Figs. 2A-2C) [68].

The expression is sometimes wrongly used in medical publication to designate diseases due both to $E$. vogeli, which is most often polycystic/multicystic and E. oligarthra, which usually presents with single cysts similar to those of $\mathrm{CE}$, in humans and in animal intermediate hosts $[11,35]$ but may also be multicystic or even microcystic (AE-like) [69].

In addition, "polycystic" may cause confusion between the disease due to E. vogeli and "polycystic" clinical types of E. granulosus and E. multilocularis infections. The adjective "polycystic" is widely used to designate a genetic nonparasitic disease of the liver and kidney, adding to the confusion.

The adjective "polycystic" is not specific to echinococcosis; "polycystic" is widely used to qualify a genetic non-parasitic disease of the liver and kidney; in addition, it has been used to distinctly qualify the disease due to E. vogeli (see below).
Comments

Scientifically correct, but not established by use.

The term with this definition was rejected by the majority of voters (median: 0).

This noun should not, in any cases, be used for alveolar echinococcosis or neotropical echinococcosis; it should not be used for E. granulosus s.l. infection in humans either: the only recommended name is "Cystic echinococcosis (CE)” (see Table 1C).

The majority of voters rejected the expression (median: 3). The expression should be replaced by "non-opened cyst cystectomy" (NOC).

See also Table $1 \mathrm{C}$ and Figure 3 and the description of the AORC framework with the definition of its various components in liver CE surgery.

See Table 1C for alternative wording regarding surgery of CE.

The only noun recommended is "cystectomy".

See also Figure 3 and the description of the AORC framework with the definition of its various components in liver CE surgery.

The only recommended name for the diseases due to $E$. vogeli and E. oligarthra is "Neotropical echinococcosis (NE)" (see Table 1C).

The adjective "multicystic" is now proposed as a non-specific description of any type of cystic echinococcosis when several/many macroscopic cysts are present and visible at imaging (see Table 1C).

The adjective "multicystic" is now proposed as a non-specific description of any type of cystic echinococcosis when several/many macroscopic cysts are present and visible at imaging (see Table 1C). 
Table 2C. (Continued)

\begin{tabular}{|c|c|c|c|}
\hline Word/expression & Definition & $\begin{array}{l}\text { Reasons for rejection, references, } \\
\text { linguistic clarifications }\end{array}$ & Comments \\
\hline $\begin{array}{l}\text { Protoscolicide, } \\
\text { Noun; } \\
\text { Protoscolicidal, } \\
\text { Adjective }\end{array}$ & $\begin{array}{l}\text { Compound (natural or } \\
\text { chemical) which is able to } \\
\text { kill the protoscolex. }\end{array}$ & 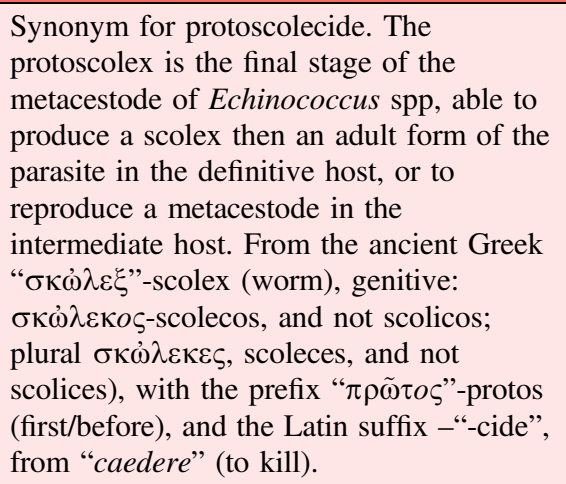 & $\begin{array}{l}\text { Should be abandoned for } \\
\text { "protoscolecide" (see Table 1C); } \\
\text { protoscolecides (protoscolecidal agents) } \\
\text { are used to kill the protoscoleces and/or } \\
\text { prevent secondary cysts after surgery. }\end{array}$ \\
\hline **Relapse, Noun & $\begin{array}{l}\text { Any type of } \\
\text { echinococcosis lesions } \\
\text { that appeared after the } \\
\text { implementation of any } \\
\text { type of treatment. }\end{array}$ & $\begin{array}{l}\text { The definition is vague and covers several } \\
\text { types of lesion appearing after attempts of } \\
\text { treatment. More precise definitions of } \\
\text { lesions observed in this situation should be } \\
\text { used. }\end{array}$ & $\begin{array}{l}\text { Should be abandoned for specific terms/ } \\
\text { expressions covering the various } \\
\text { situations encountered by clinicians (see } \\
\text { in Table 1C the definitions of "new CE } \\
\text { cyst", "reactivation", "recurrence", and } \\
\text { "secondary echinococcosis"). }\end{array}$ \\
\hline $\begin{array}{l}\text { Scolecide, Noun; } \\
\text { Scolecidal, } \\
\text { Adjective }\end{array}$ & $\begin{array}{l}\text { Compound (natural or } \\
\text { chemical) that is able to } \\
\text { kill the scolex. }\end{array}$ & 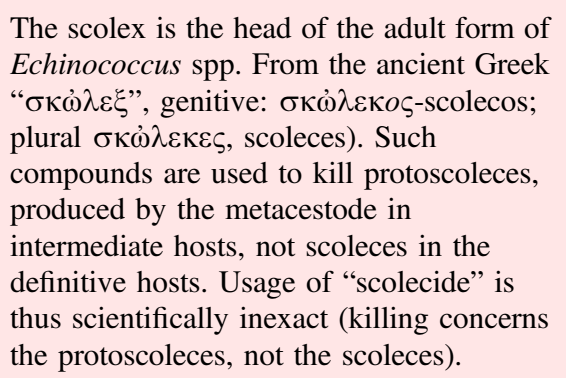 & $\begin{array}{l}\text { Should be abandoned for } \\
\text { "protoscolecide" (see Table 1C). }\end{array}$ \\
\hline $\begin{array}{l}\text { Scolicide, } \\
\text { Noun; } \\
\text { Scolicidal, } \\
\text { Adjective }\end{array}$ & $\begin{array}{l}\text { Compound (natural or } \\
\text { chemical) that is able to } \\
\text { kill the scolex. }\end{array}$ & $\begin{array}{l}\text { Synonym for scolecide. The common } \\
\text { usage of "scolicide" is both scientifically } \\
\text { inexact (killing concerns the protoscoleces, } \\
\text { not the scoleces) and etymologically wrong } \\
\text { (see also "scolecide" and "protoscolicide"). }\end{array}$ & $\begin{array}{l}\text { Should be abandoned for } \\
\text { "protoscolecide/protoscolecidal" (see } \\
\text { Table 1C). }\end{array}$ \\
\hline
\end{tabular}

\footnotetext{
* Agreement to reject the term obtained at the second stage of the consultation (the participants in the Consultation and Rating Group had to rate their approval or rejection of the words/expressions independently on a scale from 0 to 10; whenever relevant, the median of the votes is given in the "Comments" column).

** Agreement to reject a term that was not selected at the first stage of consultation; the agreement was obtained at the second stage after further discussion between experts or after recommendation by the RRG.
}

Additional colleagues, especially from South America and China, were solicited after the congress. However, only Chinese colleagues answered positively, which resulted in a relatively low participation of South American colleagues in the "Clinical aspects" subgroup, perhaps because of language issues: Spanish and Portuguese are the publication languages of most South American clinicians; publications in English from South America are mostly in biology and public health. All members of the RRG were selected by the SWG on the basis of their international academic recognition in the fields of $\mathrm{CE}, \mathrm{AE}$ and $\mathrm{NE}$. Despite the absence of face-to-face meetings to discuss the undecided questions, open email discussions were initiated by the coordinators of the subgroups, and this procedure was very efficient. If there were missing values for the poll, the project manager actively and individually contacted the voters in question in order to ask them to provide their opinion. Feedback from the RRG members was also followed by active discussions in order to reach consensus on important terms and to revise and finalize this paper.

\section{Major outcomes and conclusions}

Currently, a precise genetic definition is available for nine species: E. granulosus (Batsch, 1786) sensu stricto, E. canadensis (Webster \& Cameron, 1961), E. ortleppi LopezNeyra \& Soler Planas, 1943, E. felidis Ortlepp, 1937, and E. equinus (Williams \& Sweatman, 1963), within the E. granulosus (Batsch, 1786) sensu lato cluster and responsible for cystic echinococcosis, E. multilocularis (Leuckart, 1863), and E. shiquicus Xiao, Qiu, Nakao, Li, Yang, Chen, Schantz, Craig \& Ito, 2005, responsible for alveolar echinococcosis, and E. vogeli Rausch and Bernstein, 1972 and E. oligarthra (Diesing, 
1863), responsible for neotropical echinococcosis; the responsibility of some of the species (e.g., E. equinus (Williams and Sweatman, 1963) or E. shiquicus Xiao et al., 2005) in human infection is still being questioned; this does not challenge the genetic definition of these species (Table 1A). Recognition of additional species within E. canadensis and E. granulosus s.s. is to be expected (Table 1A). Thus, distinct Echinococcus spp. genotypes within the E. canadensis cluster may move to full species status, and the names $E$. intermedius (for G6/7), E. borealis (for G8) and $E$ canadensis (for G10) have been proposed; however, no conclusion on the number and names of these species has yet been reached [57].

Variations around the radical "hydatid" have long been used to designate diseases due to Echinococcus spp. The presence of "hydatid" cysts had long been recognized as a feature of a parasitic disease when the natural cycle of the parasite responsible for its occurrence was identified in the middle of the 19th century [18, 77]; the species was first named Taenia echinococcus before becoming Echinococcus granulosus. In humans, the disease was clearly not a "taeniasis", and "hydatid disease", "hydatidosis" (if the disease was considered) or "hydatid cyst" (if the lesion was considered) thus prevailed. It took another century before the Echinococcus sp. which causes AE was identified as a distinct species, E. multilocularis $[18,77]$. It is thus easy to understand why several terms, not related to the current name of the genus, were used for centuries, and why they were used to designate both diseases, alveolar and cystic echinococcosis. The inappropriate use of "hydatid" has been a source of confusion, both for disease surveillance and treatment indication [10, 35]. Until recently, echinococcosis surveillance by the European Centre for Disease Control (ECDC) did not distinguish between the two diseases [23]. A clear distinction between three types of diseases, with a single name for each of them, will make all studies on epidemiology, socio-economic burden, and care management more reliable. There was total agreement to never use terms based on the "hydatid" root to designate any disease due to Echinococcus spp., and to strictly restrict the use of "hydatid" to qualify a lesion or part of a lesion due to E. granulosus s.l. in intermediate hosts, entirely excluding its use to qualify anything regarding (1) E. granulosus s.l. infection of the definitive host, and (2) AE and NE. With regards to a cystic lesion, "CE cyst" should be preferred to "hydatid cyst" since the large majority of voters preferred to use this term, and did not wish to keep both names for E. granulosus s.l.-related cysts.

Although specialists of the genetics of Echinococcus spp. rapidly agreed on the correct spelling of the species E. oligarthra on historical and linguistic arguments (and not oligarthrus, as commonly spelled in the last few decades; see e.g., [5, 17]), clinicians were more hesitant on the names of the diseases that E. oligarthra and E. vogeli may cause in humans. There was no term/expression entirely satisfactory to designate both diseases. Because both are infections of the "tropical areas of the New World", "neotropical" has been commonly used in the scientific literature and was presented at the WHO-Forum in 2015 to be included among the U50-U99 "Codes for research and alternative subclassifications" of the International Statistical Code of Diseases and Related Health Problems (https://apps.who.int/ iris/bitstream/handle/10665/246208/9789241549165-V2-eng. pdf), as: U51X: "Infection due to Neotropical Echinococcosis". The suggestion of South American specialists, which was confirmed by the poll, was thus to keep this denomination. To avoid the confusion with "polycystic liver and kidney disease", a genetic disease, the adjective "polycystic" (of Greek origin) should definitively be replaced by "multicystic" (of Latin origin, but with exactly the same meaning) when multiple aggregated cysts are observed on imaging, regardless of the species; "multiple cyst-" characterizes the co-existence of several separated and independent cysts in the same organ or different organs.

It was agreed that the current international classifications already approved by the WHO-IWGE, i.e. the "CE" classification of CE cysts [82], and the PNM classification of AE lesions [37], would not be questioned, and that further work on the refinement of imaging classification of $\mathrm{AE}$ would not proceed until fixing of international recommendations. However, an unexpected and extremely useful outcome of the terminology discussions was the agreement on a new and internationally recognized system to describe surgical operations in $\mathrm{CE}$, the "AORC" framework (Fig. 3), with consensus on the single word "cystectomy" to describe the removal of the CE cyst, thus excluding "pericystectomy" when it consists of the removal of the three layers of the cyst without "pericystic" liver. This recommendation will help professionals to share a common description that is relevant in terms of perioperative risks and the risk of CE recurrence after operation. A precise description of the procedure actually performed by the surgeon for a given patient should accompany the mandatory terms (description of the removed parasite layers, area in square centimeters or percentage of cyst actually resected, closure of communications with bile ducts, content of the cyst if it was opened, etc.); this is beyond the objectives of a work on terminology and will be further discussed in the "Technical Manual" for the diagnosis and treatment of $\mathrm{CE}$, which is currently being prepared by the WHO-IWGE. For non-surgical CE interventions, the clear distinction between the PAIR (puncture, aspiration, injection, reaspiration, through a needle, without catheterization), S-CAT (standard catheterization), and Mo-CAT (modified catheterization) techniques provides accepted acronyms and will also help professionals to better understand the specific indications of each technique and the results of clinical trials.

The work in terminology aimed to cover all fields of echinococcosis; it was the first attempt at standardizing scientific and medical language in a specific area of parasitic disease echinococcosis. However, it did not claim to solve all points of debate and/or to address everything definitively. The words and expressions reported in Tables $1 \mathrm{~A}-1 \mathrm{C}$ and $2 \mathrm{~A}-2 \mathrm{C}$ do not encompass all technical aspects; such details should be considered by subgroups of specialists. Regular updating will also be necessary, following future advances in scientific and medical knowledge. Apparently "easy-to-solve" dilemmas were in fact more difficult to resolve when several disciplines reported on their own usages. This was the case for the debate between "daughter cyst" and "daughter vesicle". Purists will certainly regret that "daughter cyst" will stay in use, despite the paradoxical female gender, explained by the use of the feminine "vésicule" (vesicle) in the first descriptions in French. Although "daughter" is not justified in English, the alternative adjective "secondary" cannot replace it since it is widely used 
to designate new cysts developed in the peritoneum, pleura or meningeal space after cyst rupture and/or protoscolex spillage Although "cyst" was not fully justified either, because it has no fully developed adventitial layer, biologists readily agreed to keep the noun "vesicle" with restricted use for the in vitro situation. The results of the poll (Tables $1 \mathrm{C}$ and 2C) confirmed the problematic nature of the issue: "daughter cyst" was not preferred, "daughter vesicle" was not either, and the alternative expression "daughter hydatid" was unequivocally rejected; it was thus agreed to keep the "historical wording", i.e. "daughter cyst". We recommend the constitution of a permanent group on "terminology" common to the WAE and the WHO-IWGE so that such "unresolved" issues may be further discussed, and that the certainly numerous new terms used in the field in the future may be handled in a timely manner.

Acknowledgements. The Steering and Writing Committee would like to thank in particular Dr. Francesca Tamarozzi for her involvement in the fruitful exchanges between the WAE and the WHOIWGE, and for her very helpful revision of the final manuscript.

\section{References}

1. Addy F, Wassermann M, Banda F, Mbaya H, Aschenborn J, Aschenborn O, Koskei P, Umhang G, De La Rue M, Elmahdi IE, Mackenstedt U, Kern P, Romig T. 2017. Genetic polymorphism and population structure of Echinococcus ortleppi. Parasitology, 144, 450-458.

2. Aji T, Dong J-H, Shao Y-M, Zhao J-M, Li T, Tuxun T, Shalayiadang P, Ran B, Jiang T-M, Zhang R-Q, He Y-B, Huang J-F, Wen H. 2018. Ex-vivo liver resection and autotransplantation as alternative to allotransplantation for end-stage hepatic alveolar echinococcosis. Journal of Hepatology, 69, 1037-1046.

3. Akhan O, Salik AE, Ciftci T, Akinci D, Islim F, Akpinar B. 2017. Comparison of long-term results of percutaneous treatment techniques for hepatic cystic echinococcosis types 2 and 3b. American Journal of Roentgenology, 208, 878-884.

4. Ambregna $S$, Koch $S$, Sulz MC, Grüner B, Öztürk $S$, Chevaux J-B, Sulima M, de Gottardi A, Napoléon B, Abergel A, Bichard P, Boytchev I, Deprez P, Dumortier J, Frossard J-L, Kull E, Meny B, Moradpour D, Prat F, Vanbiervliet G, Thevenot T, Vuitton DA, Bresson-Hadni S, Vuitton L. 2017. A European survey of perendoscopic treatment of biliary complications in patients with alveolar echinococcosis. Expert Review of AntiInfective Therapy, 15, 79-88.

5. Arrabal JP, Avila HG, Rivero MR, Camicia F, Salas MM, Costa SA, Nocera CG, Rosenzvit MC, Kamenetzky L. 2017. Echinococcus oligarthrus in the subtropical region of Argentina: first integration of morphological and molecular analyses determines two distinct populations. Veterinary Parasitology, $240,60-67$.

6. Azizi A, Blagosklonov O, Lounis A, Berthet L, Vuitton DA, Bresson-Hadni S, Delabrousse E. 2015. Alveolar echinococcosis: correlation between hepatic MRI findings and FDG-PET/CT metabolic activity. Abdominal Imaging, 40, 56-63.

7. Batsch AJGK. 1786. Naturgeschichte der Bandwurmgattung und ihrer Arten insbesondere, nach den neuern Beobachtungen in einem systematischen Auszuge. Halle: Ben Johann Jacob Gebauer.

8. Ben Amor N, Gargouri M, Gharbi HA, Golvan YJ, Ayachi K, Kchouck H. 1986. Essai de traitement par ponction des kystes hydatiques abdominaux inopérables. Annales de Parasitologie Humaine et Comparée, 61, 689-692.
9. Boufana B, Stidworthy MF, Bell S, Chantrey J, Masters N, Unwin S, Wood R, Lawrence RP, Potter A, McGarry J, Redrobe S, Killick R, Foster AP, Mitchell S, Greenwood AG, Sako Y, Nakao M, Ito A, Wyatt K, Lord B, Craig PS. 2012. Echinococcus and Taenia spp. from captive mammals in the United Kingdom. Veterinary Parasitology, 190, 95-103.

10. Brunetti E, Kern P, Vuitton DA, Writing Panel for the WHO-IWGE. 2010. Expert consensus for the diagnosis and treatment of cystic and alveolar echinococcosis in humans. Acta Tropica, 114, 1-16.

11. D'Alessandro A, Rausch RL. 2008. New aspects of neotropical polycystic (Echinococcus vogeli) and unicystic (Echinococcus oligarthrus) echinococcosis. Clinical Microbiology Reviews, 21, 380-401.

12. Denk D, Boufana B, Masters NJ, Stidworthy MF. 2016. Fatal echinococcosis in three lemurs in the United Kingdom - a case series. Veterinary Parasitology, 218, 10-14.

13. Deplazes P, Rinaldi L, Alvarez Rojas CA, Torgerson PR, Harandi MF, Romig T, Antolova D, Schurer JM, Lahmar S, Cringoli G, Magambo J, Thompson RCA, Jenkins EJ. 2017. Global distribution of alveolar and cystic echinococcosis. Advances in Parasitology, 95, 315-493.

14. Diesing K. 1863. Revision der Cephalocotyleen. Abteilung: Paramecocotyleen. Sitzungsber. k. p. Akad. Wissensch. Wien, Math. Naturw. p. 48.

15. Eckert J, Deplazes P, Craig PS, Gemmell M, Gottstein B, Heath D, Jenkins D, Kamiya M, Lightowlers M. 2001. Echinococcosis in animals: clinical aspects, diagnosis and treatment, in WHO/OIE manual on echinococcosis in humans and animals: a public health problem of global concern, Eckert J, Gemmell MA, Meslin FX, Pawlowski ZS, Editors. World Organization for Animal Health (OIE): Paris. p. 72-99.

16. Eckert J, Gottstein B, Heath D, Liu F. 2001. Prevention of echinococcosis in humans and safety precautions, in WHO/OIE manual on echinococcosis in humans and animals: a public health problem of global concern, Eckert J, Gemmell MA, Meslin FX, Pawlowski ZS, Editors. World Organization for Animal Health (OIE): Paris. p. 258-267.

17. Eckert J, Rausch R, Gemmell M, Giraudoux P, Kamiya M, Liu F, Schantz P, Romig T. 2001. Epidemiology of Echinococcus multilocularis, Echinococcus vogeli and Echinococcus oligarthrus, in WHO/OIE manual on echinococcosis in humans and animals: a public health problem of global concern, Eckert J, Gemmell MA, Meslin FX, Pawlowski ZS, Editors. World Organization for Animal Health (OIE): Paris. p. 164-194.

18. Eckert J, Thompson RCA. 2017. Historical aspects of Echinococcosis. Advances in Parasitology, 95, 1-64.

19. Einsiedel EF, Eastlick DL. 2000. Consensus conferences as deliberative democracy: a communications perspective. Science Communication, 21, 323-343.

20. Gargouri M, Ben Amor N, Ben Chehida F, Hammou A, Gharbi HA, Ben Cheikh M, Kchouk H, Ayachi K, Golvan JY. 1990. Percutaneous treatment of hydatid cysts (Echinococcus granulosus). Cardiovascular and Interventional Radiology, 13, 169-173.

21. Gottstein B, Soboslay P, Ortona E, Wang J, Siracusano A, Vuitton DA. 2017. Immunology of alveolar and cystic echinococcosis (AE and CE). Advances in Parasitology, 96, 1-54.

22. Gottstein B, Wang J, Blagosklonov O, Grenouillet F, Millon L, Vuitton DA, Müller N. 2014. Echinococcus metacestode: in search of viability markers. Parasite, 21, 63.

23. Graeter T, Kratzer W, Oeztuerk S, Haenle MM, Mason RA, Hillenbrand A, Kull T, Barth TF, Kern P, Gruener B. 2016. Proposal of a computed tomography classification for hepatic alveolar echinococcosis. World Journal of Gastroenterology, 22, 3621-3631. 
24. Grenouillet F, Umhang G, Arbez-Gindre F, Mantion G, Delabrousse E, Millon L, Boué F. 2014. Echinococcus ortleppi infections in humans and cattle, France. Emerging Infectious Diseases, 20, 2100-2102.

25. Hüttner M, Romig T. 2009. Echinococcus species in African wildlife. Parasitology, 136, 1089-1095.

26. Hüttner M, Nakao M, Wassermann T, Siefert L, Boomker JDF, Dinkel A, Sako Y, Mackenstedt U, Romig T, Ito A. 2008. Genetic characterization and phylogenetic position of Echinococcus felidis (Cestoda: Taeniidae) from the African lion. International Journal for Parasitology, 38, 861-868.

27. Jabbar A, Swiderski Z, Mlocicki D, Beveridge I, Lightowlers MW. 2010. The ultrastructure of taeniid cestode oncospheres and localization of host-protective antigens. Parasitology, 137, 521-535.

28. Jacobs D, Fox M, Gibbons L, Hermosilla C. 2015. Principles of Veterinary Parasitology. Hoboken, New Jersey, USA: WilleyBlackwell.

29. Jarnagin W. 2012. Blumgart's surgery of the liver, biliary tract and pancreas, 5th edn. Philadelphia: Saunders.

30. Jones J, Hunter D. 1995. Consensus methods for medical and health services research. British Medical Journal, 311, 376380.

31. Junghanss T, da Silva AM, Horton J, Chiodini PL, Brunetti E. 2008. Clinical management of cystic echinococcosis: state of the art, problems, and perspectives. American Journal of Tropical Medicine and Hygiene, 79, 301-311.

32. Kassai T, Cordero del Campillo M, Euzeby J, Gaafar S, Hiepe T, Himonas CA. 1988. Standardized nomenclature of animal parasitic diseases (SNOAPAD). Veterinary Parasitology, 29, 299-326.

33. Kassai T. 2006. Nomenclature for parasitic diseases: cohabitation with inconsistency for how long and why? Veterinary Parasitology, 138, 169-178.

34. Kassai T. 2006. The impact on database searching arising from inconsistency in the nomenclature of parasitic diseases. Veterinary Parasitology, 138, 358-361.

35. Kern P, Menezes da Silva A, Akhan O, Müllhaupt B, Vizcaychipi KA, Budke C, Vuitton DA. 2017. The Echinococcoses: diagnosis, clinical management and burden of disease. Advances in Parasitology, 96, 259-369.

36. Kern P. 2010. Clinical features and treatment of alveolar echinococcosis. Current Opinion in Infectious Diseases, 23, 505-512.

37. Kern P, Wen H, Sato N, Vuitton DA, Gruener B, Shao Y, Delabrousse E, Kratzer W, Bresson-Hadni S. 2006. WHO classification of alveolar echinococcosis: principles and application. Parasitology International, 55(Suppl), S283-287.

38. Kinkar L, Laurimäe T, Acosta-Jamett G, Andresiuk V, Balkaya I, Casulli A, Gasser RB, van der Giessen J, González LM, Haag KL, Zait H, Irshadullah M, Jabbar A, Jenkins DJ, Kia EB, Manfredi MT, Mirhendi H, M'rad S, Rostami-Nejad M, OudniM'rad M, Pierangeli NB, Ponce-Gordo F, Rehbein S, Sharbatkhori M, Simsek S, Soriano SV, Sprong H, Šnábel V, Umhang G, Varcasia A, Saarma U. 2018. Global phylogeography and genetic diversity of the zoonotic tapeworm Echinococcus granulosus sensu stricto genotype G1. International Journal for Parasitology, 48, 729-742.

39. Kinkar L, Laurimäe T, Acosta-Jamett G, Andresiuk V, Balkaya I, Casulli A, Gasser RB, González LM, Haag KL, Zait H, Irshadullah M, Jabbar A, Jenkins DJ, Manfredi MT, Mirhendi H, M'rad S, Rostami-Nejad M, Oudni-M'rad M, Pierangeli NB, Ponce-Gordo F, Rehbein S, Sharbatkhori M, Kia EB, Simsek S, Soriano SV, Sprong H, Śnábel V, Umhang G, Varcasia A, Saarma U. 2018. Distinguishing Echinococcus granulosus sensu stricto genotypes G1 and G3 with confidence: a practical guide. Infection, Genetics and Evolution, 64, 178-184.
40. Kinkar L, Laurimäe T, Sharbatkhori M, Mirhendi H, Kia EB, Ponce-Gordo F, Andresiuk V, Simsek S, Lavikainen A, Irshadullah M, Umhang G, Oudni-M'rad M, Acosta-Jamett G, Rehbein S, Saarma U. 2017. New mitogenome and nuclear evidence on the phylogeny and taxonomy of the highly zoonotic tapeworm Echinococcus granulosus sensu stricto. Infection, Genetics and Evolution, 52, 52-58.

41. Kinkar L, Laurimäe T, Simsek S, Balkaya I, Casulli A, Manfredi MT, Ponce-Gordo F, Varcasia A, Lavikainen A, González LM, Rehbein S, Van der Giessen J, Sprong H, Saarma U. 2016. High-resolution phylogeography of zoonotic tapeworm Echinococcus granulosus sensu stricto genotype G1 with an emphasis on its distribution in Turkey, Italy and Spain. Parasitology, 143, 1790-1801.

42. Knapp J, Bart JM, Maillard S, Gottstein B, Piarroux R. 2010. The genomic Echinococcus microsatellite EmsB sequences: from a molecular marker to the epidemiological tool. Parasitology, 137, 439-449.

43. Kodama Y, Fujita N, Shimizu T, Endo H, Nambu T, Sato N, Todo S, Miyasaka K. 2003. Alveolar echinococcosis: MR findings in the liver. Radiology, 228, 172-177.

44. König C, Claussen C. 1997. Echinococcus cysticus. RoFo: Fortschritte Auf Dem Gebiete Der Rontgenstrahlen Und Der Nuklearmedizin, 167, M31.

45. Koziol U, Brehm K. 2015. Recent advances in Echinococcus genomics and stem cell research. Veterinary Parasitology, 213, 92-102.

46. Koziol U, Jarero F, Olson PD, Brehm K. 2016. Comparative analysis of Wnt expression identifies a highly conserved developmental transition in flatworms. BMC Biology, 14, 10.

47. Koziol U, Rauschendorfer T, Zanon Rodríguez L, Krohne G, Brehm K. 2014. The unique stem cell system of the immortal larva of the human parasite Echinococcus multilocularis. EvoDevo, 5, 10.

48. Laurimäe T, Kinkar L, Moks E, Romig T, Omer RA, Casulli A, Umhang G, Bagrade G, Irshadullah M, Sharbatkhori M, Mirhendi H, Ponce-Gordo F, Soriano SV, Varcasia A, Rostami- Nejad M, Andresiuk V, Saarma U. 2018. Molecular phylogeny based on six nuclear genes suggests that Echino- coccus granulosus sensu lato genotypes G6/G7 and G8/G10 can be regarded as two distinct species. Parasitology, 145, 1929-1937.

49. Laurimäe T, Kinkar L, Romig T, Omer RA, Casulli A, Umhang G, Gasser RB, Jabbar A, Sharbatkhori M, Mirhendi H, PonceGordo F, Lazzarini LE, Soriano SV, Varcasia A, Rostami Nejad M, Andresiuk V, Maravilla P, González LM, Dybicz M, Gawor J, Šarkūnas M, Šnábel V, Kuzmina T, Saarma U. 2018. The benefits of analysing complete mitochondrial genomes: Deep insights into the phylogeny and population structure of Echinococcus granulosus sensu lato genotypes G6 and G7. Infection, Genetics and Evolution, 64, 85-94.

50. Leuckart R. 1863. Die menschlichen Parasiten und die von ihnen herrührenden Krankheiten. Leipzig and Heidelberg: C. F. Winter.

51. Lopez-Neyra C, Soler Planas M. 1943. Revision del genero Echinococcus Rud y description de una especie nueva parasita intestinal del porro en America. Revista Iberica de Parasitologia, 3, 169-194.

52. Lymbery AJ. 2017. Phylogenetic pattern, evolutionary processes and species delimitation in the genus Echinococcus. Advances in Parasitology, 95, 111-145.

53. Lymbery AJ, Jenkins EJ, Schurer JM, Thompson RCA. 2015. Echinococcus canadensis, E. borealis, and E. intermedius. What's in a name? Trends in Parasitology, 31, 23-29.

54. Lymbery AJ, Jenkins EJ, Schurer JM, Thompson RCA. 2015. Response to Nakao et al. - is Echinococcus intermedius a valid species? Trends in Parasitology, 31, 343-344. 
55. McManus DP. 2013. Current status of the genetics and molecular taxonomy of Echinococcus species. Parasitology, $140,1617-1623$

56. Mohammadzadeh T, Sadjjadi SM, Rahimi H. 2014. Still and moving image evidences for mating of Echinococcus granulosus reared in culture media. Iranian Journal of Parasitology, 9, 129-133.

57. Nakao M, Lavikainen A, Hoberg E. 2015. Is Echinococcus intermedius a valid species? Trends in Parasitology, 31, 342-343.

58. Nakao M, Lavikainen A, Yanagida T, Ito A. 2013. Phylogenetic systematics of the genus Echinococcus (Cestoda: Taeniidae). International Journal for Parasitology, 43, 1017-1029.

59. Ortlepp J. 1937. South African helminths - Part I. Onderstepoort Journal of Veterinary Science and Animal Industry, 9, 311-336.

60. Ozdemir F, Ince V, Barut B, Onur A, Kayaalp C, Yilmaz S. 2015. Living donor liver transplantation for Echinococcus Alveolaris: single-center experience. Liver Transplantation, 21, 1091-1095.

61. Popa AC, Akhan O, Petruțescu MS, Popa LG, Constantin C, Mihăilescu P, Creţu CM, Botezatu C, Mastalier B. 2018. New options in the management of cystic echinococcosis - a single centre experience using minimally invasive techniques. Chirurgia (Bucharest, Romania: 1990), 113, 486-496.

62. Rausch RL, Bernstein JJ. 1972. Echinococcus vogeli sp. n. (Cestoda: Taeniidae) from the bush dog, Speothos venaticus (Lund). Zeitschrift für Tropenmedizin und Parasitologie, 23, 25-34.

63. Rausch RL, Nelson GS. 1963. A review of the genus Echinococcus Rudophi, 1801. Annals of Tropical Medicine and Parasitology, 57, 127-135.

64. Rogan MT, Hai WY, Richardson R, Zeyhle E, Craig PS. 2006. Hydatid cysts: does every picture tell a story? Trends in Parasitology, 22, 431-438.

65. Romig T, Deplazes P, Jenkins D, Giraudoux P, Massolo A, Craig PS, Wassermann M, Takahashi K, de la Rue M. 2017. Ecology and life cycle patterns of Echinococcus species. Advances in Parasitology, 95, 213-314.

66. Romig T, Ebi D, Wassermann M. 2015. Taxonomy and molecular epidemiology of Echinococcus granulosus sensu lato. Veterinary Parasitology, 213, 76-84.

67. Rudolphi CA. 1801. Beobachtungen über die Eingeweidewürmer. Archiv für Zoologie und Zootomie, 2, 1-65.

68. da Silva AM. 2011. Hydatid cyst/cystic echinococcosis: anatomical and surgical nomenclature and method to quantify the cyst content solidification. Chinese Medical Journal, 124, 2806-2812.

69. Soares Mdo C, Rodrigues AL, Moreira Silva CA, Brito EM, Gomes-Gouvêa MS, Corrêa IR, Pinho JRR, Malheiros AP, Nunes HM, Póvoa MM. 2013. Anatomo-clinical and molecular description of liver neotropical echinococcosis caused by Echinococcus oligarthrus in human host. Acta Tropica, 125, 110-114.

70. Spiliotis M, Brehm K. 2009. Axenic in vitro cultivation of Echinococcus multilocularis metacestode vesicles and the generation of primary cell cultures. Methods in Molecular Biology, 470, 245-262.

71. Tamarozzi F, Vuitton L, Brunetti E, Vuitton DA, Koch S. 2014. Non-surgical and non-chemical attempts to treat echinococcosis: do they work? Parasite, 21, 75.

72. Thompson R, McManus D. 2001. Aetiology: parasites and lifecycles, in WHO/OIE manual on echinococcosis, in humans and animals: a public health problem of global concern, Eckert J, Gemmell MA, Meslin FX, Pawlowski ZS, Editors. World Organization for Animal Health (OIE): Paris.

73. Tsai IJ, Zarowiecki M, Holroyd N, Garciarrubio A, SánchezFlores A, Brooks KL, Tracey A, Bobes RJ, Fragoso G, Sciutto E,
Aslett M, Beasley H, Bennett HM, Taenia solium Genome Consortium, Cai X, Camicia F, Clark R, Cucher M, De Silva N, Day TA, Deplazes P, Estrada K, Fernández C, Holland PWH, Hou J, Hu S, Huckvale T, Hung SS, Kamenetzky L, Keane JA, Kiss F, Koziol U, Lambert O, Liu K, Luo X, Luo Y, Macchiaroli N, Nichol S, Paps J, Parkinson J, Pouchkina-Stantcheva N, Riddiford N, Rosenzvit M, Salinas G, Wasmuth JD, Zamanian M, Zheng Y, Cai J, Soberón X, Olson PD, Laclette JP, Brehm K, Berriman M. 2013. The genomes of four tapeworm species reveal adaptations to parasitism. Nature, 496, 57-63.

74. Vuitton D, Bresson-Hadni S. 2014. Alveolar echinococcosis: evaluation of therapeutic strategies. Expert Opinion on Orphan Drugs, 2, 67-86.

75. Vuitton DA. 2009. Benzimidazoles for the treatment of cystic and alveolar echinococcosis: what is the consensus? Expert Review of Anti-Infective Therapy, 7, 145-149.

76. Vuitton DA, Gottstein B. 2010. Echinococcus multilocularis and its intermediate host: a model of parasite-host interplay. Journal of Biomedicine \& Biotechnology, 2010, 923193.

77. Vuitton DA, Wang Q, Zhou H-X, Raoul F, Knapp J, BressonHadni S, Wen H, Giraudoux P. 2011. A historical view of alveolar echinococcosis, 160 years after the discovery of the first case in humans: part 1 . What have we learnt on the distribution of the disease and on its parasitic agent? Chinese Medical Journal, 124, 2943-2953.

78. Wassermann M, Aschenborn O, Aschenborn J, Mackenstedt U, Romig T. 2015. A sylvatic lifecycle of Echinococcus equinus in the Etosha National Park, Namibia. International Journal for Parasitology, Parasites and Wildlife, 4, 97-103.

79. Wassermann M, Woldeyes D, Gerbi BM, Ebi D, Zeyhle E, Mackenstedt U, Petros B, Tilahun G, Kern P, Romig T. 2016. A novel zoonotic genotype related to Echinococcus granulosus sensu stricto from southern Ethiopia. International Journal for Parasitology, 46, 663-668.

80. Webster G, Cameron T. 1961. Observations on experimental infections with Echinococcus in rodents. Canadian Journal of Zoology, 39, 877-889.

81. Wen H, Vuitton L, Tuxun T, Li J, Vuitton DA, Zhang W, McManus DP. 2019. Echinococcosis: advances in the 21st Century. Clinical Microbiology Reviews, 32, pii: e00075-18.

82. WHO Informal Working Group. 2003. International classification of ultrasound images in cystic echinococcosis for application in clinical and field epidemiological settings. Acta Tropica, $85,253-261$.

83. WHO Informal Working Group on Echinococcosis (WHOIWGE). 1996. Guidelines for treatment of cystic and alveolar echinococcosis in humans. Bulletin of the World Health Organization, 74, 231-242.

84. Williams RJ, Sweatman GK. 1963. On the transmission, biology and morphology of Echinococcus granulosus equinus, a new subspecies of hydatid tapeworm in horses in Great Britain. Parasitology, 53, 391-407.

85. Xiao N, Qiu J, Nakao M, Li T, Yang W, Chen X, Schantz PM, Craig PS, Ito A. 2005. Echinococcus shiquicus n. sp., a taeniid cestode from Tibetan fox and plateau pika in China. International Journal for Parasitology, 35, 693-701.

86. Zhang W, Wang S, McManus DP. 2014. Echinococcus granulosus genomics: a new dawn for improved diagnosis, treatment, and control of echinococcosis. Parasite, 21, 66.

87. Zheng H, Zhang W, Zhang L, Zhang Z, Li J, Lu G, Zhu Y, Wang Y, Huang Y, Liu J, Kang H, Chen J, Wang L, Chen A, Yu S, Gao Z, Jin L, Gu W, Wang Z, Zhao L, Shi B, Wen H, Lin R, Jones MK, Brejova B, Vinar T, Zhao G, McManus DP, Chen Z, Zhou Y, Wang S. 2013. The genome of the hydatid tapeworm Echinococcus granulosus. Nature Genetics, 45, 1168-1175. 


\section{Appendix}

\section{List of the 9 participants in the Steering and Writing Group (SWG)}

Project manager: Vuitton Dominique A.

\section{Subgroup coordinators:}

Species and epidemiology: McManus Donald P., Australia; Romig Thomas, Germany.

Biology and immunology: Rogan Michael R., UK; Gottstein Bruno, Switzerland.

Clinical aspects: Menezes da Silva Antonio*, Portugal; Wen Hao, PR China.

Data collection and writing assistants: Naidich Ariel, Argentina; Tuxun Tuerhongjiang, PR China.

*Representative of the World Association of

Echinococcosis, as Past-President.

\section{List of the $\mathbf{4 2}$ participants in the Consultation and Rating Group (CRG)}

Subgroup "Species and epidemiology" (15 participants, listed in alphabetic order)

Avcioglu Amza, Turkey; Boufana Belgees, UK; Budke Christine, USA; Casulli Adriano, Italy; Güven Esin, Turkey; Hillenbrand Andreas, Germany; Jalousian Fateme, Iran; Jemli Mohamed Habib, Tunisia; Knapp Jenny, France; Laatamna Abdelkarim, Algeria; Lahmar Samia, Tunisia; Naidich Ariel, Argentina; Rogan Michael T., UK; Sadjjadi Seyed Mahmoud, Iran; Schmidberger Julian, Germany.

\section{Subgroup "Biology and immunology" (15 participants, listed in alphabetic order)}

Amri Manel*, Algeria; Bellanger Anne-Pauline, France; Benazzouz Sara*, Algeria; Brehm Klaus, Germany; Hillenbrand Andreas, Germany; Jalousian Fateme, Iran; Kachani Malika, USA/Morocco; *Labsi Moussa, Algeria; Masala Giovanna, Italy; Menezes da Silva Antonio, Portugal; Sadjjadi Seyed Mahmoud, Iran; Soufli Imene*, Algeria; Touil-Boukoffa Chafia*, Algeria; Wang Junhua, Switzerland/ PR China; Zeyhle Eberhard, Kenya.

\section{Subgroup "Clinical aspects" (12 participants, listed in alphabetic order)}

Aji Tuerganaili, PR China; Akhan Okan, Turkey; BressonHadni Solange, France; Dziri Chadli, Tunisia; *Gräter Tilmann, Germany; *Grüner Beate, Germany; Haïf Assia, Algeria; Hillenbrand Andreas, Germany; Koch Stéphane, France; Rogan Michael T., UK; Tamarozzi Francesca, Italy; Tuxun Tuerhongjiang, PR China.

* Rating from these participants, who worked together, was considered as only one rating.

\section{List of the 12 participants in the Reading} and Review Group (RRG)

\section{Subgroup "Species and epidemiology" (4 participants, listed in alphabetic order):}

Giraudoux Patrick, France; Torgerson Paul, Switzerland/ Central Asia; Vizcaychipi Katherina, Argentina; Xiao Ning, PR China.

\section{Subgroup "Biology and immunology" (4 participants, listed in alphabetic order):}

Altintas Nazmiye, Turkey; Lin Renyong, PR China; Millon Laurence, France; Zhang Wenbao, PR China.

\section{Subgroup "Clinical aspects" (4 participants, listed in alphabetic order):}

Achour Karima, Algeria; Fan Haining, PR China; Junghanss Thomas, Germany; Mantion Georges A., France.

\section{Names, affiliations and email addresses of Collaborators}

Algeria

Achour Karima, Service de chirurgie thoracique, cardiovasculaire et de transplantation rénale, Hôpital universitaire Mustapha, DZ-16000 Bab-El-Oued, Algeria;

achour.karima@gmail.com

Amri Manel, Laboratoire de Biologie Cellulaire et Moléculaire, Faculté des Sciences Biologiques, Université des Sciences et Technologie Houari Boumediene, DZ-16111 Algiers, Algeria; manelamri@yahoo.fr

Benazzouz Sara, Laboratoire de Biologie Cellulaire et Moléculaire, Faculté des Sciences Biologiques, Université des Sciences et Technologie Houari Boumediene, DZ-16111 Algiers, Algeria; sara. andl@hotmail. fr

Haïf Assia, Service de Chirurgie Pédiatrique, Université Ferhat Abbas, DZ-19000 Setif, Algeria;

haif_chu.setif@yahoo.fr

Laatamna Abdelkarim, Département de Parasitologie, Université Ziane Achour, DZ-B.P. 3117 Djelfa, Algeria;

laatamnaabdelkarim@yahoo.com

Labsi Moussa, Laboratoire de Biologie Cellulaire et Moléculaire, Faculté des Sciences Biologiques, Université des Sciences et Technologie Houari Boumediene, DZ-16111 Algiers, Algeria; touilboukoffa@yahoo.fr

Soufli Imene, Laboratoire de Biologie Cellulaire et Moléculaire, Faculté des Sciences Biologiques, Université des Sciences et Technologie Houari Boumediene, DZ-16111 Algiers, Algeria; touilbouk ffa@yahoo.fr

Touil Boukoffa Chafia, Laboratoire de Biologie Cellulaire et Moléculaire, Faculté des Sciences Biologiques, Université des Sciences et Technologie Houari Boumediene, DZ-16111 Algiers, Algeria; touilboukoffa@yahoo.fr 


\section{Argentina}

Naidich Ariel, Departamento de Parasitología, Instituto Nacional de Enfermedades Infecciosas, ANLIS "Dr. Carlos G. Malbrán”, AR-CP 1281 - Buenos Aires, Argentina; anaidich@anlis.gob.ar

Vizcaychipi Katherina, Instituto Nacional de Medicina Tropical (INMeT) Pto. Iguazú Misiones, Ministerio de Salud de la Nación, AR- CP 1281 Buenos Aires, Argentina; kvizcaychipi@gmail.com

\section{Australia}

McManus Donald P., Molecular Parasitology Laboratory, Infectious Diseases Division, QIMR Berghofer Medical Research Institute, AU-4006 Herston-Brisbane, QLD, Australia; don. McManus@qimrberghofer.edu. au

\section{China}

Aji Tuerganaili, Department of Hepatic Surgery; WHO Collaborating Centre for Prevention and Care Management of Echinococcosis; 1st Affiliated Hospital of Xinjiang Medical University, CN-830011 Urumqi, China;

dr.wenhao@163.com

Fan Haining, China; Department of Hepatic Surgery; 1st Affiliated Hospital of Qinghai University, CN-810001 Xining, China; fanhaining@medmail.com.cn

Lin Renyong, State Key Laboratory of Pathogenesis, Prevention and Treatment of High Incidence Diseases in Central Asia, CN-830011 Urumqi, China;

renyong_lin@sina.com

Tuxun Tuerhongjiang, Department of Hepatic Surgery; WHO Collaborating Centre for Prevention and Care Management of Echinococcosis; 1st Affiliated Hospital of Xinjiang Medical University, CN-830011 Urumqi, China; turgunbay@163.com

Wen Hao, WHO Collaborating Centre for Prevention and Care Management of Echinococcosis \& State Key Laboratory of Pathogenesis, Prevention and Treatment of High Incidence Diseases in Central Asia, CN-830011 Urumqi, China; dr.wenhao@163.com

Xiao Ning, National Institute of Parasitic Diseases, Chinese Centers for Disease Control, CN-200025 Shanghai, China; ningxiaol16@126.com

Zhang Wenbao, WHO Collaborating Centre for Prevention and Care Management of Echinococcosis \& State Key Laboratory of Pathogenesis, Prevention and Treatment of High Incidence Diseases in Central Asia, CN-830011 Urumqi, China; wenbaozhang2013@163.com

\section{France}

Bellanger Anne-Pauline, Laboratoire de Parasitologie et Mycologie; Centre National de Référence pour les Echinococcoses, Centre Hospitalier Régional Universitaire, FR-25030 Besançon, France; apbellanger@chu-besancon.fr

Bresson-Hadni Solange, Centre National de Référence pour les Echinococcoses, Centre Hospitalier Régional Universitaire, FR-25030 Besançon, France;

solange. bresson.sbh@gmail.com

Giraudoux Patrick, UMR Chrono-environnement; Université Bourgogne Franche-Comté, FR-25030 Besançon, France; patrick.giraudoux@univ-fcomte.fr
Knapp Jenny, France; Laboratoire de Parasitologie; Centre National de Référence pour les Echinococcoses, Centre Hospitalier Régional Universitaire, FR-25030 Besançon, France

Koch Stéphane, Service de Gastroentérologie; Centre Hospitalier Régional Universitaire, FR-25030 Besançon, France; skoch@chu-besancon.fr

Mantion Georges, Université Bourgogne Franche-Comté, FR-25030 Besançon, France; gmantion@univ-fcomte.fr

Millon Laurence, Laboratoire de Parasitologie; Centre National de Référence pour les Echinococcoses, Centre Hospitalier Régional Universitaire, FR-25030 Besançon, France; Imillon@univ-fcomte.fr

Vuitton Dominique Angèle, EA 3181, Université Bourgogne Franche-Comté, FR-25030 Besançon, France; dvuitton@univ-fcomte.fr

\section{Germany}

Brehm Klaus, Institut für Hygiene und Mikrobiologie Universität Würzburg, DE-97080 Würzburg; Germany; kbrehm@hygiene.uni-wuerzburg. de

Gräter Tilmann, Klinik für Diagnostische und Interventionelle Radiologie Universitätsklinikum Ulm, DE-89081 Ulm; Germany; tilmann. graeter@uniklinik-ulm. de

Grüner Beate, Comprehensive Infectious Diseases Center; Klinik für Innere Medizin III, Universitätsklinikum Ulm, DE-89081 Ulm, Germany;

beate.gruener@uniklinik-ulm.de

Hillenbrand Andreas, Klinik für Allgemein- und Viszeralchirurgie, Universitätsklinikum Ulm, DE-89081 Ulm, Germany;

andreas.hillenbrand@uniklinik-ulm.de

Junghanss Thomas, Sektion Klinische Tropenmedizin, Universitätsklinikum Heidelberg, Heidelberg, DE-69120 Germany; thomas.junghanss@urz.uni-heidelberg.de

Romig Thomas, Department of Parasitology, Fachgebiete Parasitologie, Universität Hohenheim, D-70593 Stuttgart, DE-70599 Stuttgart, Germany;

thomas.romig@uni-hohenheim.de

Schmidberger Julian, Klinik für Innere Medizin I, Universitätsklinikum Ulm, DE-89081 Ulm, Germany; julian.schmidberger@uniklinik-ulm.de

Italy

Casulli Adriano, WHO Collaborating Centre for the Epidemiology, Detection and Control of Cystic and Alveolar Echinococcosis; European Union Reference Laboratory for Parasites; Foodborne and Neglected Parasitic Diseases Unit, Department of Infectious Diseases, Istituto Superiore di Sanità, IT-00161 Rome, Italy;

adriano.casulli@iss.it

Masala Giovanna, Istituto Zooprofilattico Sperimentale della Sardegna, IT-07100 Sassari, Italy;

giovanna.masala@izs-sardegna.it

Tamarozzi Francesca, WHO Collaborating Centre for the Epidemiology, Detection and Control of Cystic and Alveolar Echinococcosis; Department on Infectious Diseases, Istituto Superiore di Sanità, IT-00161 Rome, Italy;

f_tamarozzi@yahoo.com 
Iran

Jalousian Fateme, Department of Parasitology, Faculty of Veterinary Medicine, University of Tehran, IR-1417466191, Iran; jalousian_f@ut.ac.ir

Sadjjadi Seyed Mahmoud, Dept. Parasitology and Mycology, School of Medicine, Shiraz University of Medical Sciences, IR-PO Box 71348-14336 Shiraz, Iran; sadjjadi316@gmail.com

Kenya

Zeyhle Eberhard, Meru University of Sciences and Technology, KE-60200 Meru, Kenya; zeana07@gmail.com

\section{Morocco}

Kachani Malika, Département de Parasitologie Institut Agronomique et Vétérinaire Hassan II, MA-BP 6202, Rabat, Morocco \& College of Veterinary Medicine, Western University of Health Sciences, US-91766-1854 Pomona, CA, USA; mkachani@westernu. edu

\section{Portugal}

Menezes da Silva Antonio, World Association of Echinococcosis (Past-President); College of General Surgery of the Portuguese Medical Association (Associação dos Médicos Portugueses), PT-1749-084 Lisbon, Portugal;

mensilvapt@yahoo.com

\section{Switzerland}

Gottstein Bruno, Institut für Parasitologie, Vetsuisse Facultät Bern, \& Immuno-parasitologie, Medizinische Fakultät, Universität Bern, CH-3008 Bern, Switzerland;

bruno.gottstein@vetsuisse.unibe.ch

Torgerson Paul, Abteilung für Epidemiologie, Vetsuisse Facultät Zürich, Universität Zürich, CH-8057 Switzerland; paul. torgerson@access.uzh.ch

Wang Junhua, Institut für Parasitologie, Vetsuisse Facultät Bern, Universität Bern, CH-3008 Bern, Switzerland; junhua.wang@vetsuisse.unibe.ch

\section{Tunisia}

Dziri Chadli, Département de Chirurgie Générale, Faculté de Médecine de Tunis, \& Centre de Simulation Médicale
Honoris, Université El Manar, TN-1068 Tunis, Tunisia; chadli.dziri@planet.tn

Jemli Mohamed Habib, Service de ParasitologieDépartement Clinique de l'École Nationale de Médecine Vétérinaire - TN-2020 Sidi Thabet, Tunisia;

jemli.medhabib@yahoo.fr

Lahmar Samia, Service de Parasitologie, Département Clinique de l'École Nationale de Médecine Vétérinaire, TN-2020 Sidi Thabet, Tunisia; drlsamia@yahoo.fr

Turkey

Akhan Okan, Department of Radiology, Hacettepe Üniversitesi/University, TR- 06230 Ankara, Turkey;

akhano@tr.net

Altintas Nazmiye, Department of Parasitology, Ege Üniversitesi/University, TR-35040 Bornova-Izmir, Turkey; nazmiye.altintas@ege.edu.tr

Avcioglu Amza, Department of Veterinary Parasitology, Ataturk Üniversitesi/University, TR-25030 Yakutiye-Erzurum, Turkey; havcioglu@atauni.edu.tr

Güven Esin, Department of Parasitology, Ataturk Üniversitesi/University, TR-25030 Yakutiye-Erzurum, Turkey; esinguven@atauni.edu.tr

United Kingdom

Boufana Belgees, National Reference Laboratory for Trichinella \& Echinococcus, National Wildlife Management Centre, Animal and Plant Health Agency, GB-YO41 1LZ Sand Hutton, York, United Kingdom;

belgees.boufana@apha.gov.uk

Rogan Michael, School of Science, Engineering \& Environment, University of Salford, GB-M5 4WT, Manchester, United Kingdom; m. t.rogan@salford. ac.uk

USA

Budke Christine, Department of Veterinary Integrative Biosciences, College of Veterinary Medicine \& Biomedical Sciences, Texas A\&M University, US-77843-4458 College Station, TX, USA; cbudke@cvm. tamu. edu 
An international open-access, peer-reviewed, online journal publishing high quality papers on all aspects of human and animal parasitology

Reviews, articles and short notes may be submitted. Fields include, but are not limited to: general, medical and veterinary parasitology; morphology, including ultrastructure; parasite systematics, including entomology, acarology, helminthology and protistology, and molecular analyses; molecular biology and biochemistry; immunology of parasitic diseases; host-parasite relationships; ecology and life history of parasites; epidemiology; therapeutics; new diagnostic tools.

All papers in Parasite are published in English. Manuscripts should have a broad interest and must not have been published or submitted elsewhere. No limit is imposed on the length of manuscripts.

Parasite (open-access) continues Parasite (print and online editions, 1994-2012) and Annales de Parasitologie Humaine et Comparée (1923-1993) and is the official journal of the Société Française de Parasitologie. 